\title{
BRIDGELESS ACTIVE POWER FACTOR CORRECTION USING A CURRENT FED PUSH PULL CONVERTER
}

\author{
A Thesis \\ presented to \\ the Faculty of California Polytechnic State University, \\ San Luis Obispo
}

\author{
In Partial Fulfillment \\ of the Requirements for the Degree \\ Master of Science in Electrical Engineering
}

by

Jeramie Seth Bianchi

June 2011 
(C) 2011

Jeramie Bianchi

ALL RIGHTS RESERVED 


\section{COMMITTEE MEMBERSHIP}

TITLE:

AUTHOR:

DATE SUBMITTED:

COMMITTEE CHAIR:

COMMITTEE MEMBER:

COMMITTEE MEMBER:
Bridgeless Active Power Factor Correction

Using a Current Fed Push Pull Converter

Jeramie Seth Bianchi

June 2011
Taufik, Professor

Ahmad Nafisi, Professor

Vladimir Prodanov, Assistant Professor 


\author{
ABSTRACT \\ Bridgeless Active Power Factor Correction \\ Using a Current Fed Push Pull Converter \\ Jeramie Seth Bianchi
}

Switched Mode Power Supplies have become increasingly popular for efficient methods of delivering power to an assortment of electronic devices. This thesis proposes a method of using a current fed push pull converter to provide active power factor correction and rectification in a single stage. While most AC-DC converters utilize a bridge rectifier to convert AC-DC and then perform DC-DC conversion, the proposed circuit will utilize its output diodes to perform rectification, thus eliminating the need for a bridge rectifier. This circuit will also inherently provide power factor correction because the input current has a continuous path for current flow due to the current fed topology where no time exists for both switches to be off. Through analog circuitry for the controller, multiple methods of AC main switching are tested, including isolation techniques using optocouplers, to prove the most efficient way to control a bidirectional switch. Simulations with PSPICE and hardware implementation of the design prove that alternative methods to provide quality power conversion for Switched Mode Power Supplies are available.

Keywords: Active Power Factor Correction, Current Fed Push Pull Converter, SMPS, Bidirectional Switching, IGBT, Bridgeless Rectification 


\section{ACKNOWLEDGMENTS}

Foremost, I would like to thank my advisor Dr. Taufik for his passion in the field of Power Electronics. Over the past couple years I have had Taufik as a professor, advisor, mentor, and great friend. I have learned so much from your extensive experience and knowledge and I am very grateful to have had such a friendly and helpful advisor. I would also like to thank all my colleagues that I have worked with in the exceptional “learn by doing” program at Cal Poly. Specifically, I would like to thank Jameson Thornton, Darwin Fernandez and Rithy Chhean for their continued advice, motivation, and assistance with innovative testing and design considerations. As well as my college colleagues I thank my friends I have met through life that have provided continued support of my goals as well as sharing many adventures that I will always remember. Lastly, but surely not least, I thank my loving parents Gene and Karen Bianchi for raising me to be a responsible, motivated, and caring person. You have always been there to guide me in the right direction, and with your amazing personalities and character as my example, I have always aimed to make you proud. 
LIST OF TABLES ....................................................................................................

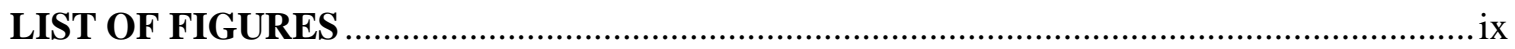

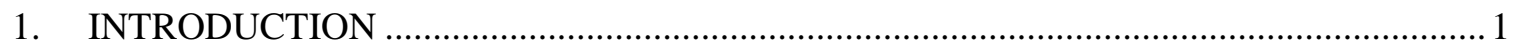

1.1 Three Types of Power ................................................................................................... 1

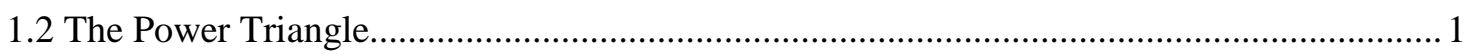

1.3 Power Factor Correction ......................................................................................... 2

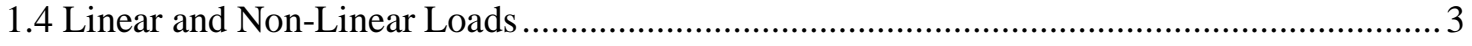

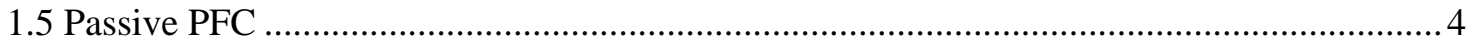

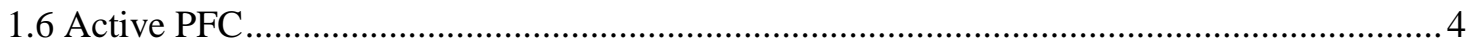

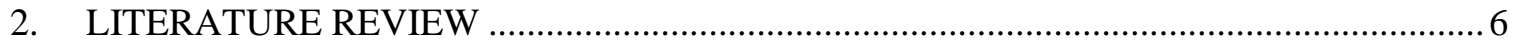

2.1 Non Isolated Topologies .....................................................................................

2.1.1 Boost Converter in DCM .................................................................................

2.1.2 Boost Converter in CCM .......................................................................................

2.1.3 Buck Converter ……………………………………………………………………

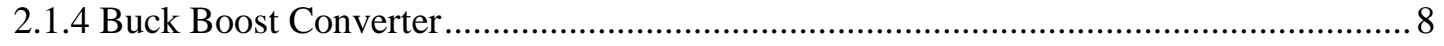

2.1.5 SEPIC Converter........................................................................................

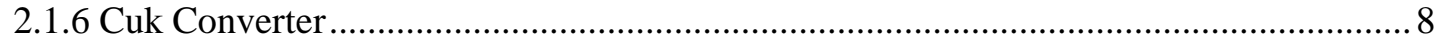

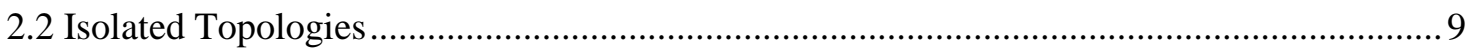

2.2.1 Flyback Converter............................................................................................

2.2.2 Forward and Push Pull Converter .............................................................................. 10

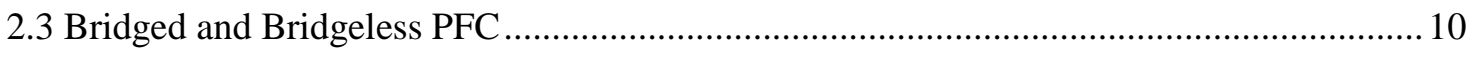

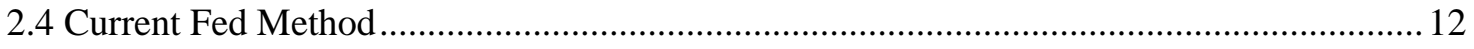

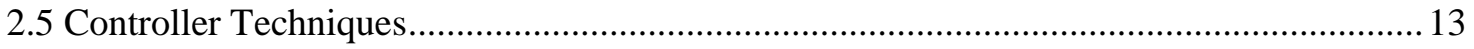

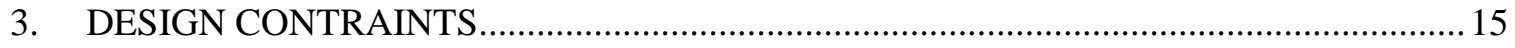

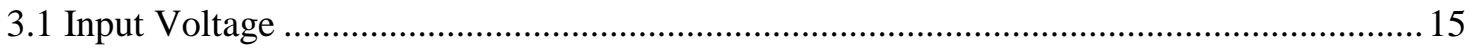

3.2 Input and Switching Frequency ………………………………………………………... 15

3.3 Output Voltage and Current........................................................................................ 16

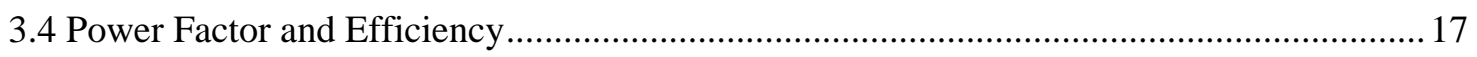

4. CONVERTER DESIGN \& SIMULATION ………………...........................................18 


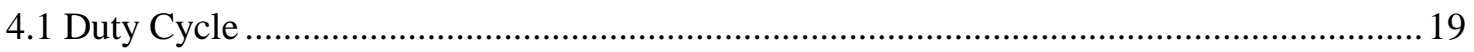

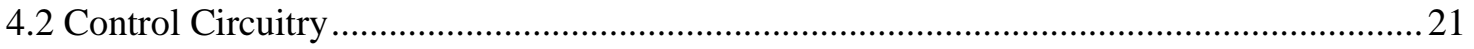

4.3 Input Voltage Phase Shift and Power Factor ..................................................................... 25

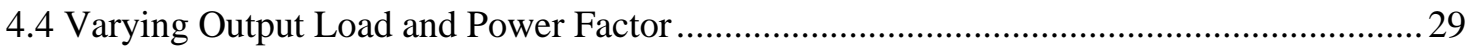

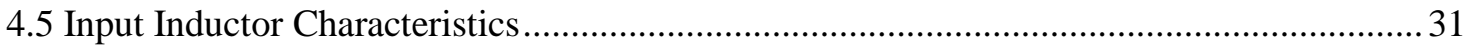

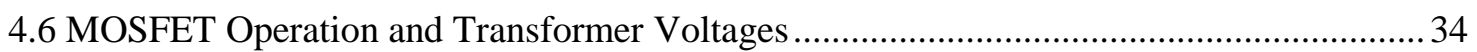

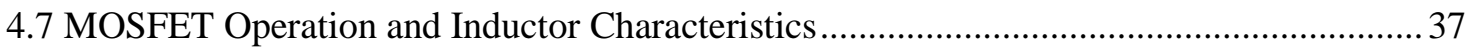

4.8 Diode Operation for Rectifying and Inductor Discharge ................................................... 40

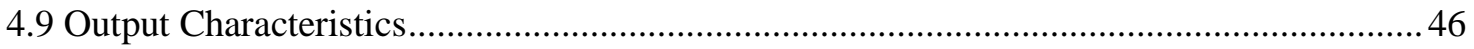

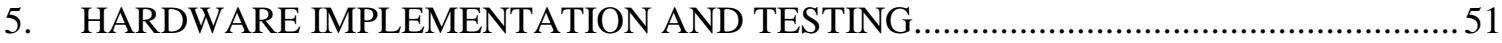

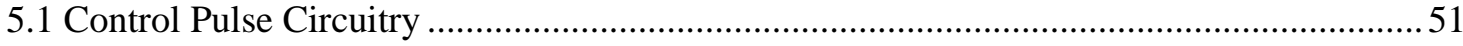

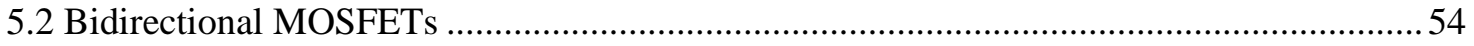

5.3 Bidirectional Insulated Gate Bipolar Transistor ............................................................... 55

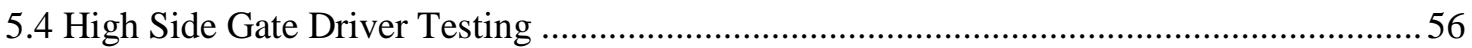

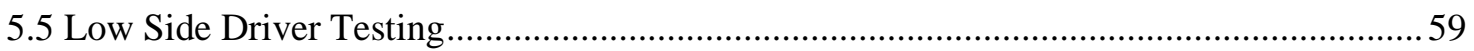

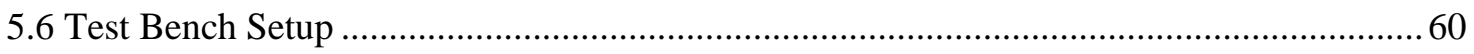

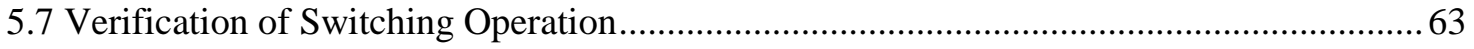

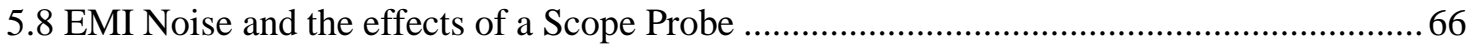

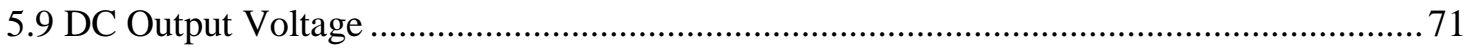

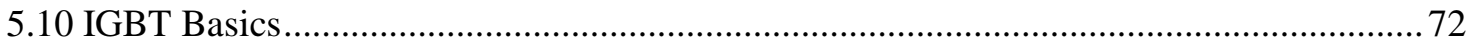

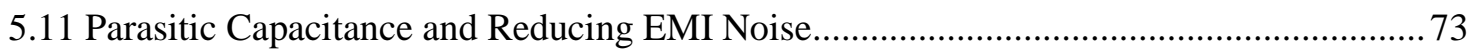

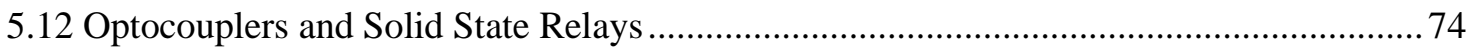

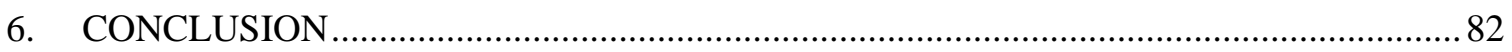

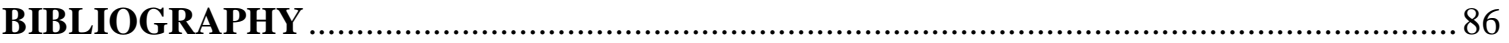




\section{LIST OF TABLES}

Table

Page

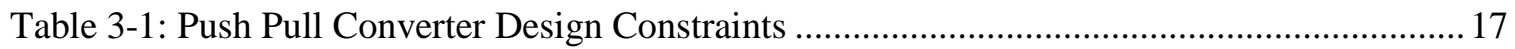

Table 4-1: Component Parts List for Hardware.......................................................................... 50

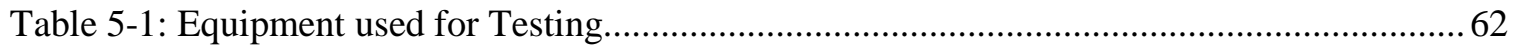

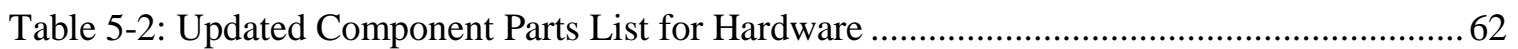




\section{LIST OF FIGURES}

\section{Figure}

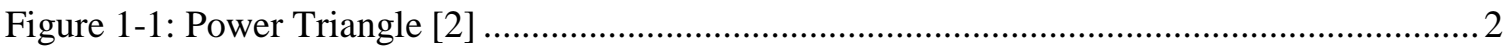

Figure 4-1: Current Fed Push Pull Converter with Pulse Switch Control .................................... 18

Figure 4-2: Switch 1 and Switch 2 Controller Configurations ................................................... 21

Figure 4-3: Comparator Voltage References and Input Triangle Waveform............................... 21

Figure 4-4: Switching Voltage (top) from Triangle Waveform and Voltage Reference (bottom) 23

Figure 4-5: Switching Voltage (top) from Triangle Waveform and Voltage Reference (bottom) 24

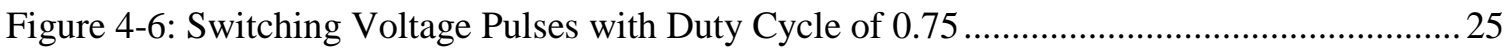

Figure 4-7: Input Voltage (green) with no phase shift and Input Current (red).............................. 26

Figure 4-8: Input Power Factor with Input Voltage not phase shifted........................................... 26

Figure 4-9: Input voltage (green) with phase shift of 90 degrees and Input Current (red) ............ 27

Figure 4-10: Input Power Factor with Input Voltage phase shifted by 90 degrees....................... 27

Figure 4-11: Input Voltage (green) with phase shift of 120 degrees and Input Current (red) ....... 28

Figure 4-12: Input Power Factor with Input Voltage phase shifted by 120 degrees...................... 28

Figure 4-13: Input Current Waveform (top) and Power Factor with $200 \Omega$ Load (bottom) ........... 30

Figure 4-14: Input Current Waveform (top) and Power Factor with $400 \Omega$ Load (bottom)........... 30

Figure 4-15: Input Current Waveform (top) and Power Factor with $800 \Omega$ Load (bottom) ............ 31

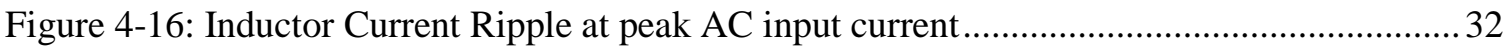

Figure 4-17: Transformer Voltage L3 (top) during Switch 1 and 2 Pulses (middle \& bottom) .... 34

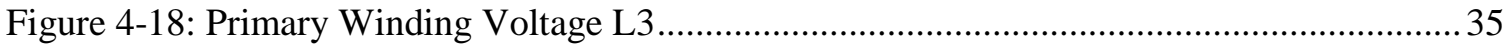

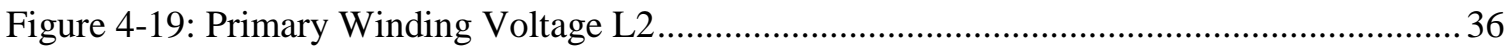

Figure 4-20: Voltage across Drain to Source of Switch 1 and Switch 2........................................ 37

Figure 4-21: Inductor Current Ripple (top) during Switch 1 and 2 Pulses (middle \& bottom)..... 38

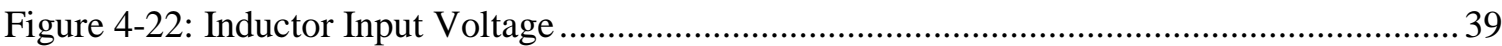

Figure 4-23: Winding L2 (blue) and L3 (orange) Currents during Switch 1 (green) and 2 (red).. 40

Figure 4-24: D1 (top) and D2 (third) voltages vs Switch Pulses S1 (second) and S2 (bottom) .... 41

Figure 4-25: Current Flow when only Switch 1 is on and positive AC current............................42

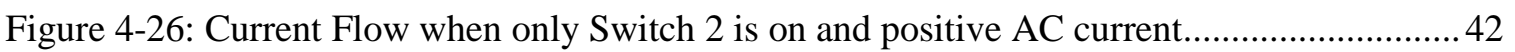

Figure 4-27: L3 Current (bottom) and D1 Current (middle) from Inductor Current (top) ............. 43

Figure 4-28: L2 Current (bottom) and D2 Current (middle) from Inductor Current (top) ............ 44

Figure 4-29: Current Flow when only Switch 2 is on and negative AC current.............................45

Figure 4-30: Current Flow when only Switch 1 is on and negative AC current............................. 46

Figure 4-31: Diode Currents D2 (middle) and D1 (bottom) rectified vs Input Current (top)........ 47

Figure 4-32: Capacitor Current (bottom) and Output Resistor Current (top) ................................. 47

Figure 4-33: Average Output Voltage (bottom) and Average Output Current (top) ...................... 48

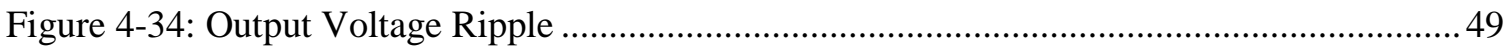

Figure 5-1: Control Pulse Circuitry Hardware Configuration Schematic...................................... 52

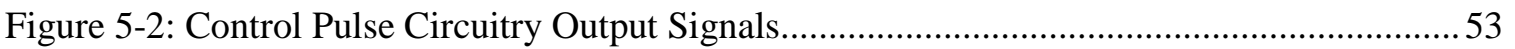

Figure 5-3: Bidirectional Switch configuration with two MOSFETs .............................................55

Figure 5-4: Bidirectional Switch Configuration with two IGBTs .............................................56

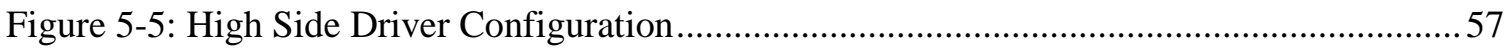

Figure 5-6: Internal High Side Gate Driver Circuitry ................................................................. 57 
Figure 5-7: Control Circuitry with Problematic Emitter Voltage Reference ................................ 58

Figure 5-8: Low Side Driver without reference emitter.............................................................. 59

Figure 5-9: Implemented Control Circuitry and Gate Drivers to Anti-Parallel IGBTs .................. 60

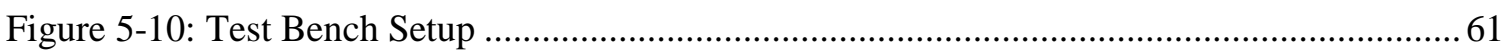

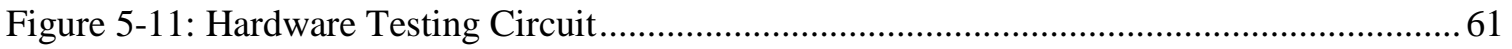

Figure 5-12: Left Switch Gate Voltage (top) and Collector to Emitter Voltage (bottom).............. 64

Figure 5-13: Right Switch Gate Voltage (top) and Collector to Emitter Voltage (bottom)........... 64

Figure 5-14: DC Power Supply Voltage and Current with Scope Probe Disconnected ................. 67

Figure 5-15: Input Power Factor and AC Current with Scope Probe Disconnected........................ 67

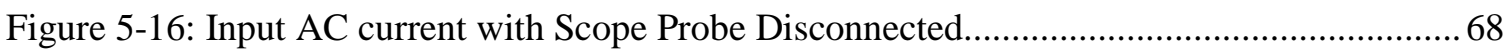

Figure 5-17: DC Power Supply Voltage and Current with Scope Probe Connected......................69

Figure 5-18: Input Power Factor and AC Current with Scope Probe Connected ........................... 70

Figure 5-19: Input Voltage and AC current with Scope Probe Connected.................................... 70

Figure 5-20: Output DC Voltage and Peak to Peak Voltage Ripple.............................................. 71

Figure 5-21: Internal Model of Insulated Gate Bipolar Transistor [27]....................................... 72

Figure 5-22: Photodiode Relay Types for Bidirectional Switching [33, 34] ............................... 74

Figure 5-23: Control Circuitry utilizing Optocoupling with BJT output..................................... 76

Figure 5-24: Photodiode pulse voltages for Switch 2 (top) and Switch 1 (bottom).......................77

Figure 5-25: BJT output pulse from Collector to Emitter not driven to Switches ......................... 77

Figure 5-26: Optocoupler BJT pulse voltage connected to IGBT gate with DC ground reference78

Figure 5-27: Gate to Emitter of the IGBTs showing AC coupling ............................................... 79

Figure 5-28: Input AC voltage (top) and Input AC current (bottom) .......................................... 80

Figure 5-29: IGBTs collector to emitter voltage for left switch (top) and right switch (bottom)... 81

Figure 6-1: Transformer Driver-IC Controls Bidirectional Switch [35]..................................... 85 


\section{INTRODUCTION}

\subsection{Three Types of Power}

Alternating current (AC) electrical power systems contain three types of power: real power, reactive power, and apparent power. The ratio between real power and apparent power is called the power factor which is a unit less value between 0 and 1 [1]. The total power delivered to a load is the apparent power and it consists of real and reactive powers. For an electrical system to obtain a power factor of 1 , all power absorbed by the load is real power, therefore real power equals the apparent power. Real power is the amount of work done for a specific time and is expressed in watts, which equals Joules per second. The more real power delivered to the load the more the load will be able to do work for the given amount of time. As power factor decreases real power decreases while apparent power stays the same. This phenomenon can be attributed to the load storing energy and sending it back to the source [1]. This loss of energy delivered to the load and instead delivered to the source is the reactive power. Reactive power can also be prevalent when the load is non linear, because the voltage and current waveforms are not exactly alike [1]. The current waveform becomes distorted from the non linear load and therefore reduces the real power available to the load.

\subsection{The Power Triangle}

Figure 1-1 shows the power triangle that relates the three types of power to the angle between real and apparent power. Using Pythagorean's theorem the apparent power can be calculated using $S=\sqrt{P^{2}+Q^{2}}$, where $\mathrm{S}$ is apparent power, $\mathrm{P}$ is real power and $\mathrm{Q}$ is reactive power. The power factor is defined as $\frac{P}{S}$ so as $\mathrm{P}$ approaches the value of $\mathrm{S}$, 
the power factor gets closer to 1, and from Figure 1-1, Q approaches 0 [1]. As the power factor approaches 1, $\Theta$ approaches 0 which confirms another definition of the power factor which is $\cos ()=\cos (0)=1$. Any theta value between 0 and 90 degrees result in a valid power factor; a power factor of 1 is when $=0$, whereas $=1$ will result in a power factor of 0 . A change in theta affects the power factor but more importantly the change in angle is directly related to the change in how much reactive power is delivered to the load.

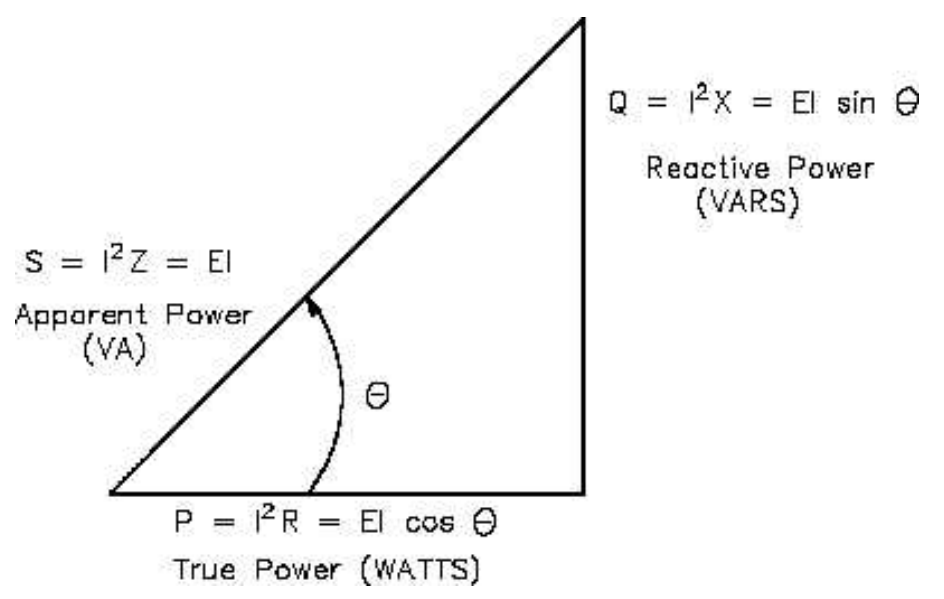

Figure 1-1: Power Triangle [2]

\subsection{Power Factor Correction}

Most important to delivering power to loads is how to get the power factor equal to one so that the most real power can be delivered to the load. Power factor correction is the method of correcting the power factor closer to one. Power factor correction is applied to different applications such as in: electrical power transmission utilities to improve the stability and efficiency of the transmission network; or, correction may be installed by individual electrical customers to reduce the costs charged to them by their electricity supplier [3]. With power factor correction, a resulting higher real power is 
beneficial because losses in transmission lines as well as voltage regulation are achieved [3]. PFC is therefore a widely used technique involved in many different circuits with two PFC approaches used for two specific types of loads. These two types of loads are linear and non linear loads, which take entirely different methods to achieve a power factor of one.

\subsection{Linear and Non-Linear Loads}

Linear loads are critical to the power generation, transmission and distribution fields because these loads, if not tuned correctly will affect the cost and efficiencies of the system negatively [3]. If the reactive power is high then ratings of wires, switches, circuit breakers and transformers must be higher to compensate for the higher currents [3]. Most often the loads in power system utilities are inductive loads such as motors, inductances in the transmission lines, and in the transformers. These inductive loads create a positive reactive power which lowers the power factor, and in order to alleviate the reactive power absorbed by the load, shunt capacitors are placed across the loads to supply negative reactive power [3]. Inductive loads cause the power factor to lag, which means that the current waveform lags the voltage waveform, whereas capacitive loads cause the power factor to lead, the current waveform leads the voltage waveform. As mentioned if the load is inductive, positive $\mathrm{Q}$ is required by the load, and results in a higher theta angle and length $\mathrm{Q}$ when referring to Figure 1-1. The negative reactive power supplied by a capacitor will reduce the positive reactive power demanded by the inductive load and therefore reduces the angle theta. The same will be true for using an inductor across a load to cancel out the negative reactive power supplied by a capacitive load.

Non linear loads are any loads that involve active components that affect the 
waveform of the current, which causes the current waveform to be out of phase with the voltage waveform. Typically a non linear load is a rectifier which includes diodes or switches, and performs by alternating the switching to create a DC output waveform [1]. Rectifiers are commonly used in switched-mode power supplies (SMPS) and in order to correct the power factor to obtain a regulated output, passive and active PFC are methods that can be applied [3].

\subsection{Passive PFC}

Passive PFC is simply a filter that can be placed in line at a specific frequency to filter the harmonics out of the current [1]. This approach results in the load now looking linear; however the one frequency filter is usually at $50-60 \mathrm{~Hz}$ and is very bulky in a non linear system [3]. The filter is comprised of either capacitors or inductors similar to the linear load PFC technique however; this method compared to active PFC for non linear loads is inefficient. The PF achievable with this method is only $60-70 \%$ with some cost savings compared to active PFC.

\subsection{Active PFC}

Active PFC is a widely used method in power electronic systems to control the amount of power drawn by the load [1]. The method of active PFC is based on controlling the current in a way so that it can follow the voltage waveform as closely as possible [1]. Active PFC is commonly applied to SMPS because within SMPS, rectifiers are used which create harmonics. The reason why it is important to use active PFC for SMPS is because SMPS are present in millions of personal computers used today [1]. If the most efficient method is not used, the regulation of voltages and currents on the utility side will not be sufficient, and therefore power equipment such as transformers would be 
ruined by issues such as harmonics. PFC is also critical to SMPS because the harmonics on the input of rectifiers result in higher rectifier currents and therefore efficiency of the rectifiers is reduced due to this higher unwanted RMS current [4]. Also because the current and voltage are out of phase, reactive power created in the circuit has to be accounted for with higher component VA ratings [4]. In order to reduce these effects in SMPS's, PFC is essential and many methods are available to solve the power factor problem. 


\section{LITERATURE REVIEW}

Power electronics has advanced significantly and new approaches are being taken to solve the issue of PFC. In order for power to be delivered to households efficiently the regulatory standard IEC 1000-3 has been adopted in North America to insure that input harmonics during AC-DC conversion are eliminated [8]. To successfully meet regulation standards and increase the power factor of the power conversion process, many DC-DC converters have been used [6]. Currently two approaches, bridged and bridgeless PFC, have been implemented to improve PF using DC-DC converters [1]. Bridged PFC is the most commonly used PFC technique which employs the use of a rectifier followed by filtering with capacitors and a DC-DC converter for waveform smoothing [6]. The most commonly used DC-DC converter for PFC after the rectification stage is the boost converter [1].

\subsection{Non Isolated Topologies}

\subsubsection{Boost Converter in DCM}

The boost converter can operate in Continuous Conduction Mode or Discontinuous Conduction Mode for PFC, however at high power levels the CCM boost converter is preferred [1]. Many methods can be used to increase the efficiency of the standard boost converter PFC as well as the efficiency of other topologies. One such method is soft switching techniques using snubbers to reduce switching losses [8]. These techniques and others while important to increasing efficiency are only additional components that control turn off and turn on states within the basic PFC converters $[1,5]$. For simplicity, the converters themselves with their advantages and disadvantages will be 
addressed to better understand what is present in PFC techniques today.

\subsubsection{Boost Converter in CCM}

The boost converter PFC in CCM operation has advantages of having good Electromagnetic Interference performance, reduced switch ratings and inherent high output voltage $[1,8]$. However the boost converter can only step up the output DC voltage and this limits its use in that the output must stay higher than the peak of the input line voltage [1]. The high output voltage also requires a fast recovery rectifier, and the configuration of the boost causes voltage stresses on the diode $[1,8]$. The boost rectifier in DCM operation however solves some of the problems the CCM boost has by eliminating the need for a fast recovery rectifier because no current is flowing when the switch turns on, so effects of reverse recovery current are not an issue [1]. The drawbacks to the DCM boost are it has large current ripple from the inductor which increases stress on the rectifier and switch, a larger filter is therefore needed, and the power is limited to lower power levels [1].

\subsubsection{Buck Converter}

The buck converter PFC is another method which has its advantages over the previous boost converter. The buck converter is fundamentally different than the boost in that it steps down the voltage, which allows its lower DC voltage at the output to not be required to be above the peak input line voltage [10]. Since the voltages are lower for the buck, voltage stresses on components are also lower than that of the boost [10]. The buck converter however has some drawbacks in that it needs an ultra fast recovery diode bridge due to the discontinuous input current [10]. The converter also has a high frequency input current which results in the need for a high frequency shunt filter 
between the source and bridge to reduce harmonic components [10].

\subsubsection{Buck Boost Converter}

A buck-boost converter is another variation that uses a part of the boost and buck technology to successfully step up or step down the output DC voltage [7]. The versatility in output voltage is an advantage because the output voltage can be more or less than the peak AC input voltage [7]. The problem with the buck-boost and also more with the buck converter is the lower DC output voltage causes the input current to be non sinusoidal and with higher input current frequency, the AC harmonic input content is higher with this topology [7].

\subsubsection{SEPIC Converter}

A SEPIC converter is another viable option in PFC applications. The SEPIC converter combines the best qualities of both the boost converter and flyback converter [22]. This converter will reduce current ripples at the input for low level DC outputs, thus

eliminating the need for a high frequency filter at the AC side, and the voltage stresses on the switches are reduced [10]. While this converter is very good for high voltage applications when operated in CCM, it is better for low voltage options only when operated in DCM mode [22]. In DCM mode, the current ripple is higher, which causes high current stresses on components and results in a higher total harmonic distortion [22]. In CCM operation, the converter overcomes the limit on voltage levels at a cost of needing two control loops [22].

\subsubsection{Cuk Converter}

Lastly of the main types of non-isolated DC-DC converter PFC methods is the 
Cuk converter. The Cuk converter is advantageous in that it has continuous input and output currents, a ripple free input current, small output filter and a wide voltage operating range [11]. While this topology adds more inductors to previous buck and boost converter designs to produce cleaner waveforms, the circuit does have flaws with the added components. Adding components, especially inductors, increases cost and size of the converter [12]. The Cuk converter also has higher power handling capability requirements on the semiconductor devices [11].

\subsection{Isolated Topologies}

While each of these converters mentioned have their benefits and drawbacks in specific applications depending on the trade offs, one area of DC-DC converters that has a major advantage is isolated converters used for PFC. Isolation of the circuit is attributed to a transformer or multiple transformers in the converter [14]. Converters of this type are flyback, forward, and push pull converters. Of these three, the push pull converter is derived from a forward converter and for sake of argument, focus will be on the push pull converter, with details of the push pull inherently addressing the forward converter as well [18].

\subsubsection{Flyback Converter}

The flyback converter is an overall good choice for being used as a single circuit for a complete power supply [14]. The benefit of using a flyback converter is it is very minimalistic in the components necessary, which reduces the size and cost of a power supply that uses this converter [15]. Also noteworthy in why designers choose to use a flyback converter is because it has good harmonic regulation, high frequency isolation between the input and output, as well as the ability for it to be used for multiple outputs 
easily $[14,15]$. The flyback PFC however is limited to half a line cycle for the fastest output voltage response [14]. As well, its output voltage is limited by a bulk capacitor because the capacitor must filter twice the line frequency of the output current [14]. This bulk capacitor needed results in an increase in size when voltage levels decrease [14]. The common application for a flyback PFC technique is in the hundreds of watts range [14].

\subsubsection{Forward and Push Pull Converter}

For the forward and push pull converters, the main difference is that the push pull converter has a reset transformer while the forward does not [19]. The push pull converter can also handle higher power levels than the forward converter due to the hysteresis curve for the transformers of the push pull moving through two quadrants rather than one as seen by the forward converter [19]. The push pull converter is well known for its simplicity and ability to scale up to high power. Fundamentally, the push pull has great application toward power supplies because the transformers and filters are much smaller than that of the forward converter [19]. With this converter the voltage output can be stepped up or down, multiple outputs are easily available, it has low output ripple current, and low input current ripple [19]. Specific however to voltage stresses, the push pull converters primary switches must be rated at least twice the value of the input voltage [19].

\subsection{Bridged and Bridgeless PFC}

Now of all the PFC techniques already discussed, each converter mentioned was with reference to implementing a bridged PFC approach. This means there was a need for a rectifier before the DC-DC converter; however, bridged PFC is not necessarily the best 
way to achieve high power factors efficiently [5]. Bridgeless PFC is a viable solution that was introduced a long time ago, but designers are just now showing more interest in the technology [5]. The technology eliminates the need for the rectifier bridge stage of the power factor correction process and uses only the DC-DC converters mentioned to provide the PFC. Of all the converters mentioned each one is capable of providing bridgeless PFC.

Bridgeless PFC is a beneficial alternative to bridged PFC because the technique reduces the number of semiconductors contributing to switching losses [12]. The bridgeless boost over the regular boost reduces overall conduction losses from the elimination of the rectifier [5]. However the bridgeless boost requires more complex control circuitry, has a higher startup in rush current, and increased common mode noise because there is a direct connection of switches [5]. The common mode noise however for the bridgeless buck-boost does not change with respect to the bridged version [9]. One problem that is associated with the bridgeless technique is with input voltage sensing. Some methods taken to compensate for the input voltage sensing are using a line frequency transformer, optical coupler, or resistor divider networks [9].

All non-isolated topologies are capable of becoming bridgeless with the switches existent within the topologies being utilized in a rectification fashion. The SEPIC and Cuk converters are other possibilities with bridgeless and make use of the method to excel past their bridged counterparts. For both topologies, they offer easy implementation of transformer isolation, natural protection of inrush current at startup, lower input current ripple, and less EMI [12]. The converters also allow easy control with PWM signals, which greatly simplifies their cost and size $[12,13]$. The SEPIC unfortunately, 
when operated in DCM mode results in a high output ripple and also requires an additional gate drive transformer [13].

The benefits of bridgeless methods are very important in simplifying power supply design because when correcting power factor in one stage, the volume, size and final cost of the converter are reduced [16] Another benefit alongside the bridgeless approach is being able to use an isolated topology with the bridgeless method. PFC can be done within one single circuit using a flyback or push pull converter if the following criteria are met: galvanic isolation is present (such as with the transformer in a push pull converter), output voltage is high or output voltage ripple is not very restrictive, and dynamic requirements can be achieved [14]. Current uses for PFC with isolated topologies are mainly focused in utilizing flyback converters; however with push pull converters, a much higher voltage is obtainable. Further benefiting the use of isolated topologies in a single stage solution for SMPSs is to utilize a current fed approach within the converter.

\subsection{Current Fed Method}

A current fed method when added to bridgeless isolated converters is a great way to add extra features to the design. The current fed option works by removing the output inductor and instead placing the inductor at the input of the converter [16]. This simple yet very effective method has many benefits, such as allowing for multiple outputs much easier because the output is much more tightly coupled $[17,19]$. The input inductor also provides protection for the transformers against saturation [17]. With respect to the push pull converter, the current fed option results in reduced switching losses [19]. The push pull converter must operate its switches differently for the current fed technique which 
attributes to reduced switching losses. In order for the current fed technique to work with the push pull converter, the switches must have small overlap at the switching transition so that the inductor current is maintained [19]. Alternatively, the push pull would have its switches operate with no overlap because with no inductor, if the switches were both on simultaneously, the voltage source would be shorted [18]. Another benefit to the current fed push pull converter is the turn's ratios can be smaller, which results in a lower leakage inductance as compared to the voltage fed push pull converter [24]. Lastly the current fed push pull converter prevails over the normal push pull converter because the input inductor prevents the possibility of flux imbalance the main preventative measure against the transformer saturating [25].

\subsection{Controller Techniques}

Now in order to finalize a PFC for operation, a controller must be chosen to regulate how the current will be in phase with the input voltage. Common control techniques that have been implemented for PFC are primarily analog. A few widely used control techniques applied using analog are average current mode control, one cycle control, and PWM control [9, 21]. These techniques as well as many others can be implemented in multiple different ways and has commonly been done with all the types of converters already described [5-10, 21]. The popularity for average current mode control stems from the ability for it to maintain a stable low distortion sinusoidal line current without the need for slope compensation while operating at a fixed switching frequency [9]. One line cycle control to contrast, has no multiplier requirement, no input voltage sensing and no input inductor sensing requirement [21]. While these analog methods are numerous in possibilities because of the long history of progress with them, 
digital control techniques are becoming more common in power factor correction applications.

Digital control methods today are utilizing Digital Signal Processor and microcontroller technology because more complicated algorithms can be implemented with ease [5]. Digital controllers are low in cost, easily redesigned due to programmability, and immune to temperature and aging [5, 20]. Compared to analog, digital controllers are a perfect solution for testing new complicated PFC controller designs quickly [20]. With respect to Digital Signal Processor and Field Programmable Gate Array controllers, FPGA control provides parallel processing possibility and the availability to program in assembly or C [23]. Fully customizable and endless in possibilities, microcontrollers and FPGAs are becoming the standard for implementing controls with PFC converters.

To overcome the issues of low quality power delivered to SMPS, a Current Fed Push Pull converter will be utilized with control circuitry to correct input power factor to 1. Using two control signals, one for each of the switches and the power stage converter, a system will be designed with PSPICE simulation software and implementation of the converter in hardware will be performed. Once the testing has been done, the converter will test the effectiveness of power factor correction as well as providing a single stage option to eliminate a bridge rectifier. Combining rectification and power factor correction with one power converter will eliminate the number of components used as well as the overall cost of the converter. 


\section{DESIGN CONTRAINTS}

\subsection{Input Voltage}

The proposed Push Pull power supply with active power factor correction must follow specific design constraints in order to provide sufficient characteristics for Switch Mode Power Supply (SMPS) use. In the U.S., common inputs to SMPS range anywhere from $80 V_{r m s}-280 V_{r m s}$ where the nominal AC voltages delivered to homes is either $240 V_{r m s}$ or $120 V_{r m s}$. For standard SMPS application, the nominal voltage is $120 V_{r m s}$ because this is the most widely used voltage delivered to rectifiers for conversion to a lower DC voltage for computer applications. However, this design is only for proving that the converter provides power factor correction. Therefore, the input applied to the Push Pull converter will be $20 V_{r m s}$ nominal because with a lower input voltage, voltage and current stresses on the components will be reduced. This reduced component stress reduces the cost of components used to perform hardware implementation, but does not restrict the scope of SMPS application because designs can be adjusted to accommodate $120 V_{r m s}$.

\subsection{Input and Switching Frequency}

The input frequency at which this input voltage will be delivered is going to be $60 \mathrm{~Hz}$ because utilities in the U.S. standardize the frequency to this value. If the power supply were to be designed in most countries outside the US, a standard of $50 \mathrm{~Hz}$ would be used.

The other critical frequency in SMPS operation is the switching frequency of the switches which allows for power factor correction by switching the current faster than the 
input line frequency so that the input current can closely match the input voltage waveform. Typical switching frequencies of offline SMPS's are anywhere from $25 \mathrm{kHz}$ to $500 \mathrm{kHz}$ where higher frequencies result in smaller components used in the SMPS [26]. The reason for the smaller size in components is because the sizing of the inductor, capacitor, and power transformers are inversely proportional to the switching frequency [26]. While higher switching frequencies yield a smaller SMPS, higher frequencies also contribute to more switching losses which result in lower efficiency. To compensate for both tradeoffs, while designing with size not being a critical factor, and efficiency more important, a mid range switching frequency of $100 \mathrm{kHz}$ is going to be implemented for the proposed Push Pull power supply.

\subsection{Output Voltage and Current}

The output is critical in providing power to the load as well as a sufficient voltage for the operation of all DC appliances connected to the output. With this application however, the circuit is only being tested to provide power factor correction. As the controller is implemented, it does not provide output voltage regulation because there is not an output feedback to the controller. Therefore the resulting output voltage and output current is predetermined based on the input voltage applied to the converter and selected switching speed on and off times which will later be addressed as duty cycle. For applications as a SMPS, a DC-DC converter would need to be implemented on the output of this converter to provide a solution for implementing AC-DC conversion, power factor correction, and load regulation. Many possibilities for this converter are available in implementing the desired SMPS characteristics, but before these can be considered, an ideal PF of 1 must be achievable. 


\subsection{Power Factor and Efficiency}

For this SMPS to be viable for useful operation, efficiency and power factor must meet specific standards. For a power supply to meet Energy Star guidelines, the efficiency must be above $80 \%$. While this efficiency is definitely achievable with added circuitry such as snubbers and soft switching techniques, this design does not investigate those options. This circuit is a bare essential testing circuit for concept and efficiency, and while in the future it will need to be considered, it will not be addressed as a priority at this moment.

The power factor for many power factor corrected SMPS's need to meet standards based on international regulations. For passive PFC, power factors of 0.85 can be obtained, but because this Push Pull converter is an active PFC circuit, the power factor required is higher. This Push Pull converter must be able to obtain a power factor of 0.9 at full load to meet Energy Star guidelines. If the power supply meets all criteria described and listed in Table 3-1, then the Push Pull power supply with active power factor correction is a promising solution for SMPS applications.

Table 3-1: Push Pull Converter Design Constraints

\begin{tabular}{|c|c|}
\hline Circuit Design Variable & Design Value \\
\hline Input Voltage & $20 \mathrm{Vrms}$ \\
\hline Input Frequency & $60 \mathrm{~Hz}$ \\
\hline Switching Frequency & $100 \mathrm{kHz}$ \\
\hline Power Factor & $>0.9$ \\
\hline
\end{tabular}




\section{CONVERTER DESIGN \& SIMULATION}

The proposed converter for power factor correction and rectification is shown in Figure 4-1. It is a current fed push pull converter and each component value listed are actual component values that will be addressed to finalize the circuit for hardware implementation. Explanations and simulations will be presented so that successful hardware implementation can be verified.

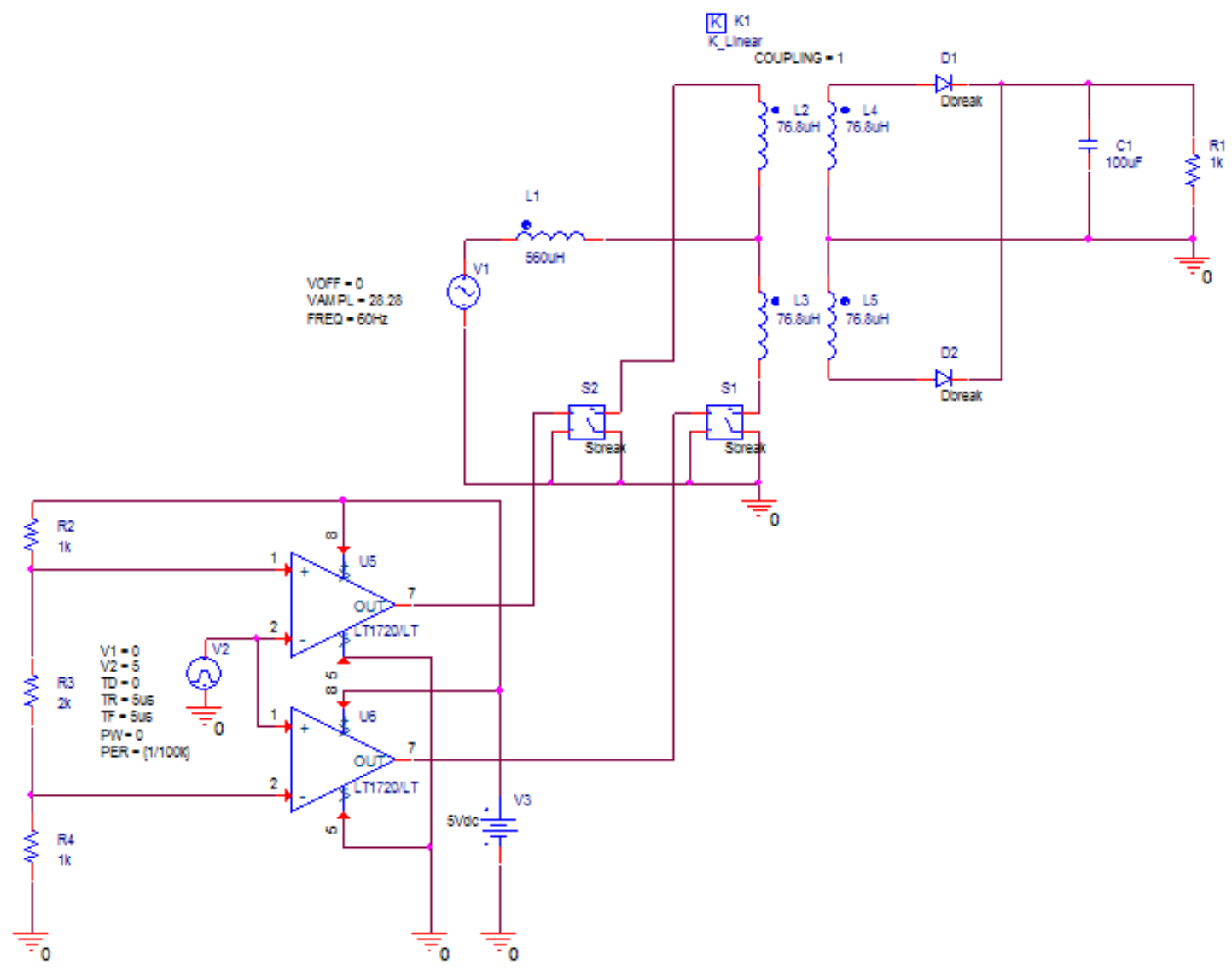

Figure 4-1: Current Fed Push Pull Converter with Pulse Switch Control 


\subsection{Duty Cycle}

The fundamental operation of this converter to perform power factor correction is accomplished through the two switches. Each of these switches will be designed to operate at $100 \mathrm{kHz}$. While each switch is running at the same frequency, they do not turn on and off at the exact same time because of the different voltage references in Figure 4-1. In order for the switching operation for this converter to be successful in providing rectification as well as inductor charge and discharge paths, switch 1 is delayed by half a period or $5 \mu \mathrm{s}$. The duty cycle that is chosen for each switch must be equal and more importantly, the duty cycle must be greater than 0.5 so that the inductor current is not allowed to stop instantaneously. If the inductor current is forced to stop, the voltage across the inductor will spike very high and the switches will fail.

In considering the chosen duty cycle for the converter, the duty cycle is the direct contributor to how long the inductor will charge and discharge because it determines the on time of the converter as well as the off time of the converter by how long the switches remain on and off. The time at which one switch is on and the other switch is off is during the time when the inductor is discharging. So determining the duty cycle will directly affect the time allowed for the inductor to charge which is during the on time of both switches as well as the time right after the inductor has fully discharged. When testing simulations of the converter in Figure 4-1 at different operating duty cycles, differences with the output voltage and operating currents were observed. For a lower duty cycle which was tested to be 0.55 , the output voltage was roughly $114 \mathrm{~V}$, which resulted in lower voltage and current ratings for components than the duty cycle of 0.75 , which resulted in $120 \mathrm{~V}$ output and slightly larger operating currents, roughly tens of 
milliamps larger. Consider that this converters design does not incorporate a feedback loop to control the output because this is only testing proof of design for power factor correction, so duty cycle is directly related to the value of output voltage. When the duty cycle however was driven higher at 0.95 , the converter would begin to saturate the input inductor because more time was allowed to charge the inductor than was needed and not enough time was given for the inductor to discharge through the output path of the diodes.

Also important when considering duty cycle is the overlap time between the two switches, because as mentioned if there is no overlap, the current stopping instantly through the input inductor will produce large voltage spikes. So to account for safety factors in reducing the chance for realistic time delays and capacitive gate to source charging affecting the overlap, a 0.75 duty cycle was chosen to ensure sufficient switch on time overlap. In Figure 4-2, control circuitry to produce the pulses required to drive the MOSFETs on and off is shown. 


\subsection{Control Circuitry}

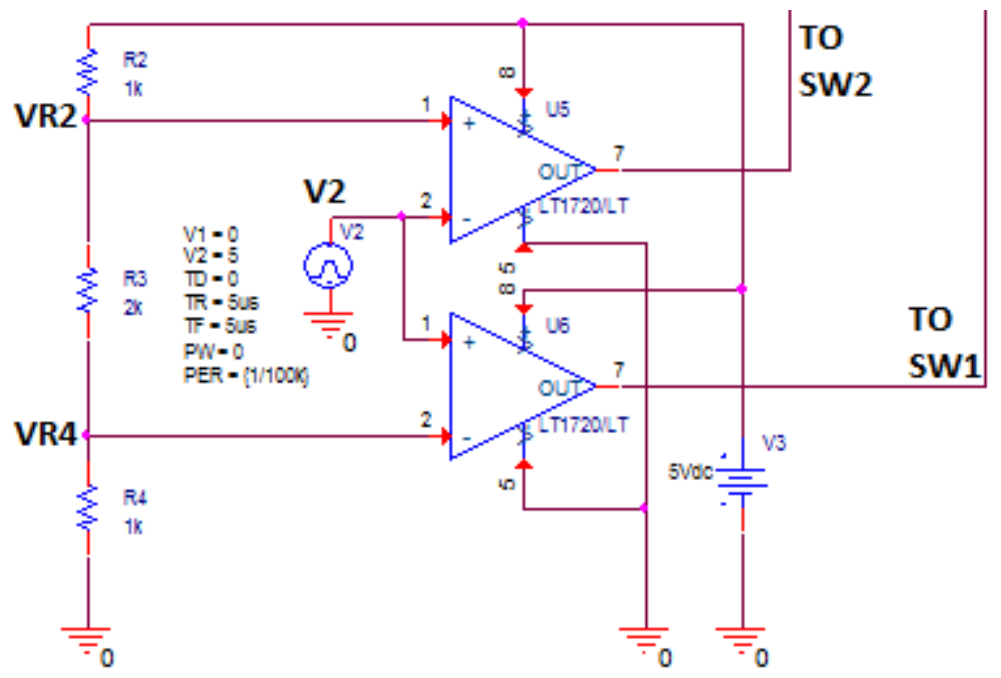

Figure 4-2: Switch 1 and Switch 2 Controller Configurations

The operation of the controller in Figure 4-2 utilizes a triangle waveform applied at node V2 and comparators to create two square wave pulses so that one pulse is delayed with respect to the other pulse. Figure 4-3 shows the triangle waveform generated at node V2, as well as the two constant voltage values that are measured at node VR2 shown in red and VR4 shown in blue.

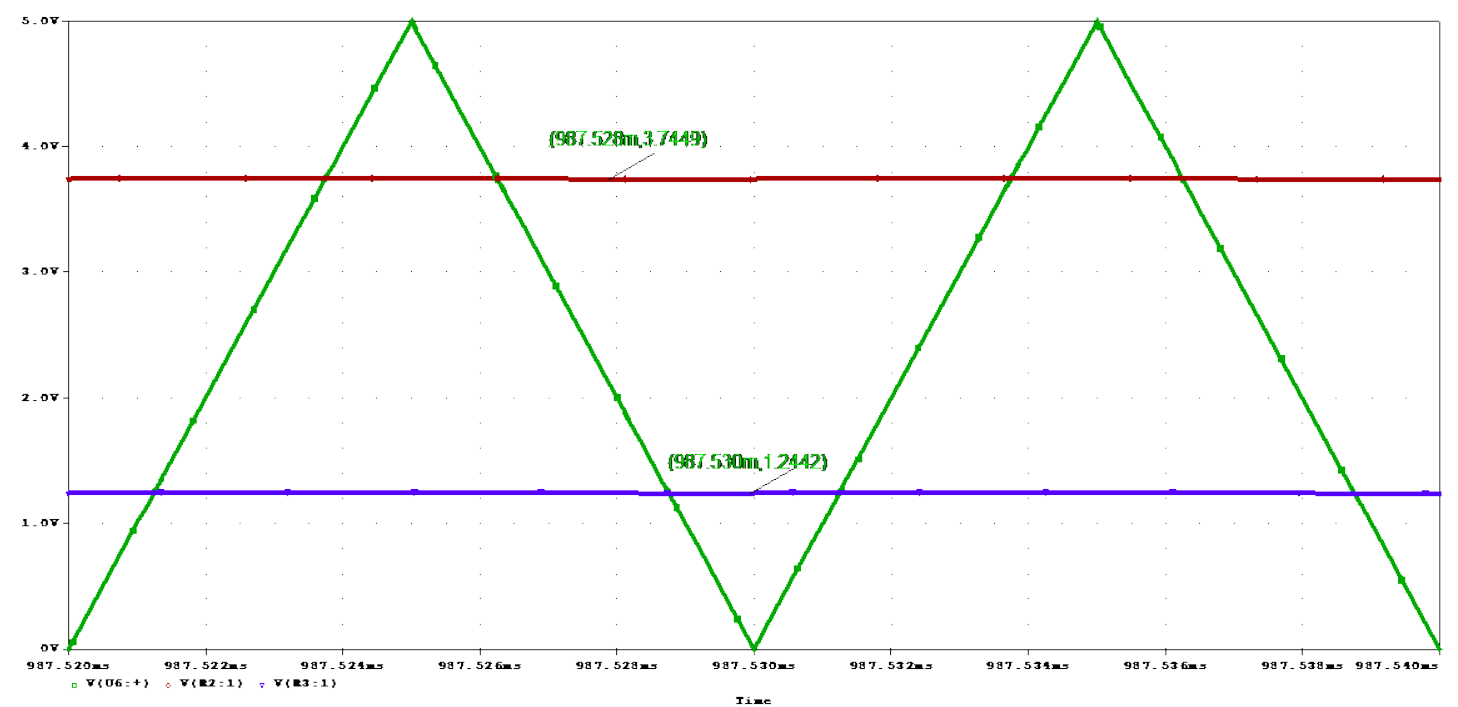

Figure 4-3: Comparator Voltage References and Input Triangle Waveform 
The top comparator in Figure 4-2 operates when a triangle waveform is fed to the negative input and a reference voltage is provided to the positive input of the comparator at node VR2. The output voltage of this comparator will exhibit an instant change when the reference voltage is passed by the alternating triangle waveform. Figure 4-4 shows the triangle waveform and the voltage reference at VR2, which is calculated to be $3.75 \mathrm{~V}$ by the equations below. Whenever the triangle waveform at node $\mathrm{V} 2$ passes $3.75 \mathrm{~V}$, the output waveform will drop to almost zero volts because the normally higher positive input potential to the comparator is now lower than the negative terminal to the comparator, so the input goes low. Then when the triangle waveforms slope is on the negative slope cycle and it passes the $3.75 \mathrm{~V}$ reference, a voltage rise in the output will occur because the reference at positive input has returned to being higher than the negative input.

$$
\text { Slope }=\frac{5 V}{5 \mu s}=1 \frac{V}{\mu s}
$$

Given: Duty Cycle of 0.75

Time at which Triangle Wave is $3.75 \mathrm{~V}=3.75 \mu \mathrm{s}$

$$
V_{\text {ref-high }}=1 \frac{V}{\mu s} * 3.75 \mu s=3.75 \mathrm{~V}
$$




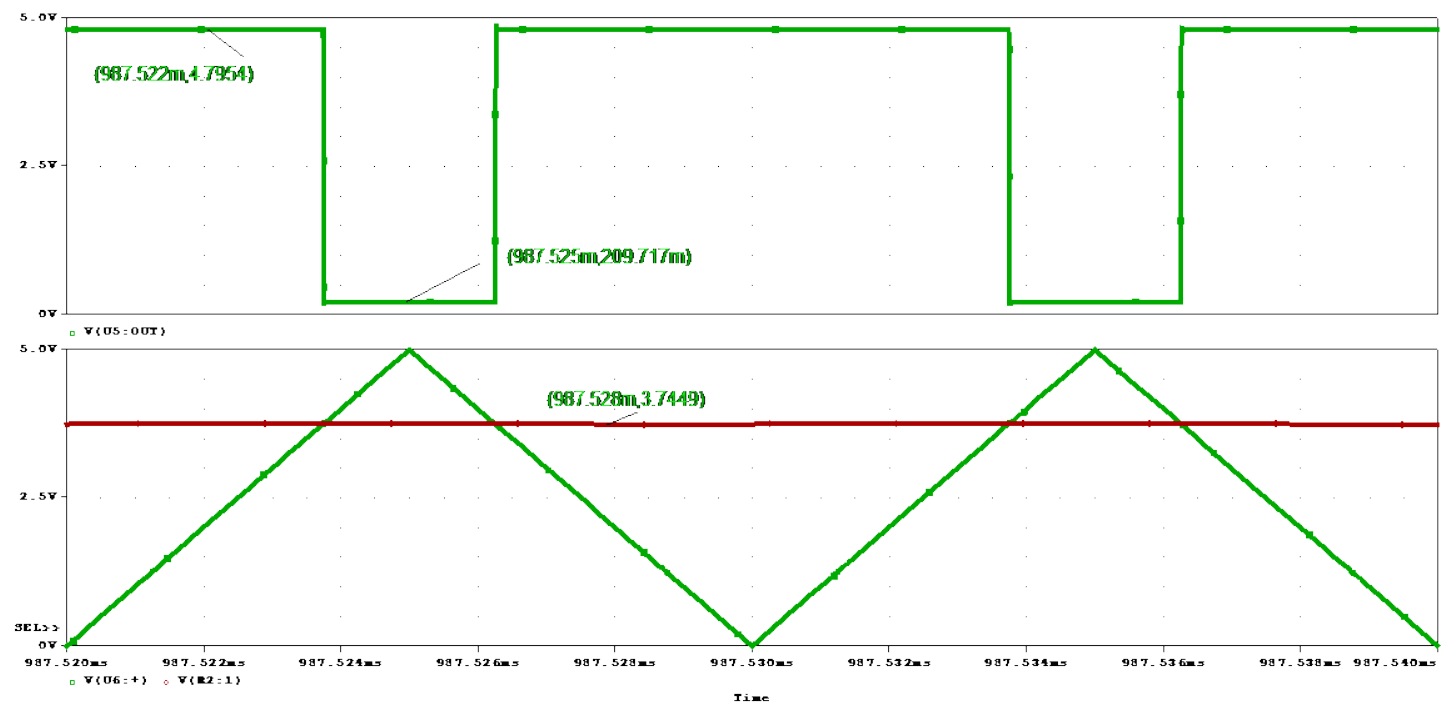

Figure 4-4: Switching Voltage (top) from Triangle Waveform and Voltage Reference (bottom)

The bottom comparator in Figure 4-2 must provide the same switching functions as the first comparator however an overlap must be created so that the pulse is allowed to be on while the other pulse is off. This is accomplished by applying the triangle waveform pulse to the positive input of the second comparator and the voltage reference to the negative input. This will now provide an inverted switching signal in relation to the first and at a different switching time. From the equations below, the timing of this signal with respect to the first signal can be determined to be half a period based on the voltage reference chosen at VR4. Figure 4-5 shows that when the voltage reference is exceeded the pulse will now go high and when the voltage reference is passed on the negative slope of the triangle waveform, the pulse will go low. This method of applying the voltages to opposite polarity inputs of the comparators creates the overlapping characteristic needed for the current fed topology and can be confirmed with the pulses compared in Figure 4-6. 


$$
\text { Slope }=\frac{5 V}{5 \mu s}=1 \frac{V}{\mu s}
$$

Given: Duty Cycle of 0.75

Time at which Triangle Wave is $1.25 \mathrm{~V}=1.25 \mu \mathrm{s}$

$$
V_{r e f-h i g h}=1 \frac{V}{\mu s} * 1.25 \mu s=1.25 \mathrm{~V}
$$

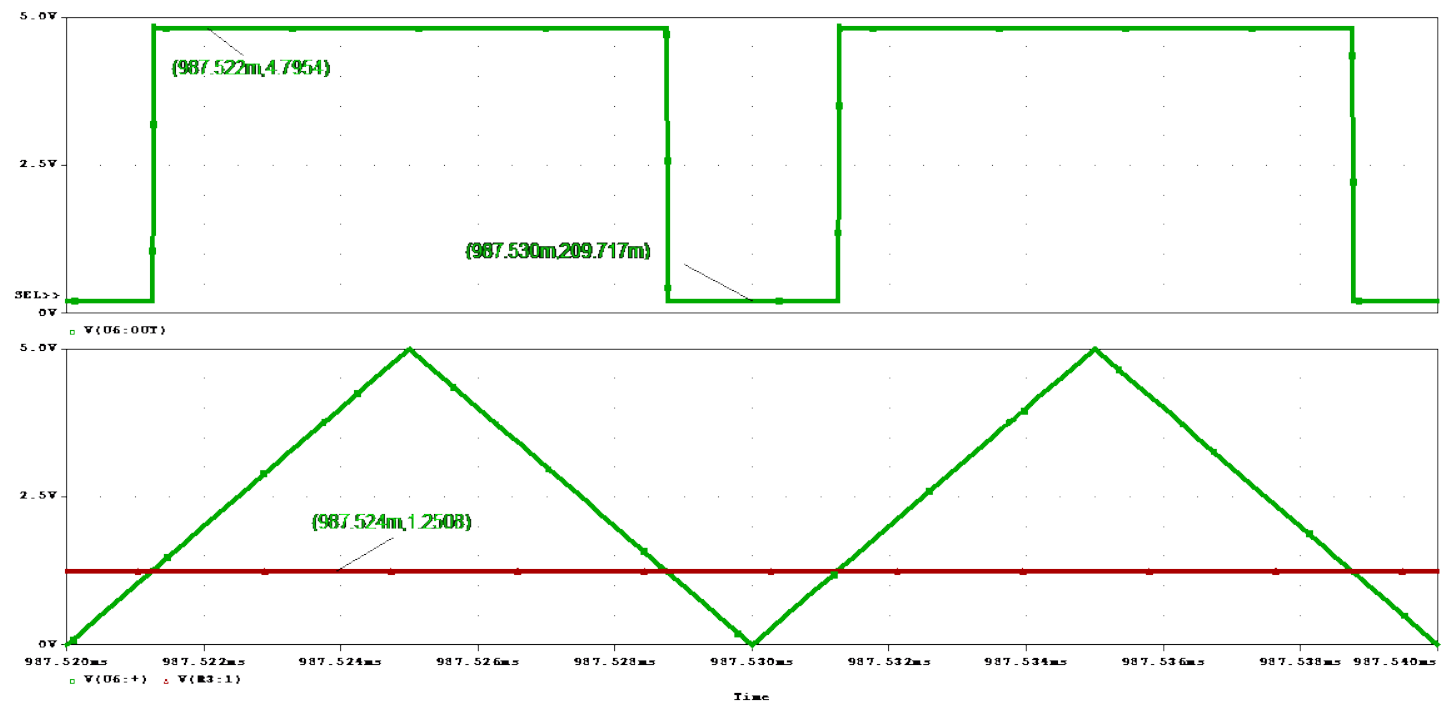

Figure 4-5: Switching Voltage (top) from Triangle Waveform and Voltage Reference (bottom) 

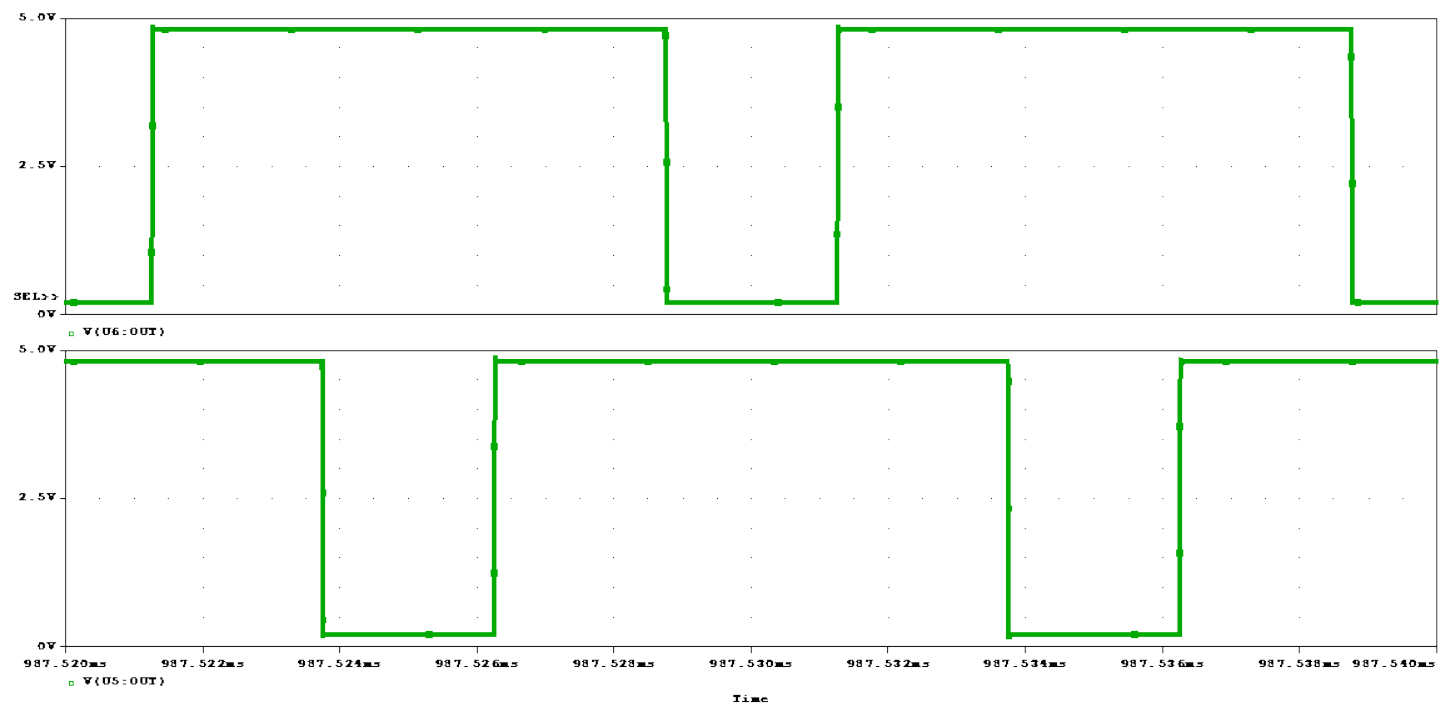

Figure 4-6: Switching Voltage Pulses with Duty Cycle of 0.75

From the circuit in Figure 4-2, the resistor values are determined based on the voltage drops that result from the voltage applied to the comparators. Since 5V is applied to turn on the comparators which are chosen because the applied triangle wave has a $5 \mathrm{~V}$ peak, the resistors chosen must divide the voltage down by $1.25 \mathrm{~V}$ across the top resistor to obtain $3.75 \mathrm{~V}$ and then $2.5 \mathrm{~V}$ so that the second reference is $1.25 \mathrm{~V}$. This results in a $1 \mathrm{k} \Omega$ resistor for the top and bottom resistor and a $2 \mathrm{k} \Omega$ for the middle resistor while the lowest resistor will be $1 \mathrm{k} \Omega$ so that the voltage drops are either a quarter or half of the supplied voltage.

\subsection{Input Voltage Phase Shift and Power Factor}

In order for this converter to successfully correct power factor, the input voltage must be tested to change in phase with respect to 0 degrees. If the input current can be started at the time where the input voltage begins to rise from $0 \mathrm{~V}$, then the PF is driven close to 1 . Testing this ensures that as in real world applied voltage, the sine wave is 
never guaranteed to start at exactly the same point when the circuit is turned on. Figure 4-7 through Figure 4-12 show that whether the input voltage has a phase angle of 0 degrees, 90 degrees or 120 degrees, power factor close to 1 is maintained.

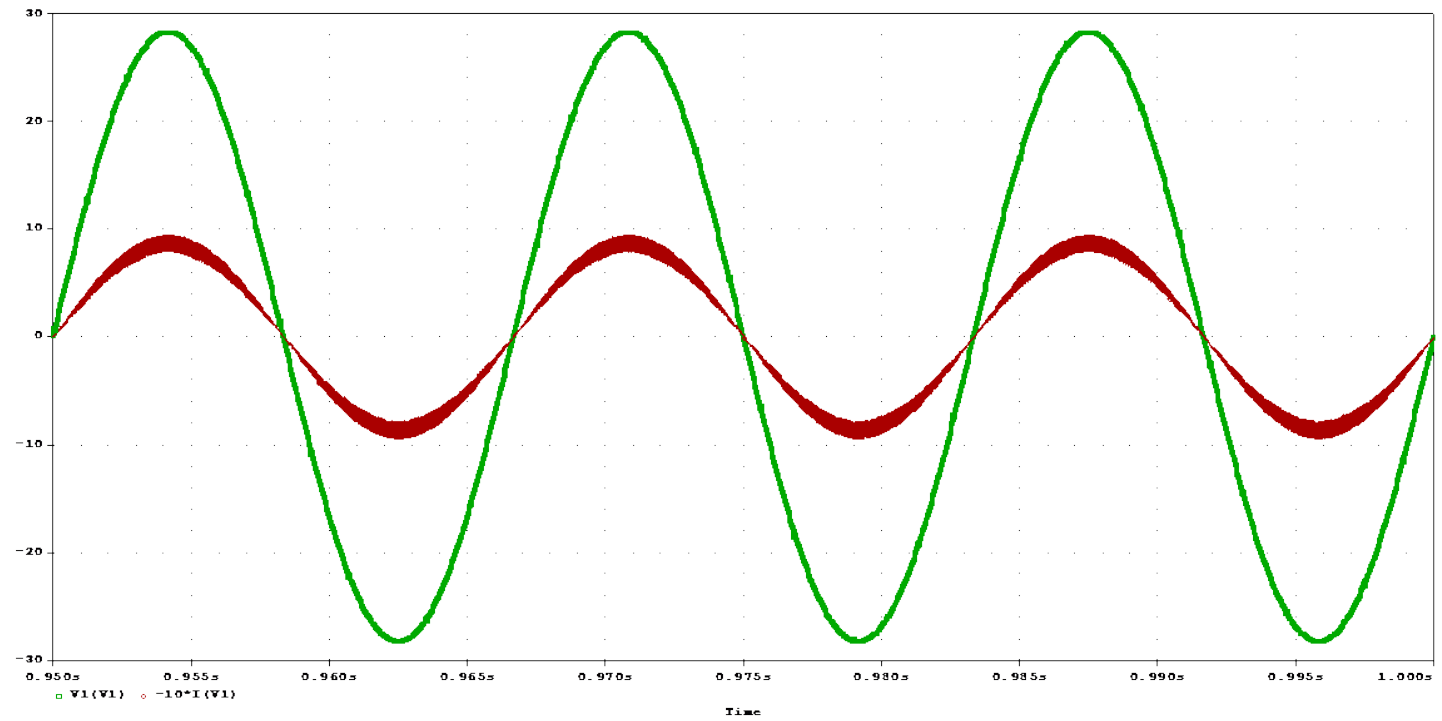

Figure 4-7: Input Voltage (green) with no phase shift and Input Current (red)

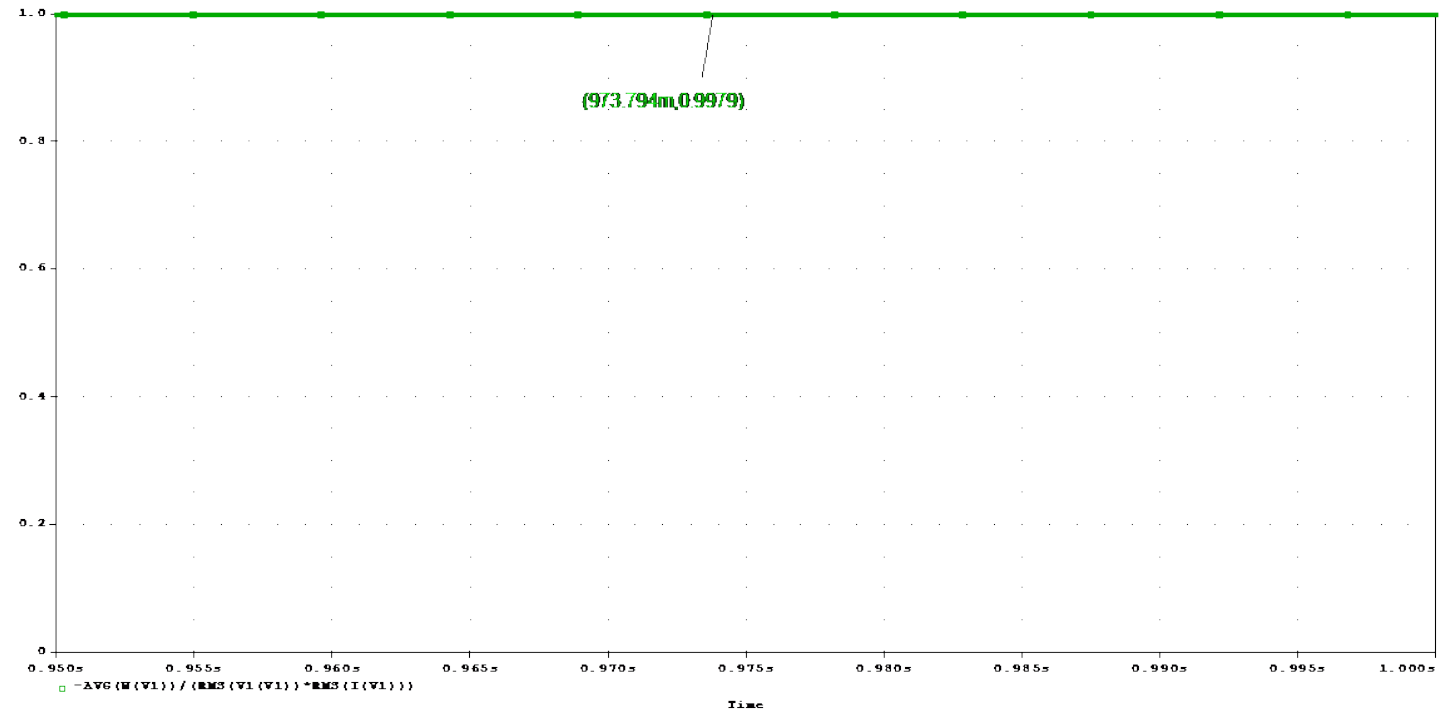

Figure 4-8: Input Power Factor with Input Voltage not phase shifted 


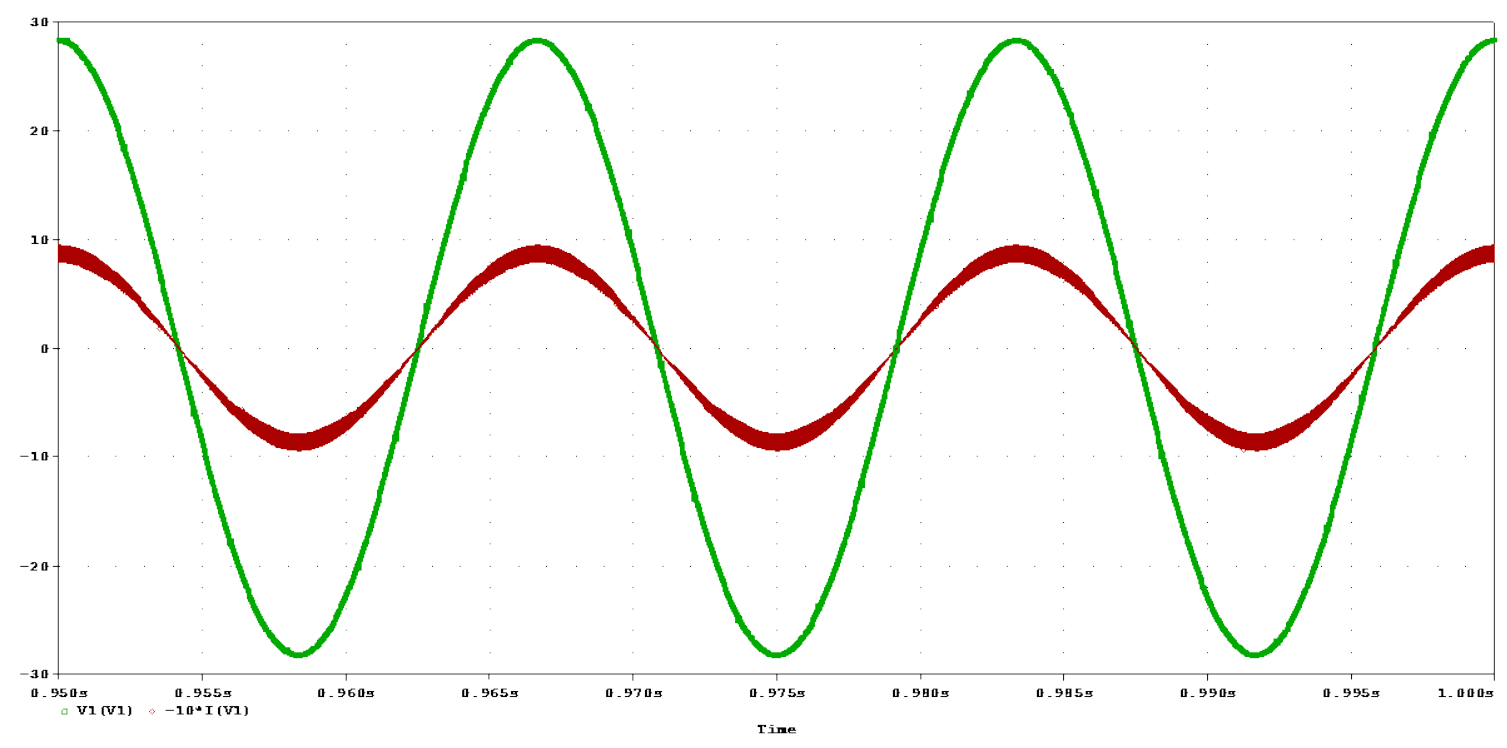

Figure 4-9: Input voltage (green) with phase shift of 90 degrees and Input Current (red)

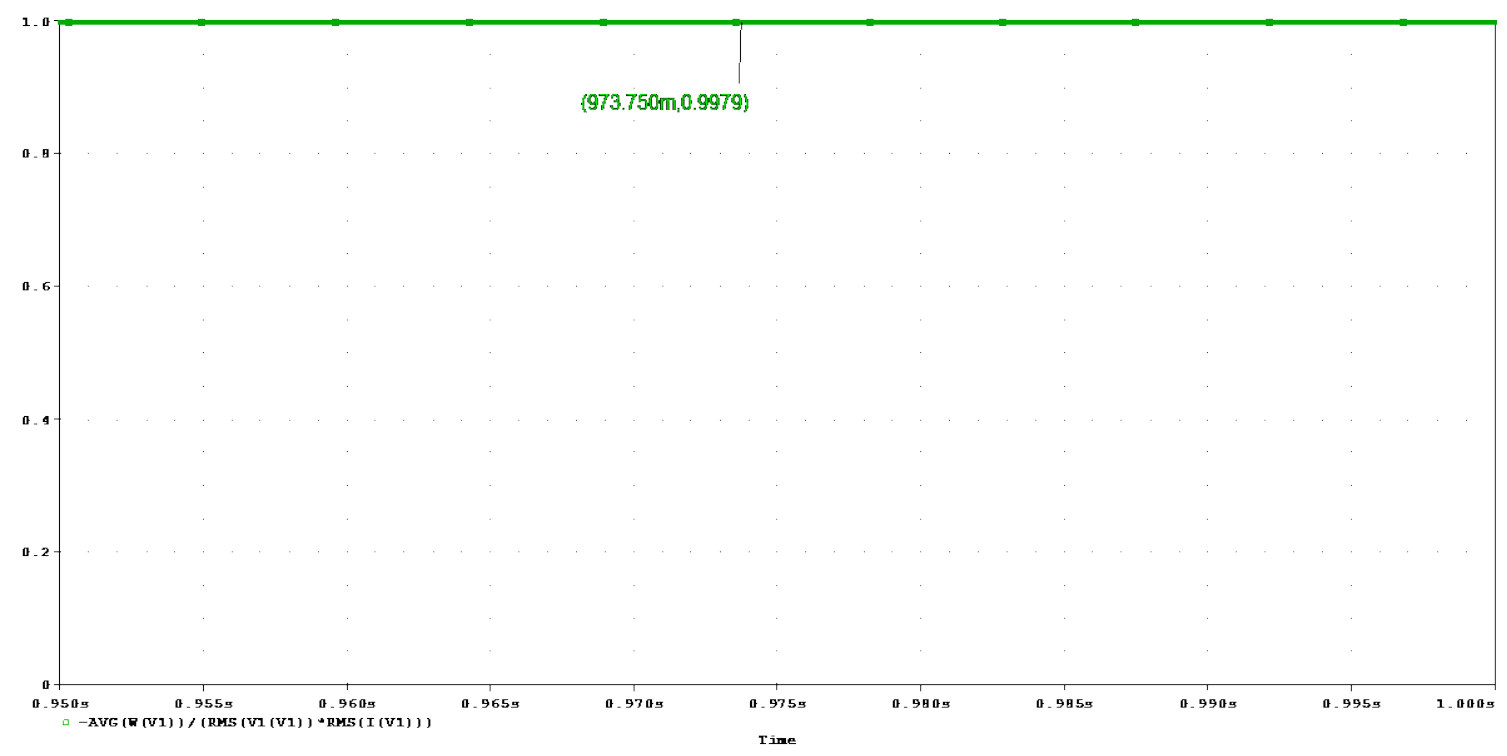

Figure 4-10: Input Power Factor with Input Voltage phase shifted by 90 degrees 


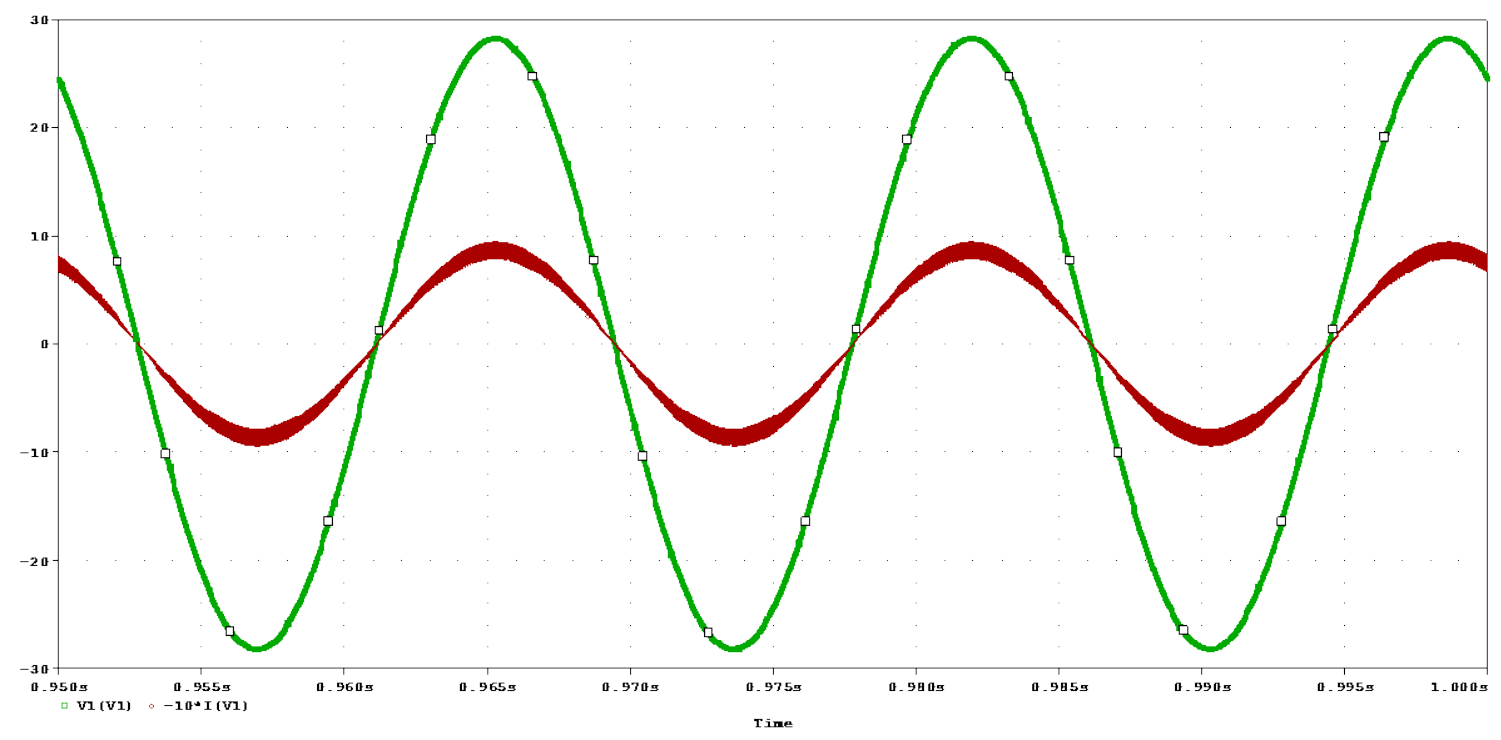

Figure 4-11: Input Voltage (green) with phase shift of 120 degrees and Input Current (red)

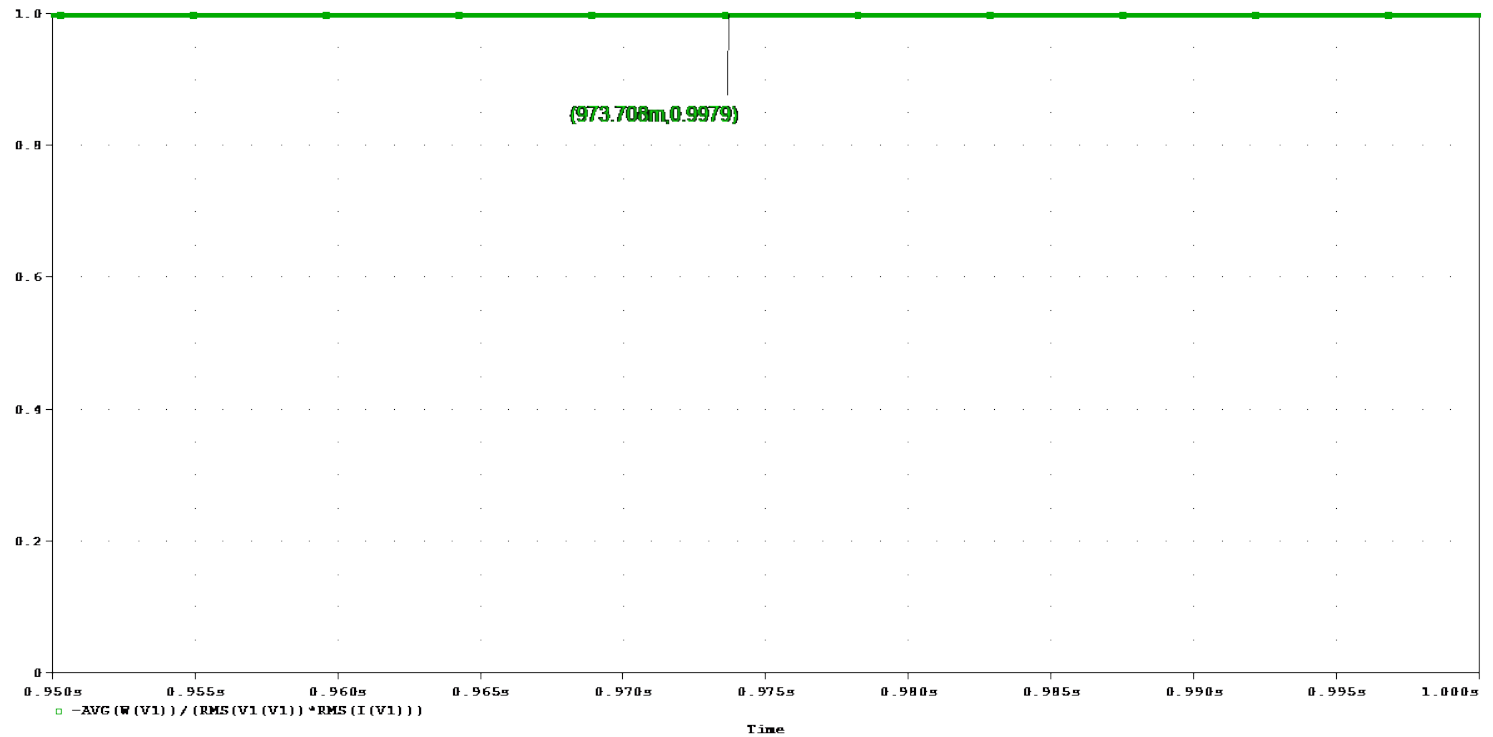

Figure 4-12: Input Power Factor with Input Voltage phase shifted by 120 degrees 
As shown Figure 4-7 through Figure 4-12, the power factor can be maintained for any shift in input voltage. While this is the most important aspect of the converter, understanding the converters operation is crucial in providing an explanation of how the power factor can be maintained at 1 . For this converter to force the input current to follow the input voltage without an input voltage sensing controller is very unique. Normally controllers base the switching pulses for the switches on what the input voltage is doing so that the current can be forced to follow its timing. In this circuit however, because the current fed operation of the push pull converter requires current to always flow through the converter on the primary side, and a load draws current continuously, the current is forced by nature of the circuit's configuration, to start when the input voltage rises. Also, the rectification stage is isolated from the input current, so a direct result of the output capacitor averaging the switching voltages of the diodes that provide rectification is not transferred back to effect the input current.

\subsection{Varying Output Load and Power Factor}

Another important component that can affect the power factor is the change in output load. For the load condition of $1 \mathrm{k} \Omega$ that is simulated, the power factor is 0.998 . This load is actually simulating a low load with respect to current because as resistance increases; current decreases, which is normally a measurement of load in converters. While this is very good for purposes of implementing this circuit in hardware, loads are not always constant. To confirm that power factor can be maintained close to 1 , varying loads of $200 \Omega, 400 \Omega$ and $800 \Omega$, are simulated and the corresponding power factor will be measured to make sure this circuit continues to provide power factor correction. As 
resistive load decreases, the current representation of load increases, so for a $200 \Omega$, the highest current compared to the other resistive loads will result.

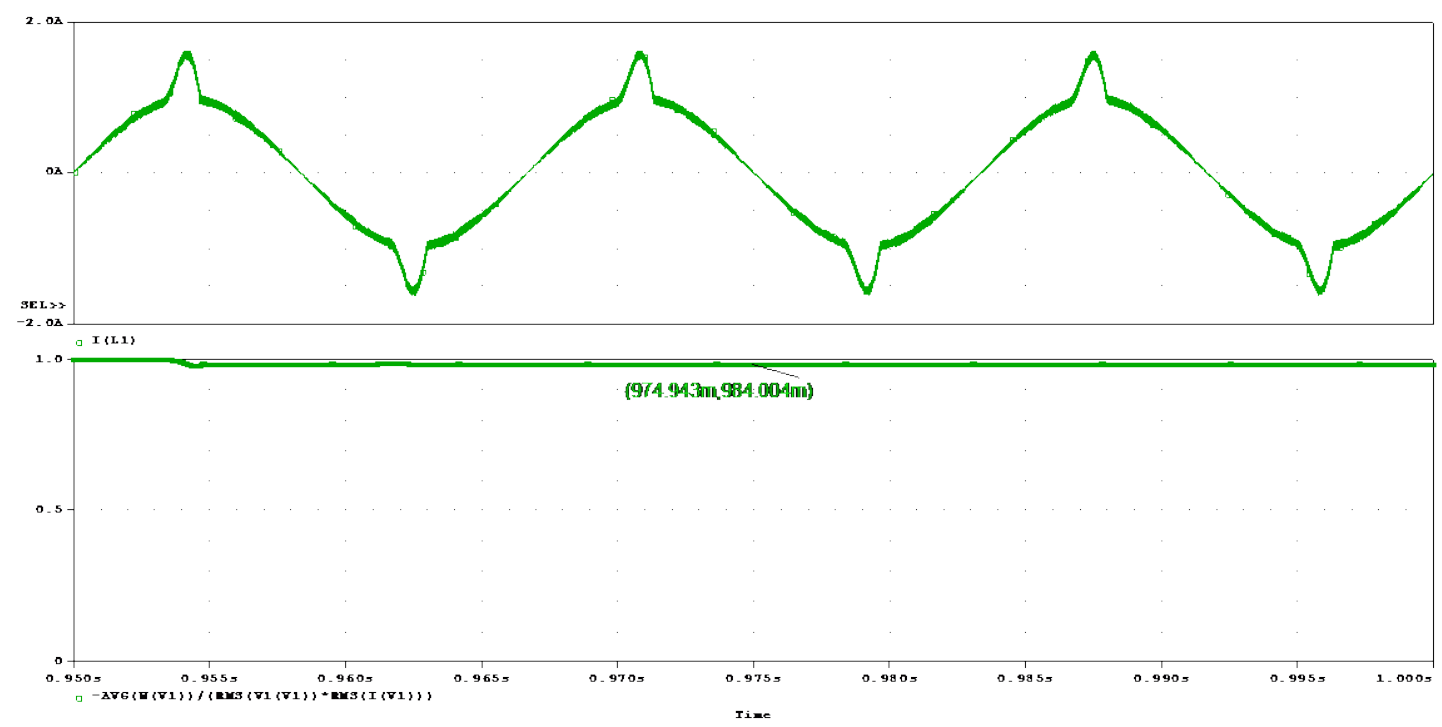

Figure 4-13: Input Current Waveform (top) and Power Factor with 200 $\Omega$ Load (bottom)

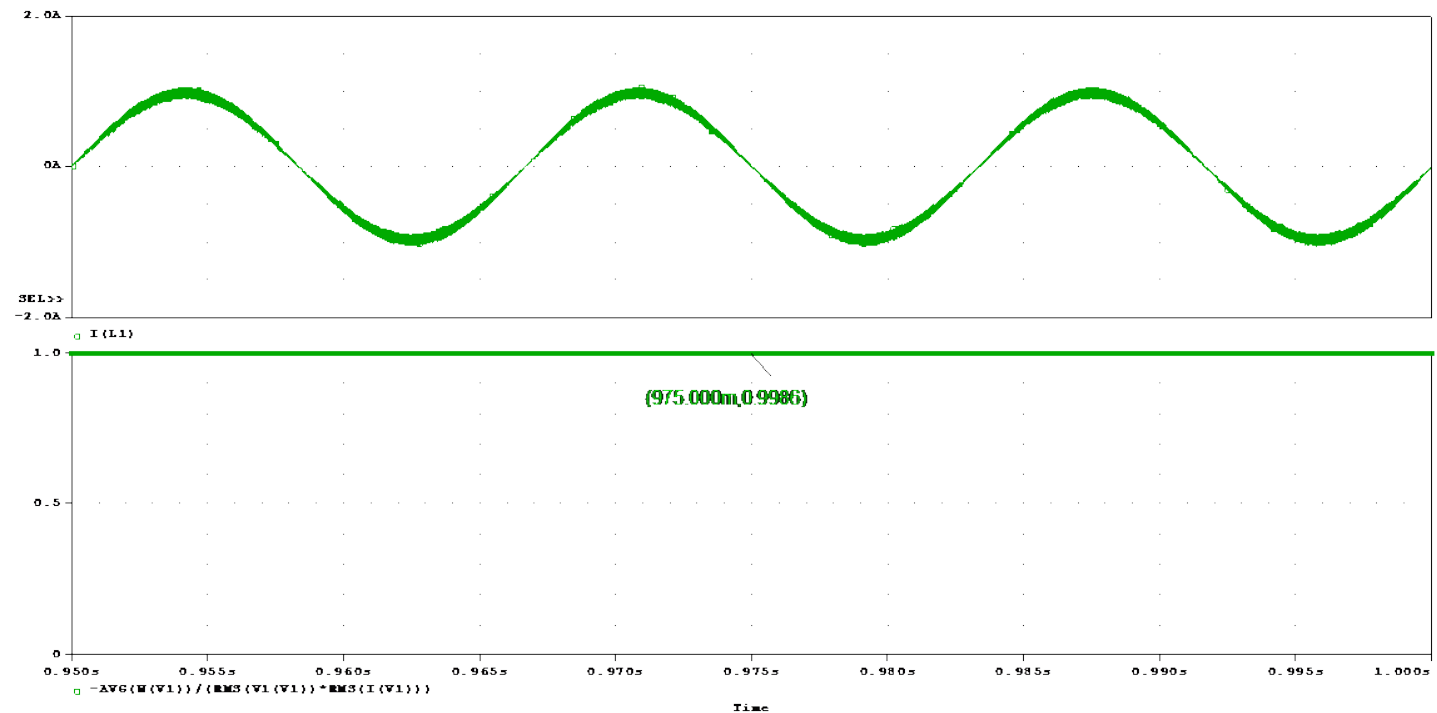

Figure 4-14: Input Current Waveform (top) and Power Factor with $400 \Omega$ Load (bottom) 


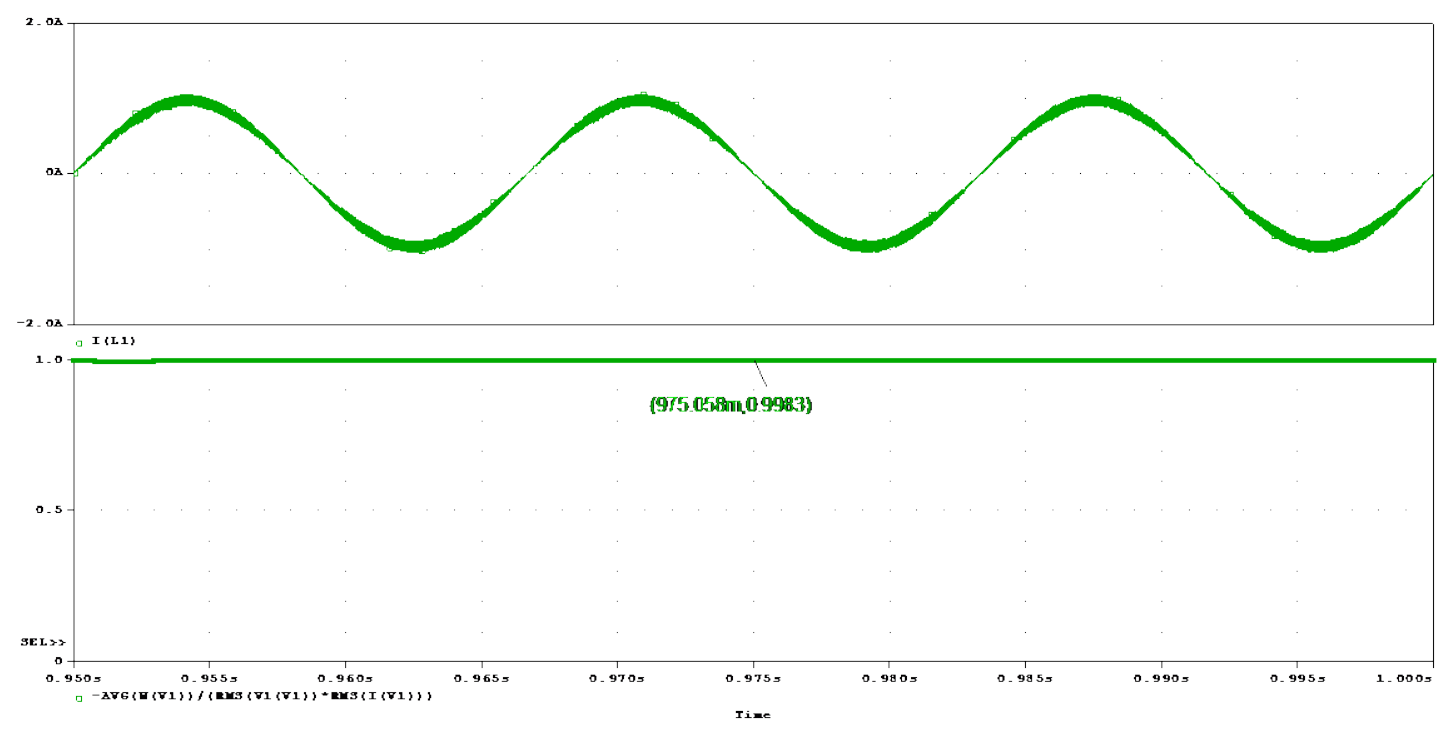

Figure 4-15: Input Current Waveform (top) and Power Factor with $800 \Omega$ Load (bottom)

Notice from Figure 4-13 through Figure 4-15 that as current load increases, or resistive load decreases, power factor begins to decrease. The input current does not exhibit a pure sinusoidal waveform, but when viewing the power factor, it only decreases by 0.01 . This is not a significant drop and power factor is still maintained above 0.98 , verifying it is a viable option for a power factor correction circuit.

\subsection{Input Inductor Characteristics}

As this converter operates to match the input current to the sine wave of the input voltage, high frequency switching, and more importantly, inductor charging and discharging is occurring during the low frequency alternating input sine wave current. The input current ripple that causes the current waveforms in Figure 4-7, Figure 4-9 and Figure 4-11 to be more pronounced than the input voltage is due to the input inductors charging and discharging characteristics. This charging and discharging of the inductor is 
shown in Figure 4-16 which is a zoomed in view at a higher frequency during the lower frequency input current.

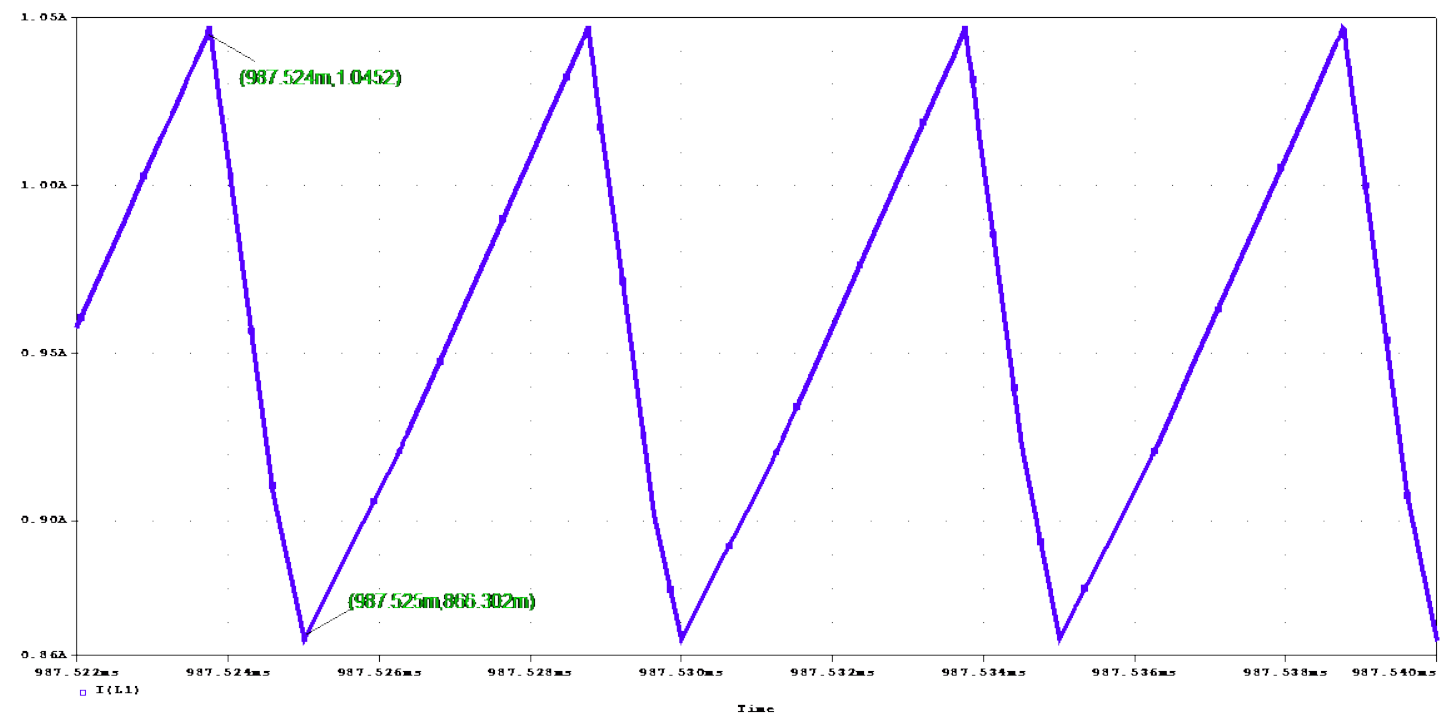

Figure 4-16: Inductor Current Ripple at peak AC input current

The input inductor current ripple in Figure 4-16 is a result of the size of the inductor chosen and the voltage across the inductor itself. Equation 4-1 is the voltage equation across an inductor, and using this equation below, a derivation shown in respect to inductor current ripple gives Equation 4-2 to obtain inductance.

$$
\begin{gathered}
V_{L 1}=L_{1} * \frac{d i_{L 1}}{d t} \\
\frac{d i_{L 1}}{d t}=\frac{V_{s}}{L_{1}} \\
\frac{\Delta i_{L 1}}{\Delta t_{o n}}=\frac{V_{s}}{L_{1}} \\
\frac{\Delta i_{L 1}}{\left(\frac{1}{2} * D\right) T}=\frac{V_{s}}{L_{1}}
\end{gathered}
$$




$$
L_{1}=\frac{V_{s}}{\Delta i_{L 1}}\left(\frac{1}{2} * D\right) T
$$

Using Equation 4-6 above which can be confirmed by the relation of inductor charging to the pulse on time in Figure 4-16, the inductance can be calculated below. For the current ripple desired, a specific limit of $0.2 \mathrm{~A}$ was chosen which allows for up to $20 \%$ ripple in respect to the $1 \mathrm{~A}$ peak that is observed on the input current. Also for the input voltage used, it is the peak input sine wave voltage. Using these two values the inductance calculated below was found to be $530 \mu \mathrm{H}$. For design considerations in choosing this inductance a $560 \mu \mathrm{H}$ inductor is chosen. However this input inductance has an effect on how the converter operates with respect to the transformer winding inductance.

$$
L_{1}=\frac{\sqrt{2} * 20 \mathrm{~V}}{0.2 \mathrm{~A}}\left(\frac{1}{2} * 0.75\right) * 10 \mu \mathrm{s}=530.33 \mu \mathrm{H}
$$

With a chosen inductor of $560 \mu \mathrm{H}$ and through simulation testing, the inductance of the transformer in Figure 4-1 was determined to be the correct size in conjunction with the inductor. What this means is, when testing the circuit in Figure 4-1 in simulation with different inductance values for the transformer, the higher the inductor value in relation to the inductance of the transformer winding would result in a higher power factor. However there was a limit to the range. If for example the inductor were $1000 \mu \mathrm{H}$ and the transformer inductance was maintained at $76.8 \mu \mathrm{H}$, then the currents and voltages would be driven higher because the inductors operation would be driven into discontinuous conduction mode. The reason for discontinuous conduction mode in a higher inductor value was because the current would charge for a longer period of time in the larger inductor. However since the ratio between inductor value and transformer inductance 
value was high, the discharge would occur quickly because the inductor was seeing a low inductance in the transformer to discharge through, therefore discharging the input current to zero.

\subsection{MOSFET Operation and Transformer Voltages}

In order to understand the charging and discharging of the input inductor, the MOSFETs switching signals must be understood. The push pull converter has two modes of operation, the time at which both switches are on at the same time, and when one switch is on while the other is off. When both switches are on at the same time as shown in Figure 4-17 where the two pulses are high at the same time, the voltages across both primary windings are zero.

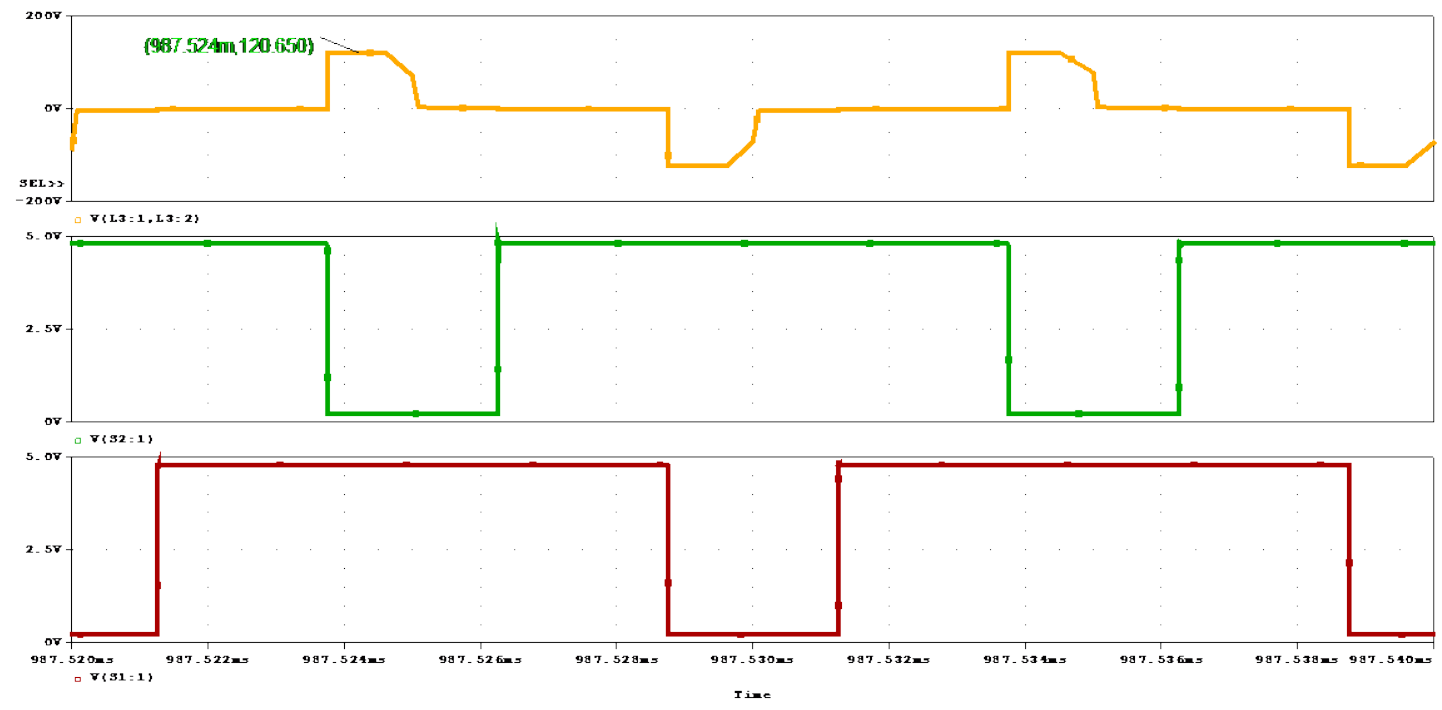

Figure 4-17: Transformer Voltage L3 (top) during Switch 1 and 2 Pulses (middle \& bottom)

The reason for this is because as the current splits through both windings, a current enters the dotted terminal of primary winding L3, and current leaves the dotted terminal of primary winding L2, which cancels the flux of both windings. Each primary 
winding at any given time always has the same voltage because each winding is coupled to one another. The primary winding voltages of L2 and L3 can be viewed in Figure 4-18 and Figure 4-19 showing zero volts when both switches are on as well as the waveforms being identical. When one switch does turn off, the voltages across both windings increases to $120 \mathrm{~V}$ because both are coupled to one another and the loop with one switch off, results in the highest spike across the switch and KVL to find the division of voltages across the winding and inductor.

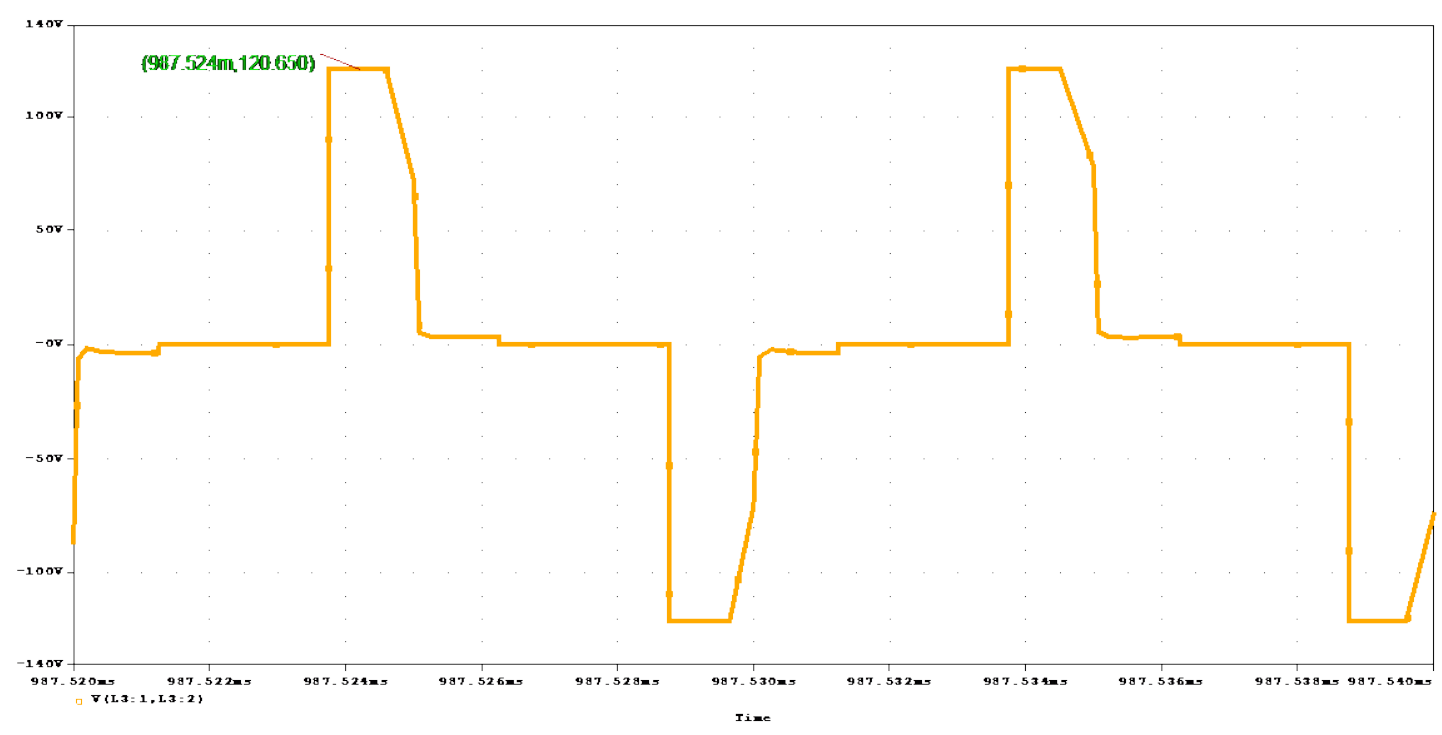

Figure 4-18: Primary Winding Voltage L3 


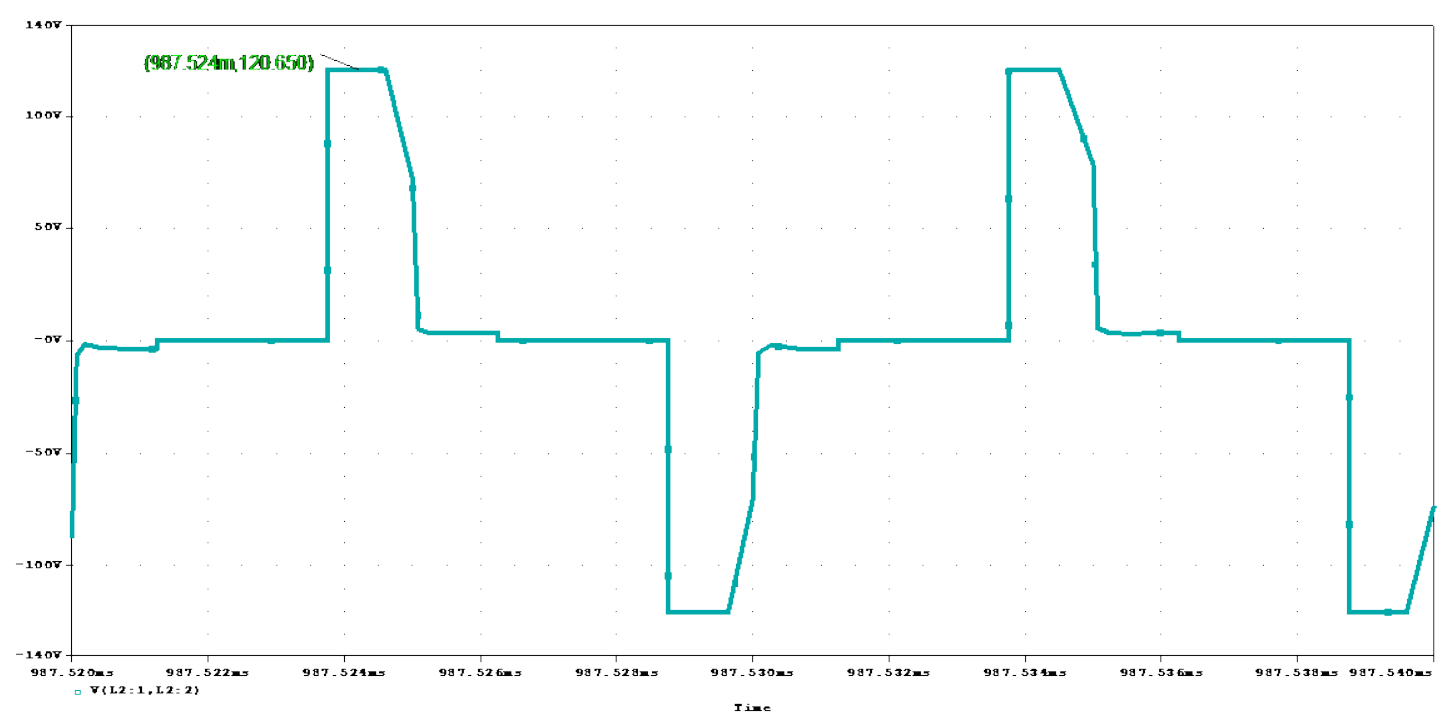

Figure 4-19: Primary Winding Voltage L2

It's important to understand also that the voltages across both primary windings are only high for half of the time when one switch has turned off and the other switch is on. The reason for this, which will be addressed later in reference to the inductors current and its charging/discharging paths, is because the input inductor only needs half of the off time of one switch to fully discharge its stored energy through the output diodes. So when the switch that is on is done providing a path to discharge the input inductor, current will cease through the output diode and the input inductor will begin to charge again.

As well as both primary transformer windings having zero volts across them, the switches also have zero volts ideally, because they are conducting. Figure 4-20 shows that this voltage is in fact zero volts and the waveforms are very similar to the primary winding voltages because one path conducts to charge the inductor and the alternate winding voltage is induced accordingly. The blue voltage spike is switch 2's drain to source voltage while the orange voltage spike is switch 1's drain to source voltage. 


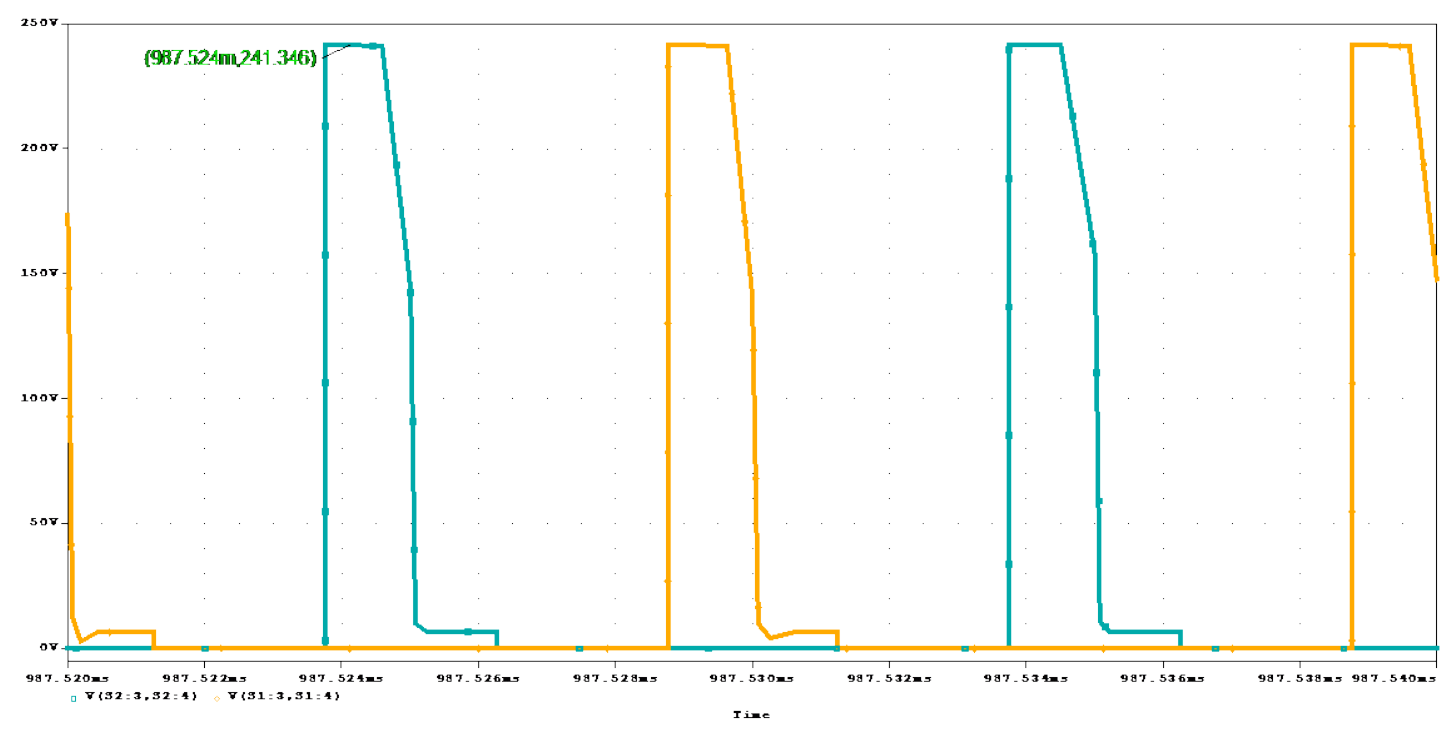

Figure 4-20: Voltage across Drain to Source of Switch 1 and Switch 2

\subsection{MOSFET Operation and Inductor Characteristics}

During the time when both switches are on, since an input voltage is applied and all other voltages across the switches and primary transformer windings are zero, the inductor current exhibits a constant positive slope as shown in Figure 4-21. 


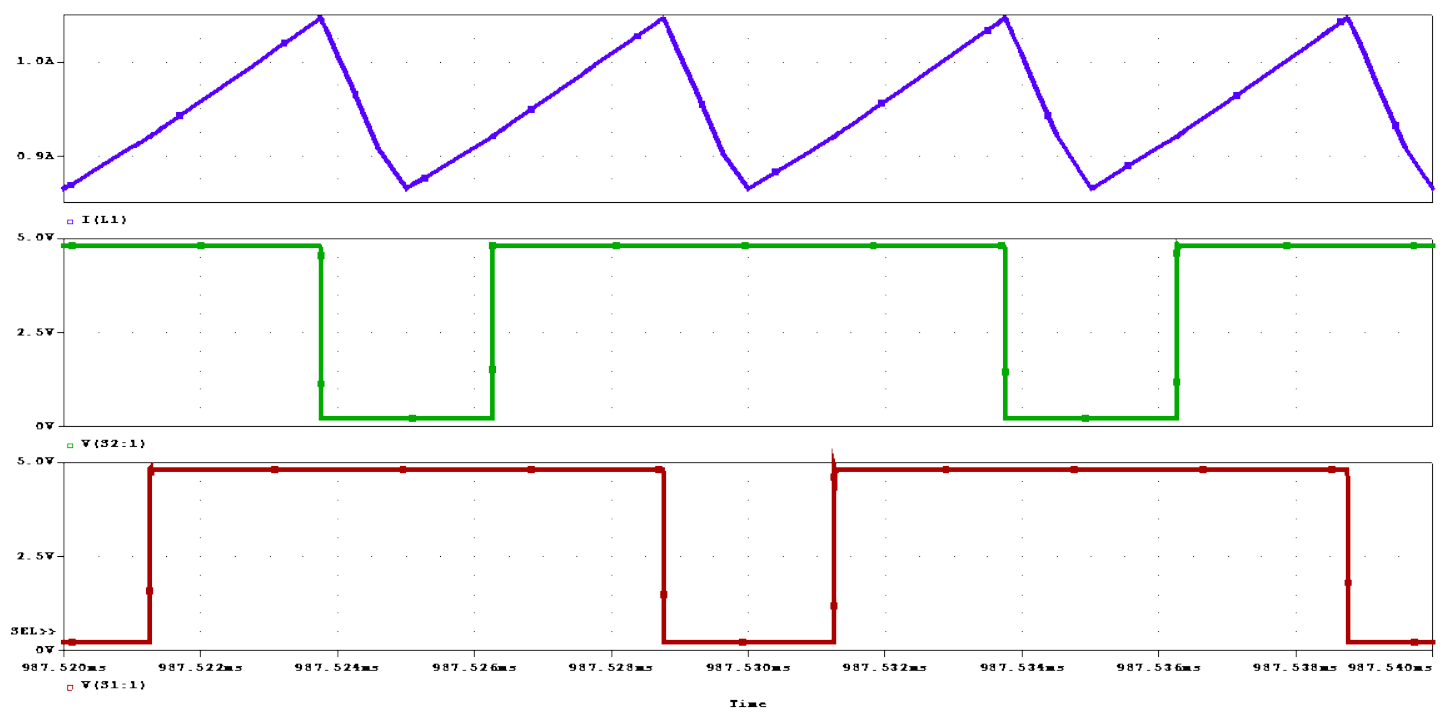

Figure 4-21: Inductor Current Ripple (top) during Switch 1 and 2 Pulses (middle \& bottom)

The inductor voltage shown in Figure 4-22 verifies that the peak positive voltage of the input is solely across the inductor. By the equations below, confirmation of voltages across the primary side components can be verified with simulation results.

$$
\begin{gathered}
V_{S}=V_{L x}+V_{\text {Prim } L 3}+V_{S W 1} \\
V_{S W 1} \cong 0 V(\text { when switch is operating }) \\
V_{\text {Prim } L 3} \cong 0 \mathrm{~V} \\
V_{S}=V_{L 1}
\end{gathered}
$$

When the switch is off however, the inductor and transformer have a voltage across them with respect to the drop across the switch and the voltage applied at the input. Using the same equation as above but solving for inductor voltage with respect to the drop across transformer winding and switch results in the same voltage in Figure 4-22 of $-92 \mathrm{~V}$. 


$$
\begin{gathered}
V_{S W 1}+V_{L x}-V_{\text {Prim } L 3}-V_{S}=0 \\
V_{L x}=-V_{S W 1}+V_{\text {Prim } 33}+V_{S} \\
V_{L x}=-241 \mathrm{~V}+120 \mathrm{~V}+28.28 \mathrm{~V}=-92.72 \mathrm{~V}
\end{gathered}
$$

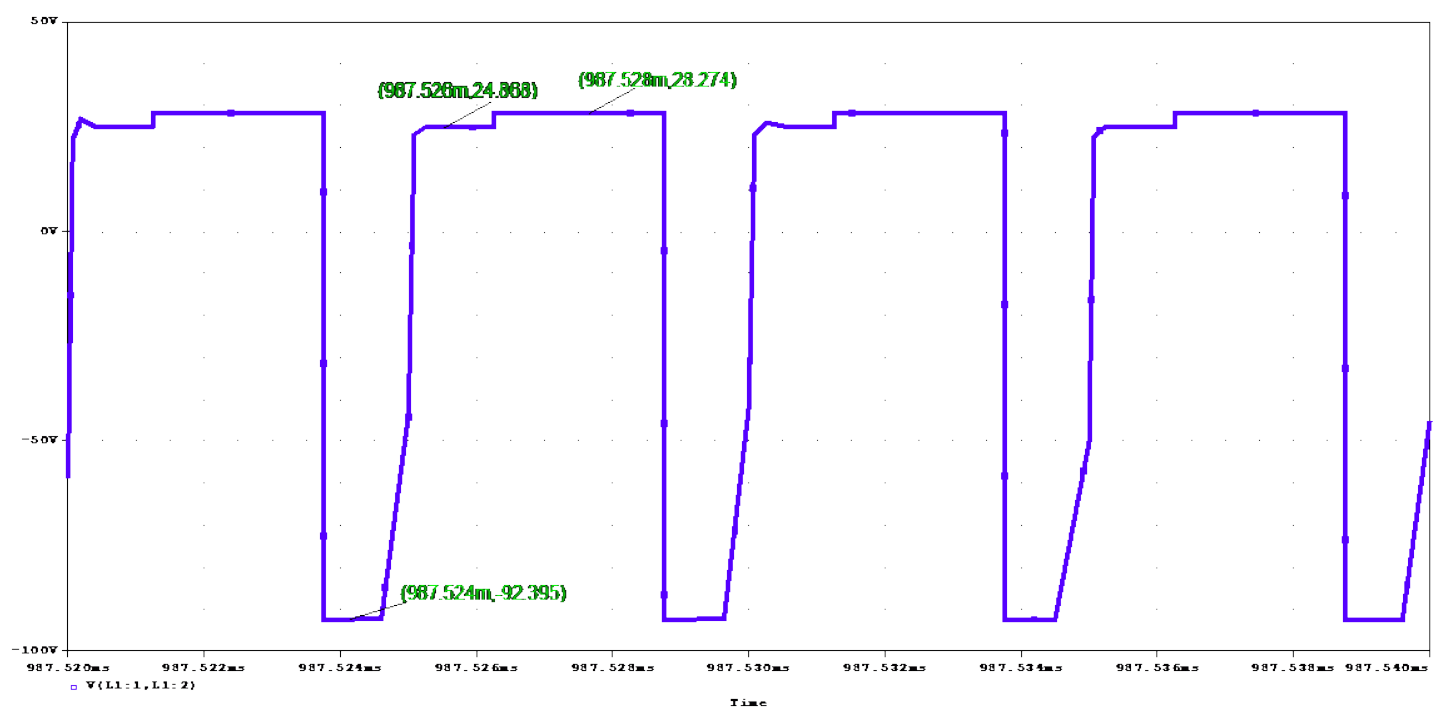

Figure 4-22: Inductor Input Voltage

During the time when both switches are on, the switch that has been on for most of the time and about to turn off provides the path for the inductor current. As shown in Figure 4-23, switch 2 has been on for $7.5 \mu$ s and during the time when the other switch turns on the inductor finishes its charging cycle. 


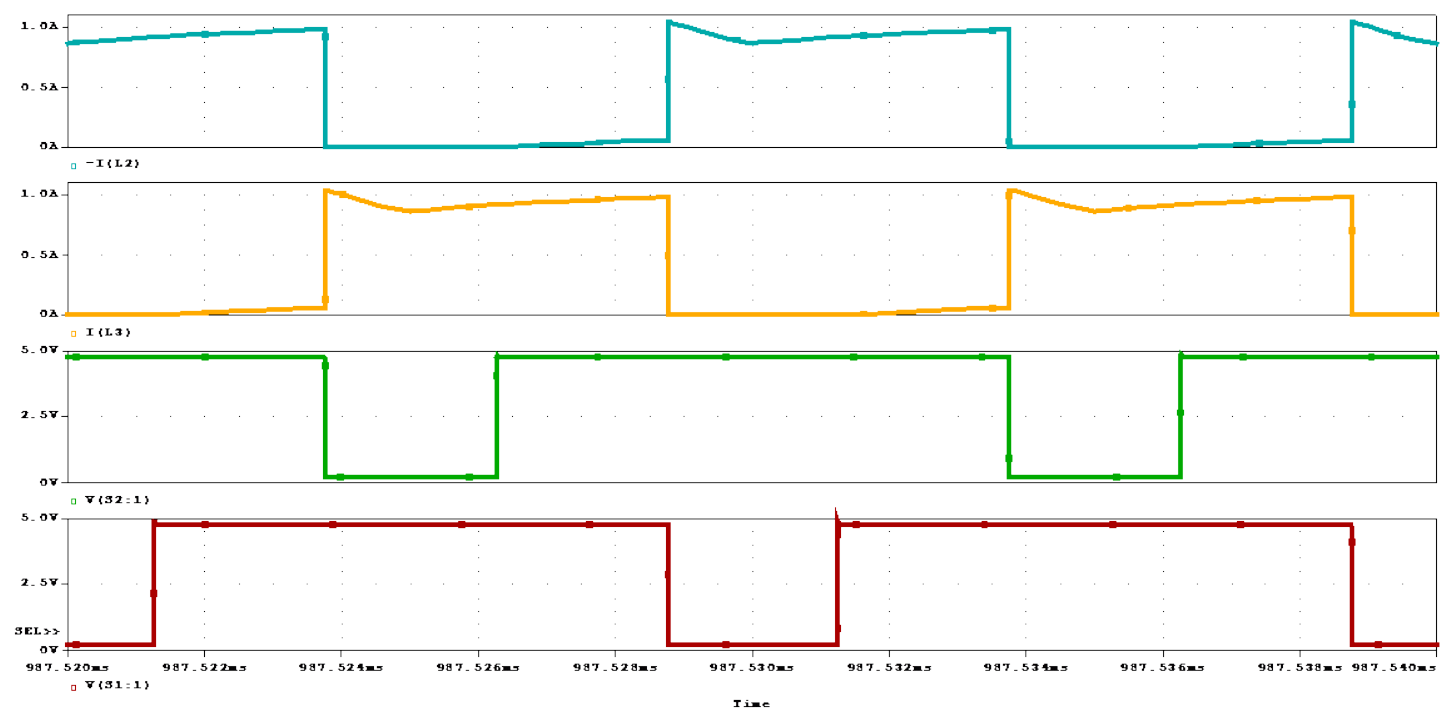

Figure 4-23: Winding L2 (blue) and L3 (orange) Currents during Switch 1 (green) and 2 (red)

\subsection{Diode Operation for Rectifying and Inductor Discharge}

Now when both switches are on and the inductor current is ramping up, no current flows through either output diode. The reason for this is because the inductor is charging and storing energy. The discharging of the inductor occurs after the time when both switches were on, and when one switch immediately turns off. As shown in Figure 4-24, both diodes have a peak inverse voltage of approximately $100 \mathrm{~V}$ during the time when both switches are on. 

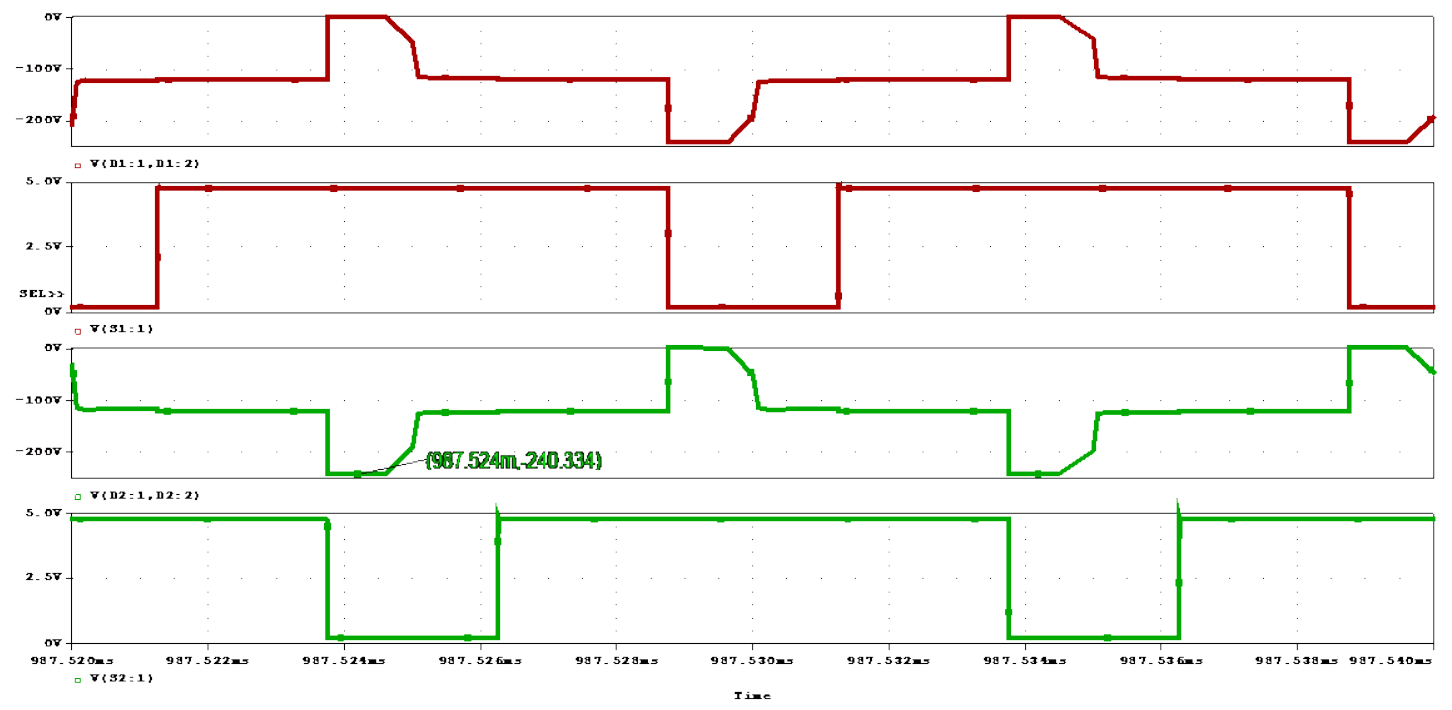

Figure 4-24: D1 (top) and D2 (third) voltages vs Switch Pulses S1 (second) and S2 (bottom)

Now when current is provided a path through only one switch, primary winding voltages of the transformers, as well as secondary windings of the transformers have induced voltages due to flux produced in the transformer cores based on current flowing into or out of dotted terminals of the transformers. Four cases exist for the discharge path of the input inductor through the transformer windings and corresponding current through the output diodes. Two of these cases are when positive AC current exists for half of the period of the $60 \mathrm{~Hz}$ low frequency input current. The current flow for when switch 1 is on by itself and positive AC current is in Figure 4-25 while the current flow through switch 2 being on by itself during positive AC current is in Figure 4-26. 


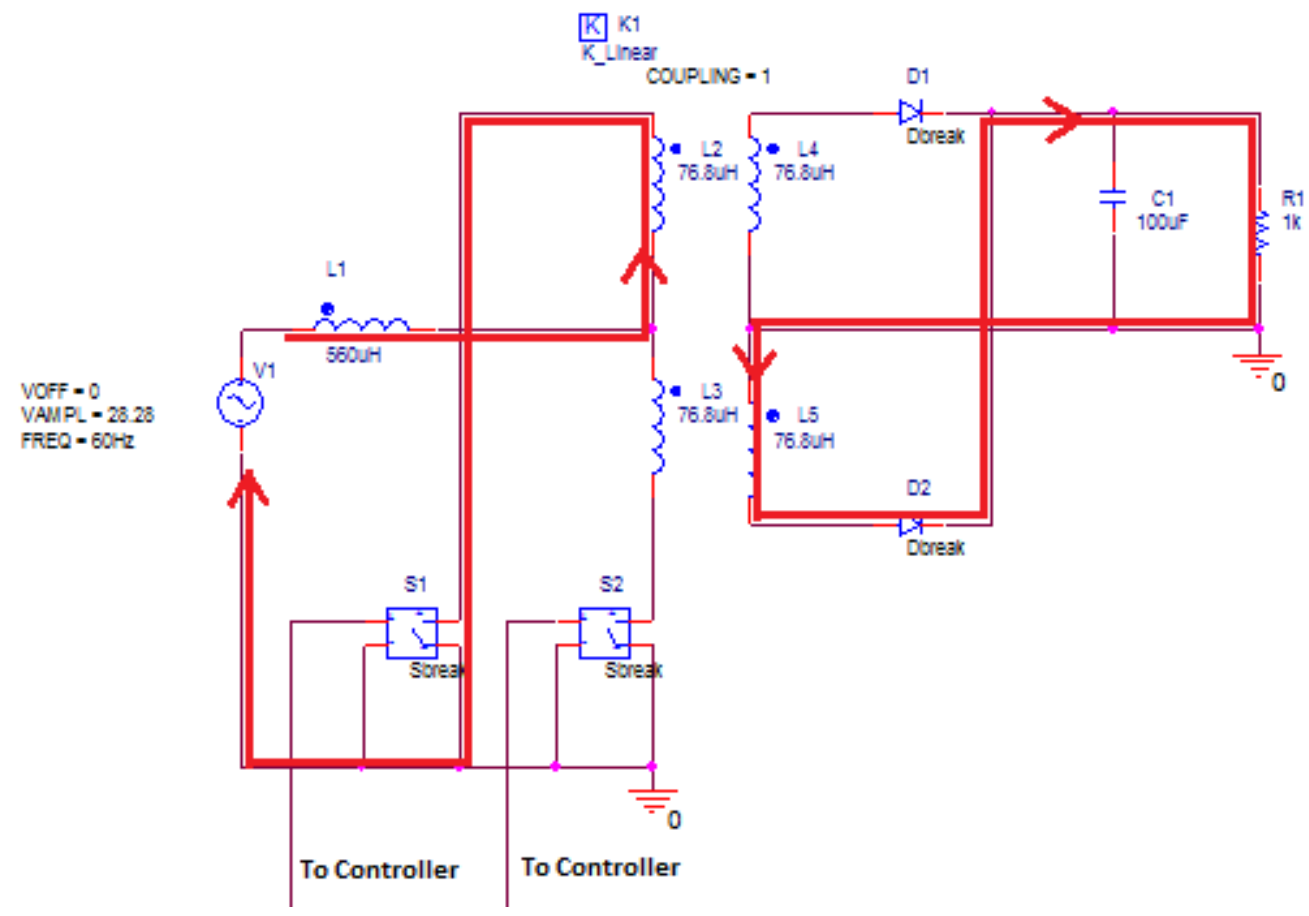

Figure 4-25: Current Flow when only Switch 1 is on and positive AC current

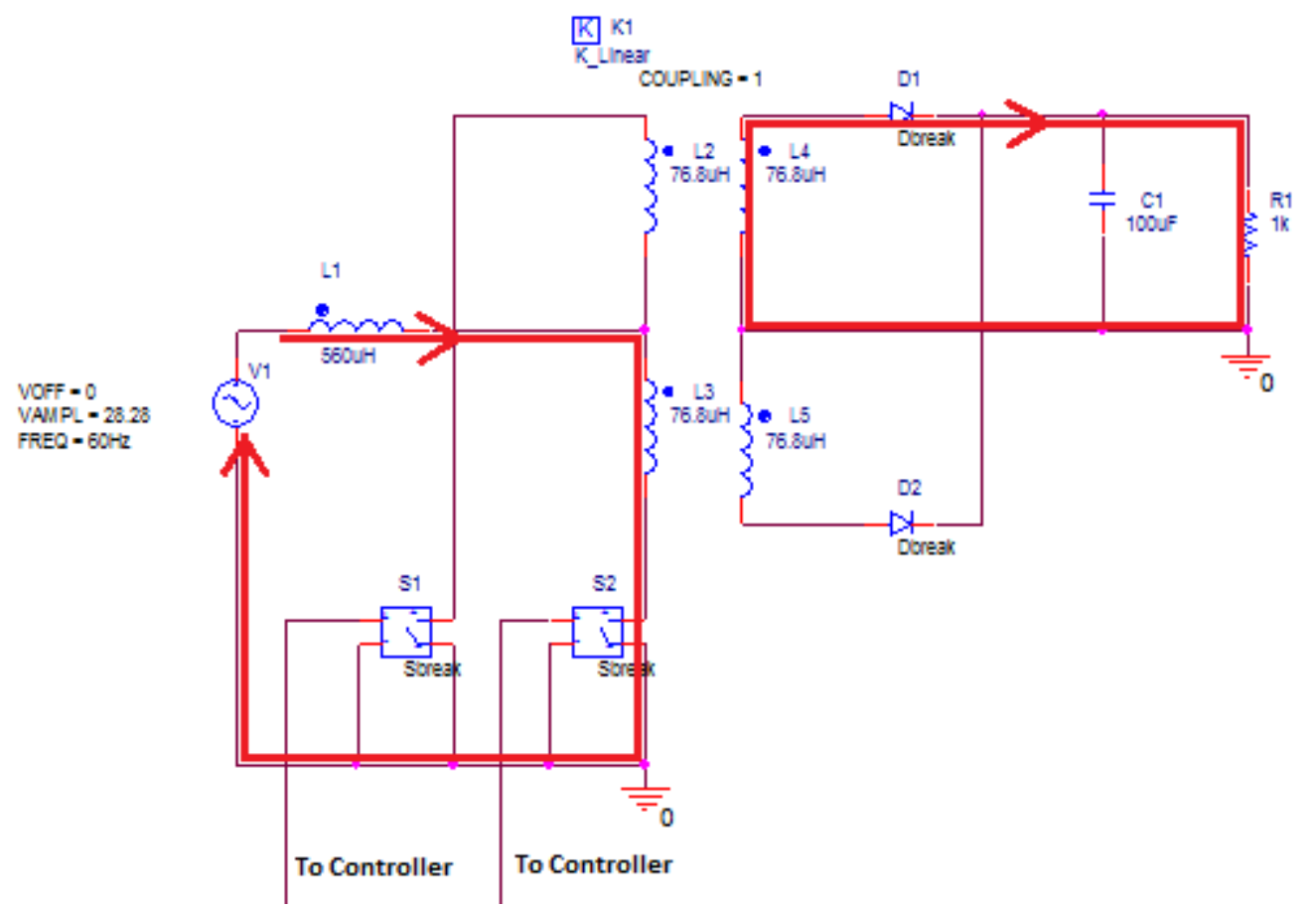

Figure 4-26: Current Flow when only Switch 2 is on and positive AC current 
When switch 2 turns off and switch 1 remains on, a new discharging and charging cycle of the inductor occurs as shown in Figure 4-25. As switch 2 turns off, only one path for the inductor current is available, which is through switch 1 and primary transformer winding L3 exists. Therefore as shown in Figure 4-25 and Figure 4-27, diode 1 on the output provides the path to the output for inductor current to discharge. The discharge path through D1 is a resultant of the inductor current in Figure 4-27 discharging through the primary winding L3.
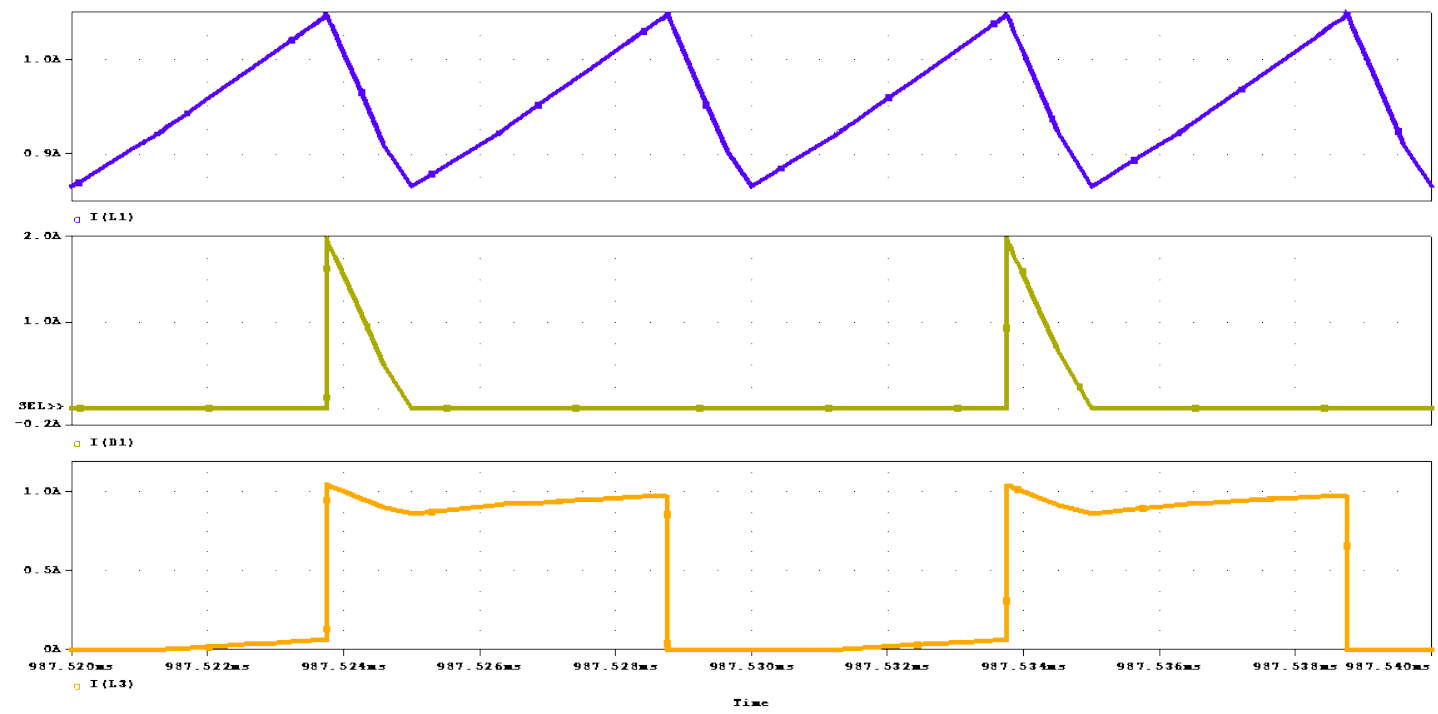

Figure 4-27: L3 Current (bottom) and D1 Current (middle) from Inductor Current (top)

Since the inductor current flows into the dotted terminal of winding L3, the current must flow out of a dotted terminal on the secondary side of the transformer. This path is through winding L4 shown in Figure 4-25 which is also the path through diode 1 which is forced to be forward biased.

In Figure 4-27, once the diode 1 is done discharging, the input inductor now starts charging through the same winding L3, while current through D1 stops because energy 
has not been stored in the input inductor. The charging through L3 continues until switch 1 turns off as shown in Figure 4-23.

While switch 1 has turned off, switch 2 has already turned on and is ready to provide the next discharge path for the inductor when switch 2 is off. As current flows through switch 2, the inductor discharges through the primary transformer winding L2 shown in Figure 4-26. Since the current leaves the dot on the winding, diode 2 on the output conducts to discharge the current as shown in Figure 4-26 and Figure 4-28 because current flows into the dot terminal of the secondary winding L5.

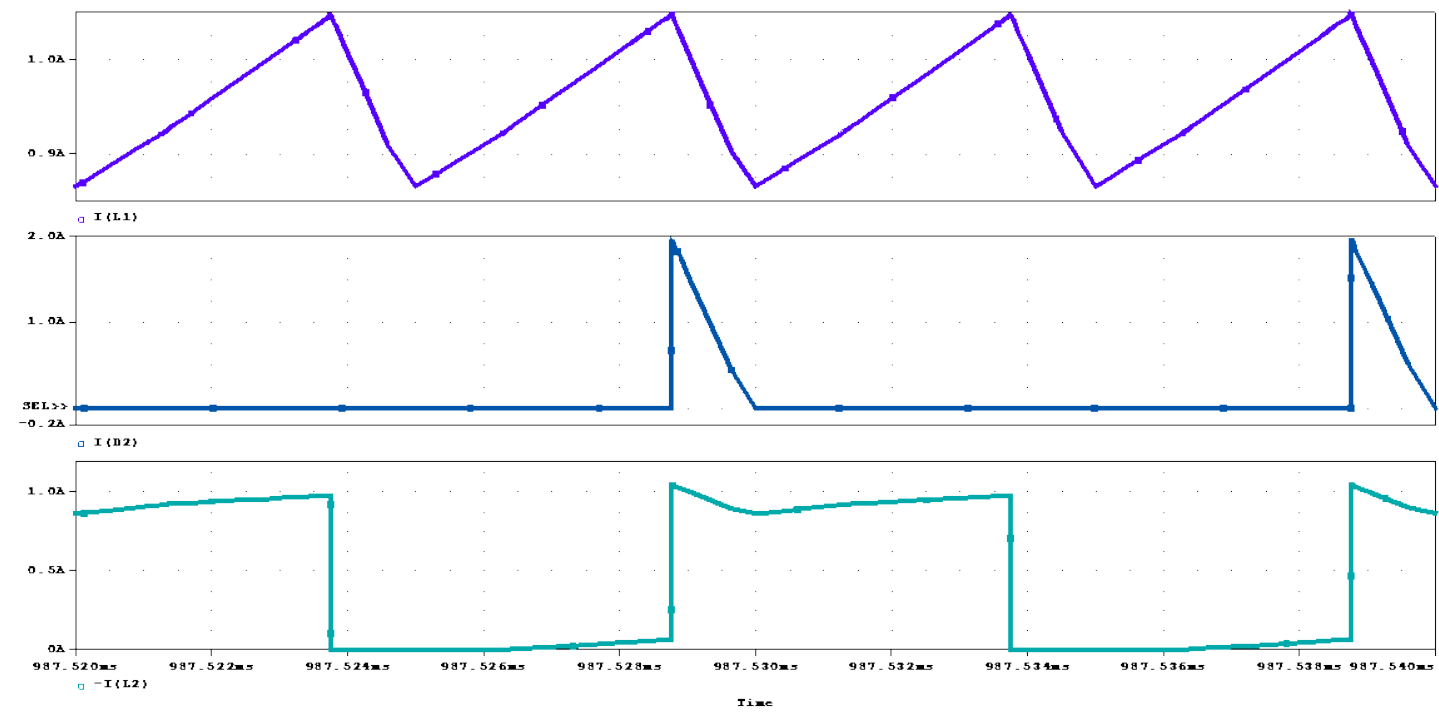

Figure 4-28: L2 Current (bottom) and D2 Current (middle) from Inductor Current (top)

As mentioned earlier, the input inductor has four cases of discharging paths through the output diodes. Two were already presented, however two more cases exist for the current flow when the input AC current is on its negative half cycle. When this negative half cycle exists, the current waveforms will look exactly the same as Figure 4-27 and Figure 4-28, however instead of the current through winding L3 going through 
D1 as in Figure 4-27, inductor input current will discharge through winding L3 and pass through D2 because of the current direction as shown in Figure 4-29. The reason for this is because for the negative half cycle of input AC current, the current now leaves the dot of winding L3 as shown, which must enter the dotted terminal of the secondary side, and the only path provided is through D2 as it is forward biased. Figure 4-30 is the other possible case when negative AC current passes through switch 1 and the direction of current follows the dotted terminals as previously explained. The discharge path for the inductor in this last case will now be winding L4 using D1 because of the dot convention.

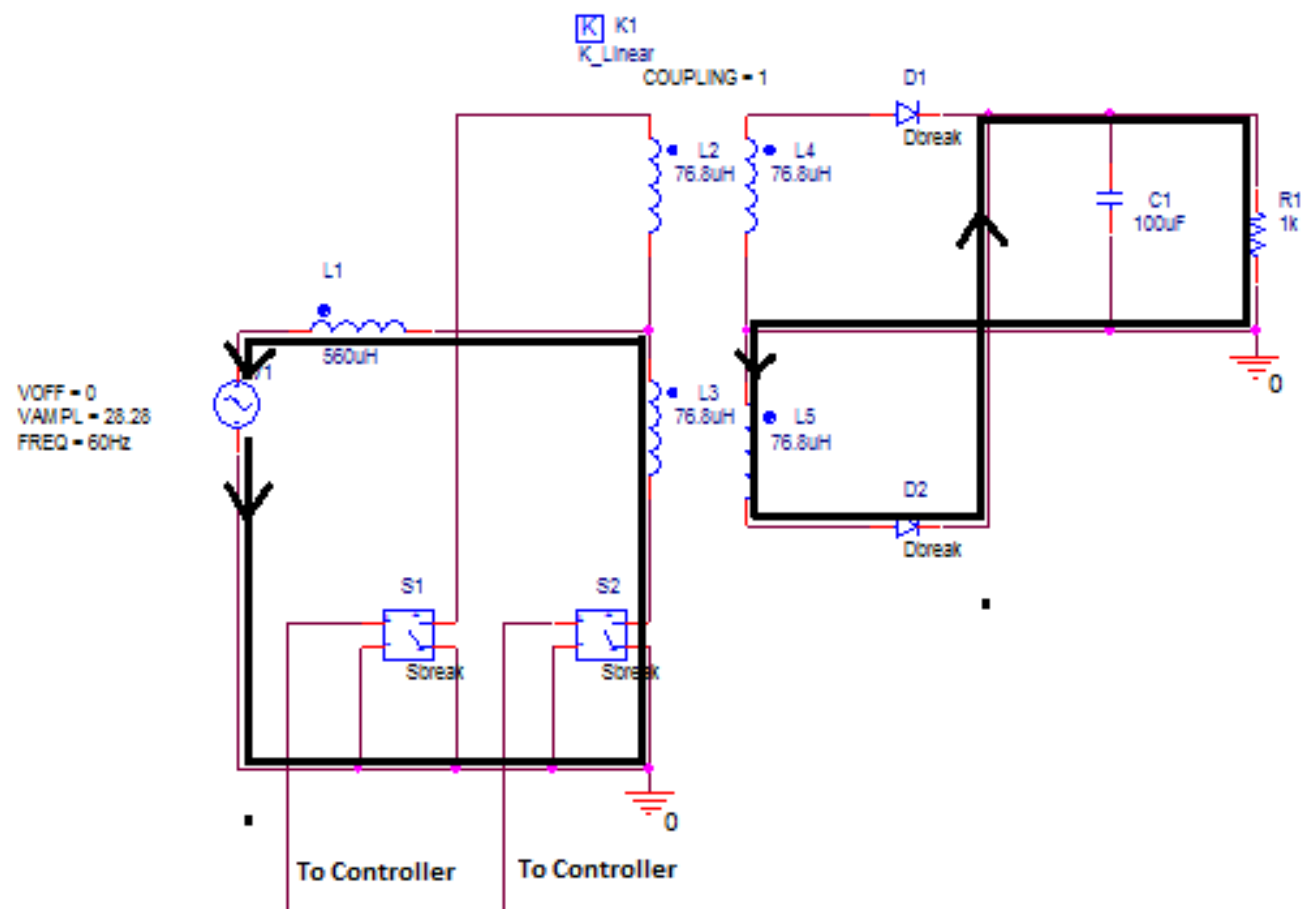

Figure 4-29: Current Flow when only Switch 2 is on and negative AC current 


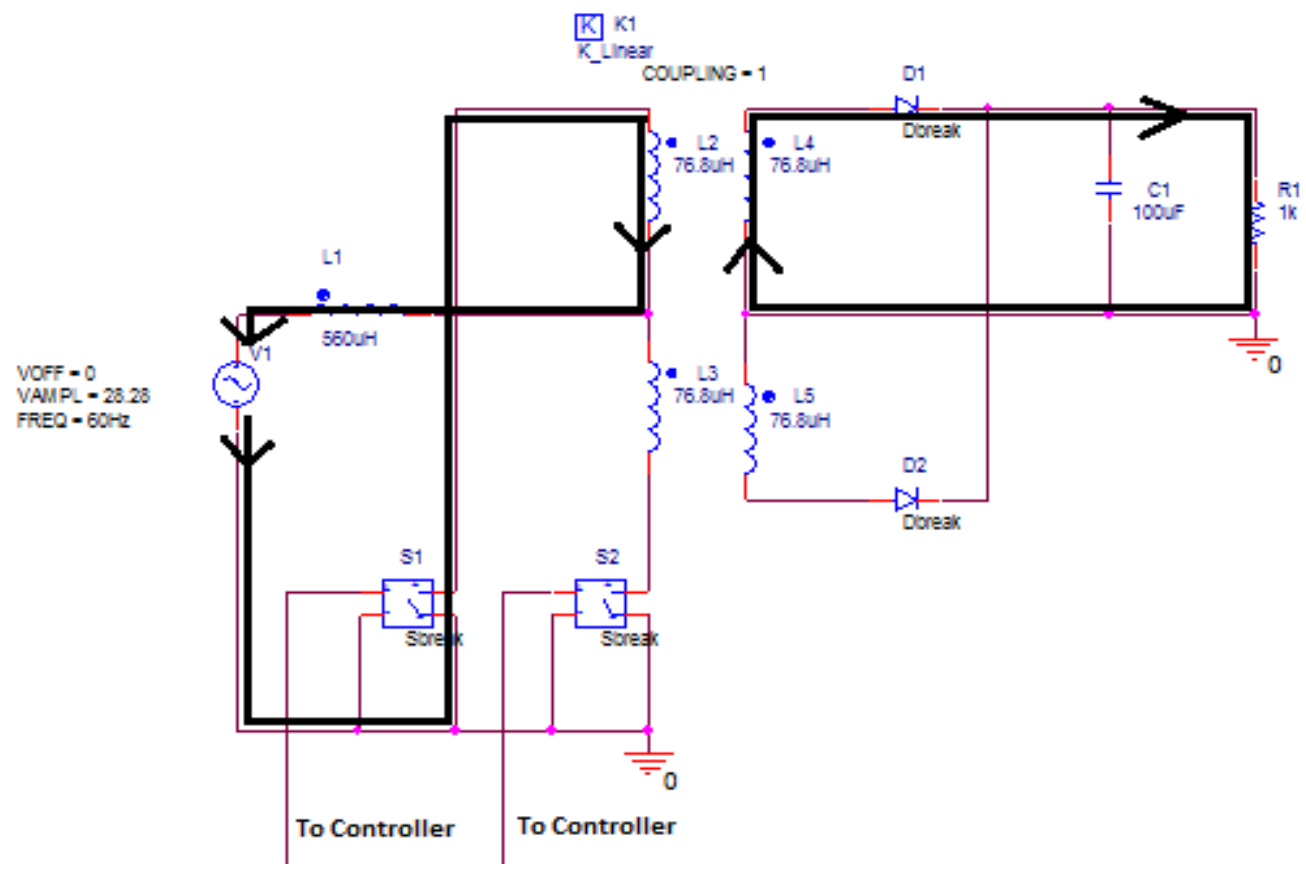

Figure 4-30: Current Flow when only Switch 1 is on and negative AC current

\subsection{Output Characteristics}

This charging and discharging of the inductor is critical in providing a current path and switching operation. The operation continues indefinitely and the switching between paths provided by switch 1 and 2 provides the rectification allowed by diode 1 and 2. As the path through each diode switches, the output is a rectified waveform proved by Figure 4-31 . 

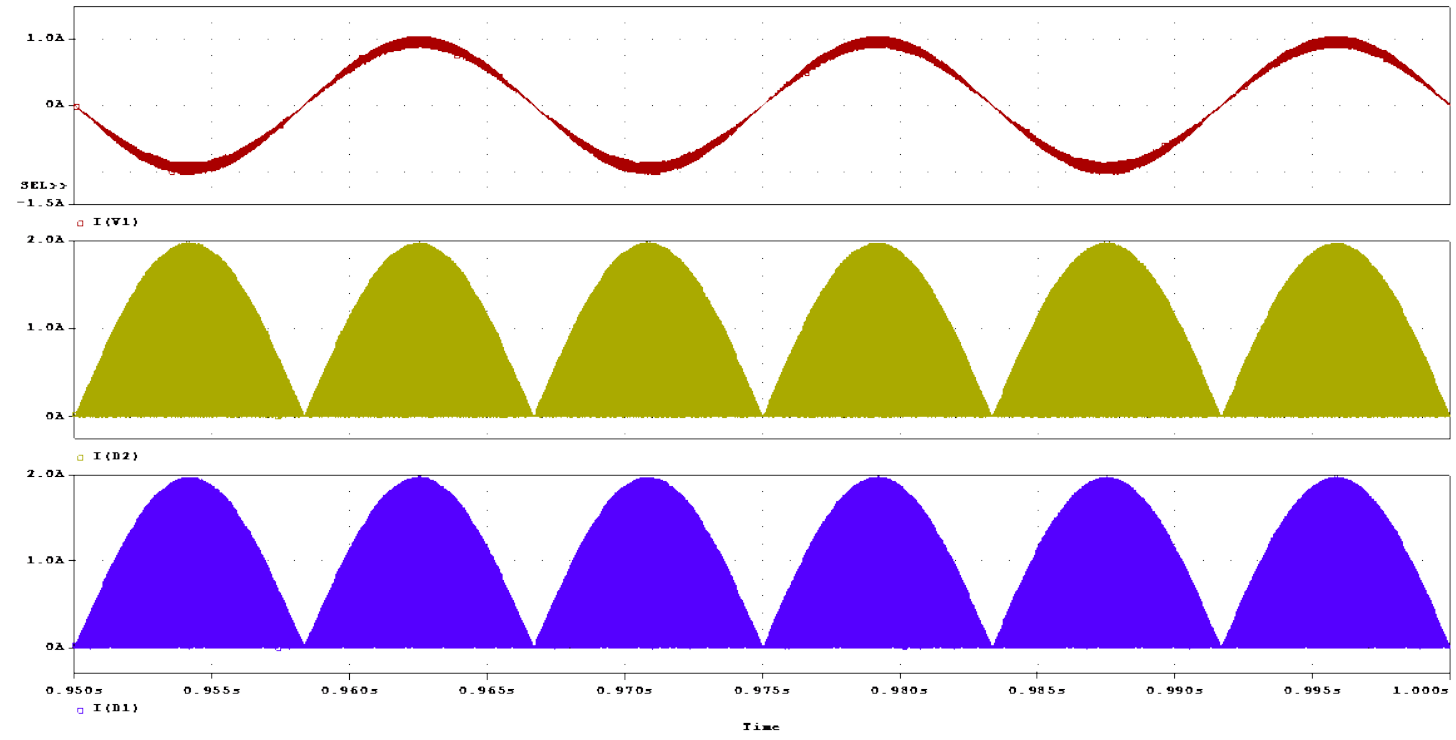

Figure 4-31: Diode Currents D2 (middle) and D1 (bottom) rectified vs Input Current (top)

The output capacitor provides filtering of the diodes AC component current shown in Figure 4-32. This figure also shows that after filtering from the capacitor, the output current is a constant current. Both current and voltage through and across the output resistor respectively, are DC as shown in Figure 4-33.

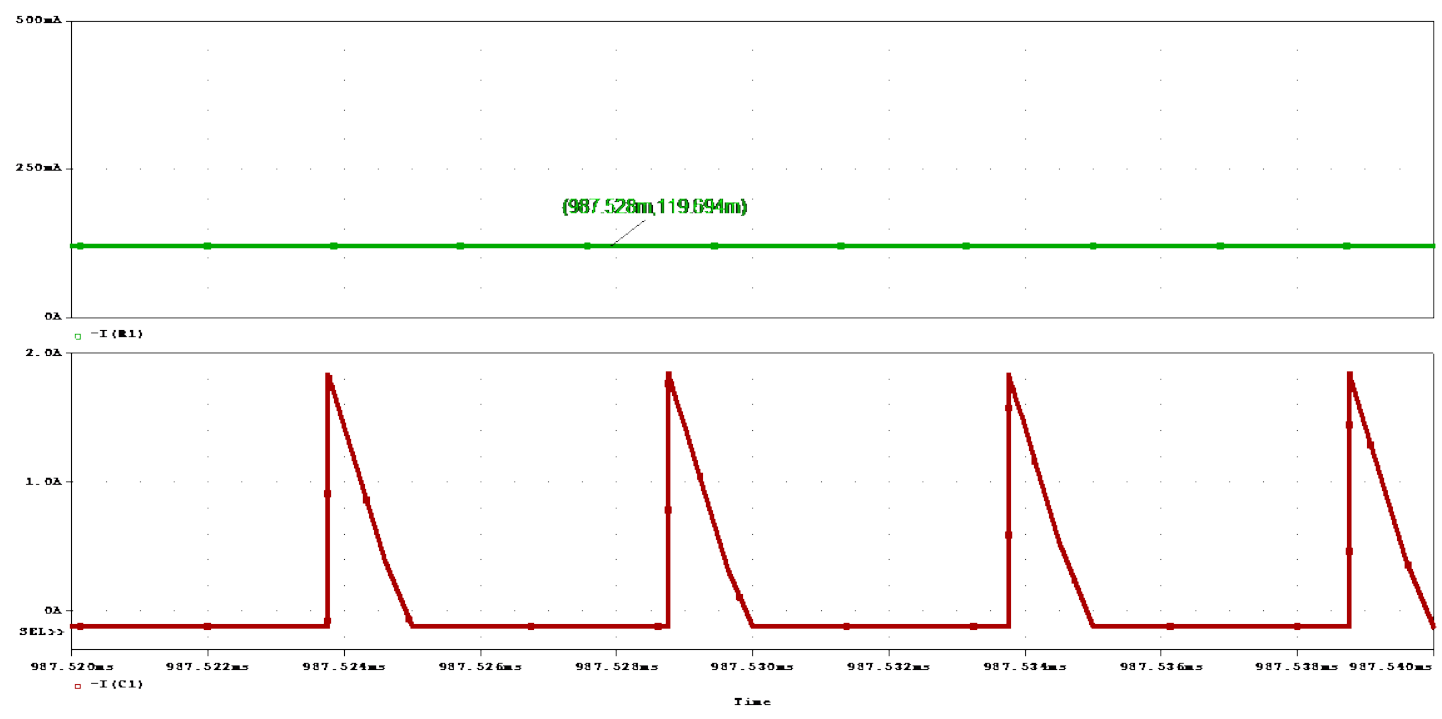

Figure 4-32: Capacitor Current (bottom) and Output Resistor Current (top) 


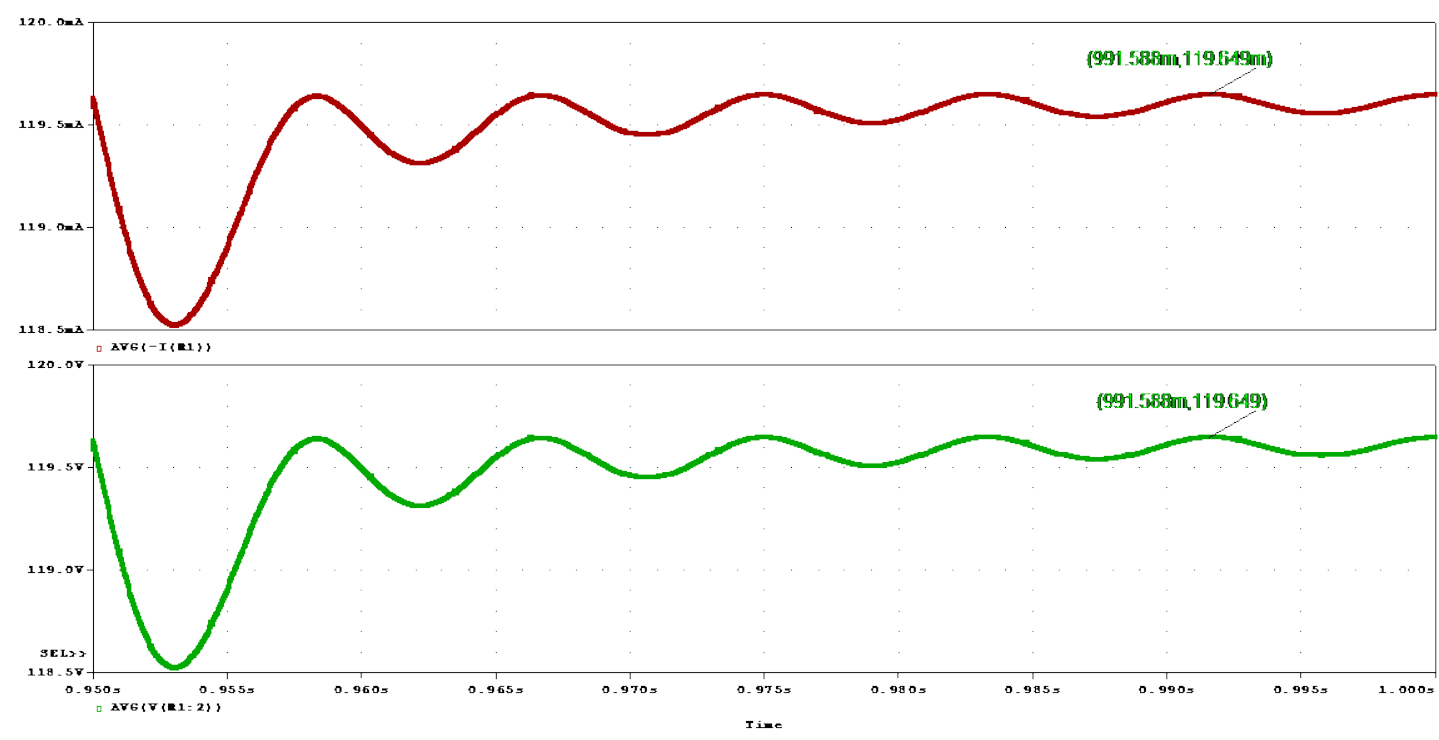

Figure 4-33: Average Output Voltage (bottom) and Average Output Current (top)

The outputs, while averaged in Figure 4-33, are not truly constant because the size of the capacitor directly affects the amount of voltage ripple still present. The voltage ripple in Figure 4-34 was not a critical component of this design because a DC-DC converter driven by this output could further smooth the waveform to be very close to constant. The push pull converter satisfactorily provides PF correction and rectification but no output voltage regulation exists, which as well can be achieved by a Buck or Boost DC-DC converter. 


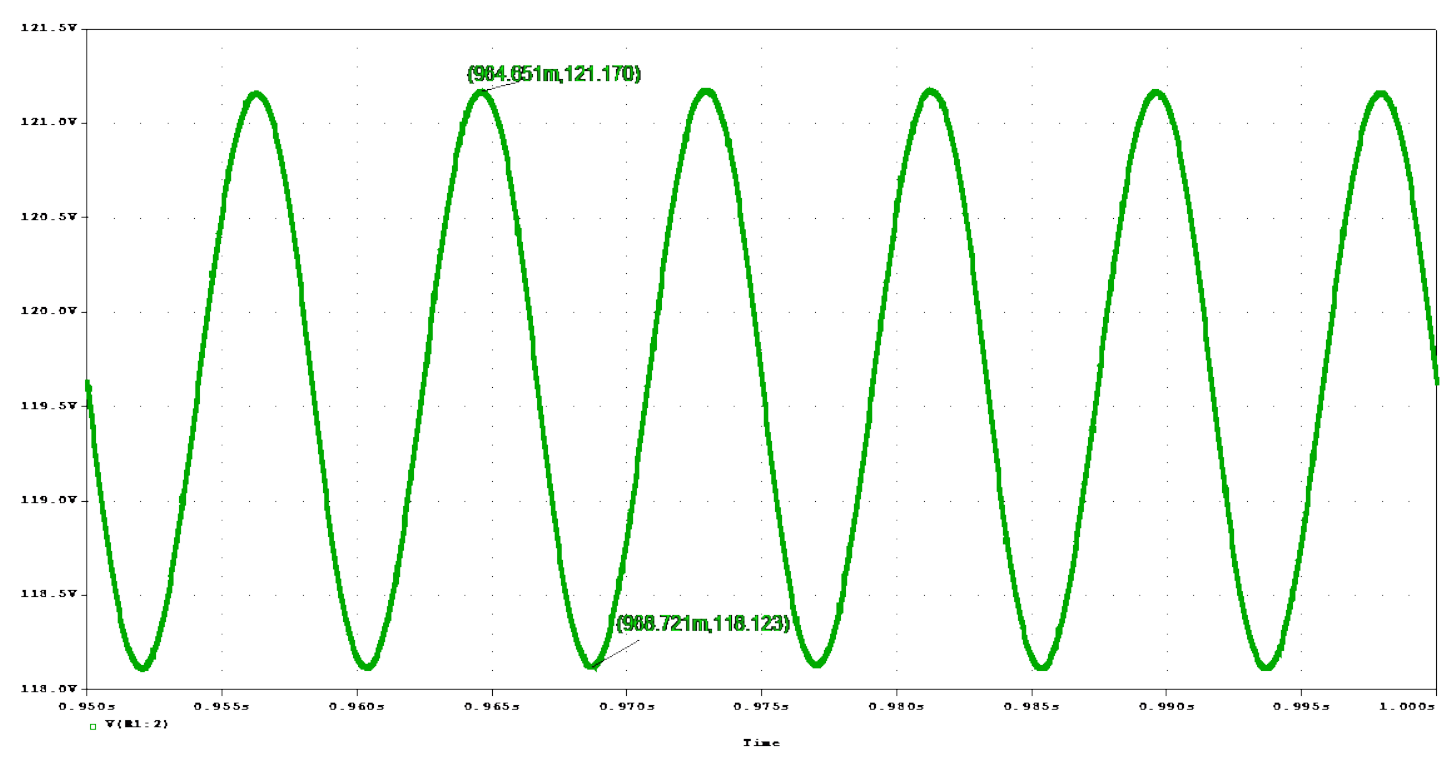

Figure 4-34: Output Voltage Ripple

From the simulation results presented the components can be rated to withstand the currents and voltages. The peak current through the primary side is $1 \mathrm{~A}$ and so all components on the primary side must withstand this current. These components are the switches, transformer, and inductor. As well as the components on the primary side withstanding current, they must be able to withstand voltage stresses. The voltage stress across the switches is no more than $250 \mathrm{~V}$. In order to provide a safety rating factor to withstand this voltage, the switch, inductor, and transformer must have a rating of at least 250Vrms.

The secondary side of the push pull converter has slightly different currents. The peak current through the output diodes is $1.5 \mathrm{~A}$. As well as these output diodes withstanding this current, the diodes and output capacitor must withstand the peak inverse voltage and output voltage across them respectively. The diode peak inverse voltage is no more than $250 \mathrm{~V}$, similar to the input switches. While the capacitor averages the output voltage and has a voltage of no more than $150 \mathrm{~V}$ across it. So based on these 
current and voltage ratings, the components chosen to implement the push pull converter are listed Table 4-1 along with the reference number to more detailed component specifications in manufacturer datasheets. Note that the gate driver is chosen to implement between the comparator control circuitry and switching circuit so that the MOSFETs can be driven at sufficient current and biasing voltage as well as buffering the control signal outputted from the comparators from the gate of the MOSFETs.

Table 4-1: Component Parts List for Hardware

\begin{tabular}{|c|c|}
\hline Component & Part Number \\
\hline Inductor & PCV-2-564-02L \\
\hline Transformer & HP5-1200L \\
\hline Switches & FDPF8N50NZF \\
\hline Diodes & SRP600G-E3/54 \\
\hline Capacitor & UVR2F101MHD \\
\hline Comparators & LTC1720 \\
\hline Gate Driver & IR2117 \\
\hline Control Resistors & $6-1 \mathrm{k} \Omega 1 / 4 \mathrm{~W}$ \\
\hline Load Resistor & $1-1 \mathrm{k} \Omega 10 \mathrm{~W}$ \\
\hline
\end{tabular}




\section{HARDWARE IMPLEMENTATION AND TESTING}

Before the final hardware implementation of the Current Fed Push Pull Converter can be completed, separate parts of the circuit must be tested individually to ensure correct operation. Specifically the control portion of the circuit is tested as a standalone circuit and then the control circuitry can be implemented with the power stage of the converter for final testing. While the converter is fundamentally the power stage portion which provides power transfer from the input to the output and power factor correction; the driving force behind the power stage operation is the control circuitry.

\subsection{Control Pulse Circuitry}

While in Chapter 4 the control circuitry was modeled with LTC1720 comparators, LM393 comparators were readily available to use in generating two square wave control signals. Figure 5-1 shows the schematic for the implemented control circuitry and corresponding comparator IC layout. In Figure 5-1, note that on the output of each comparator there is a $1.5 \mathrm{k} \Omega$ resistor pulled up to the rail. The purpose of this pull up resistor is to operate the LM393 chip because the chip does not have input referencing or push pull characteristics that are in the LTC1720 chip so the output must be pulled up to rail for the chip to operate. Also note that all resistors used for the voltage reference divider to the input of the comparators are increased to $1.5 \mathrm{k} \Omega$ as well because currents are limited further so devices implemented later are not provided a current above rated current specified. 


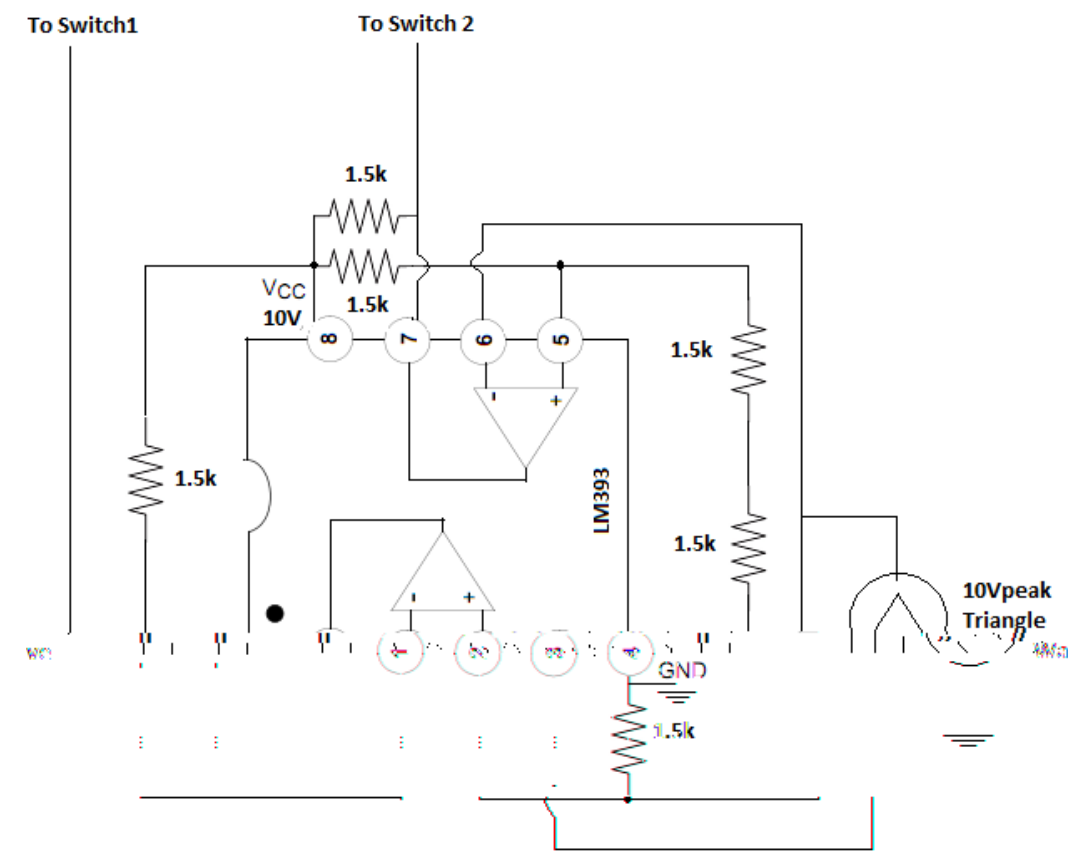

Figure 5-1: Control Pulse Circuitry Hardware Configuration Schematic

The voltage rail supplied to the resistor divider was also increased to $10 \mathrm{~V} \mathrm{DC}$ as shown in Figure 5-1. The voltage was increased because while in simulation 5V was sufficient, the switches chosen for implementation require a minimum of $3 \mathrm{~V}$ turn on so the input pulse would need to be increased as well so that the turn on voltage is far enough away from minimum gate turn on voltage to trigger the MOSFET on. The $10 \mathrm{~V}$ was chosen because gates of MOSFETs can be driven up to $20 \mathrm{~V}$, so $10 \mathrm{~V}$ is sufficient enough for the gate pulse. For the $10 \mathrm{~V}$ square wave to be achieved on the output, referring to Figure 5-1, the triangle waveform is changed to $10 \mathrm{~V}$ peak so that it is referenced now to the new supply of $10 \mathrm{~V}$. The resistor divider stays the same though because the voltages at each input are scaled by double the value from the design in Chapter 4 based on 5Vpeak. Using the $10 \mathrm{~V}$ peak triangle waveform as the input with a $5 \mathrm{~V}$ DC offset, the reference voltages are now $7.5 \mathrm{~V}$ and $2.5 \mathrm{~V}$ to achieve the $75 \%$ duty 
cycle. Figure 5-2 shows the oscilloscope measurement of the two output pulses from the hardware implementation of the control pulse circuitry.

Investigating the signal it can be noted that one output goes to a more extreme rail to rail. This is attributed to small differences in the pull up resistors which allow one signal to be pulled higher or lower. Note that the signals are both based on the same input triangle wave which results in exact same frequencies. The duty cycles of both however are not exactly $75 \%$ but are fairly close. This is because the voltage divider does not divide the voltage to exactly $7.5 \mathrm{~V}$ and $2.5 \mathrm{~V}$. Some variation in the reference voltages will cause the rise and fall of the pulses to happen at a slightly different time than calculated for a voltage along the triangle wave with respect to the time it takes for the triangle wave to rise.

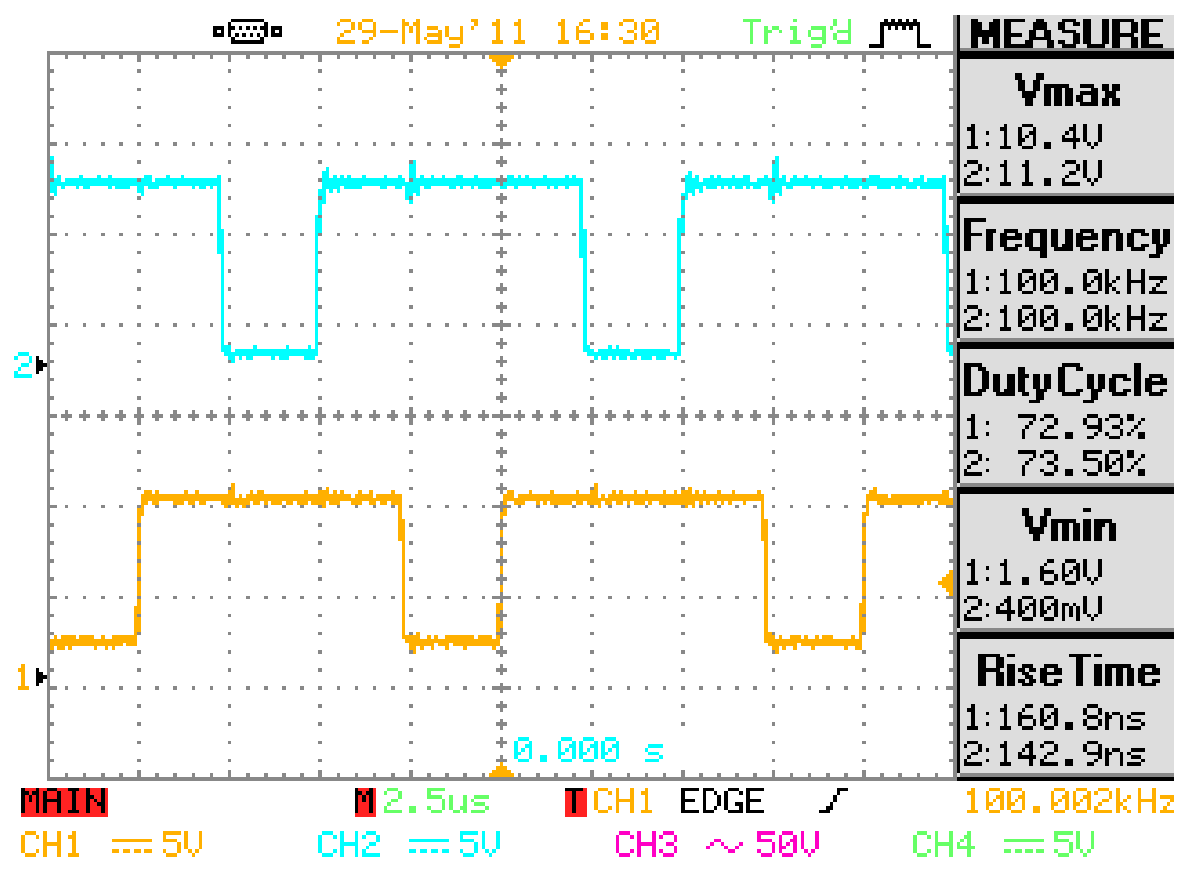

Figure 5-2: Control Pulse Circuitry Output Signals 
In order for the control pulses in Figure 5-2 to drive the MOSFETs an

intermediate gate driver must be inserted between the control pulse circuitry and the gate of the MOSFET. However to clarify, each switch in Figure 4-1 is comprised of two actual MOSFETs. The configuration of these switches with each other must be coupled so that input AC current is allowed to flow bi-directionally. Hence, the converter requires four switches total, with two individual switches configured in a way that would allow bidirectional current flow as the Sbreak PSPICE simulation model allowed. The reason the switches must be bidirectional is because AC main current passes through these switches as opposed to a unidirectional DC current normally used to operate a Push Pull converter.

\subsection{Bidirectional MOSFETs}

Firstly, the configuration for the MOSFETs used to allow current to flow in both directions is shown in Figure 5-3. The N-channel MOSFETs are connected in antiparallel so that the drain of one MOSFET is connected to the source of the other MOSFET, while the drain of the opposite MOSFET is coupled to the source of the first MOSFET. This coupling also requires that the gate voltages be turned on and off at the same time so that no matter the direction of the current, it will pass from drain to source through either MOSFET. While this method was tested, a major characteristic of the MOSFET did not allow the current to be stopped when the switches were turned off at the gate. As shown in Figure 5-3, the red diodes are internal body diodes that are within the packaged MOSFET. These diodes allowed the current to continue to flow in both directions because when the gate voltage was turned off, two paths were still provided for positive and negative current flow. 


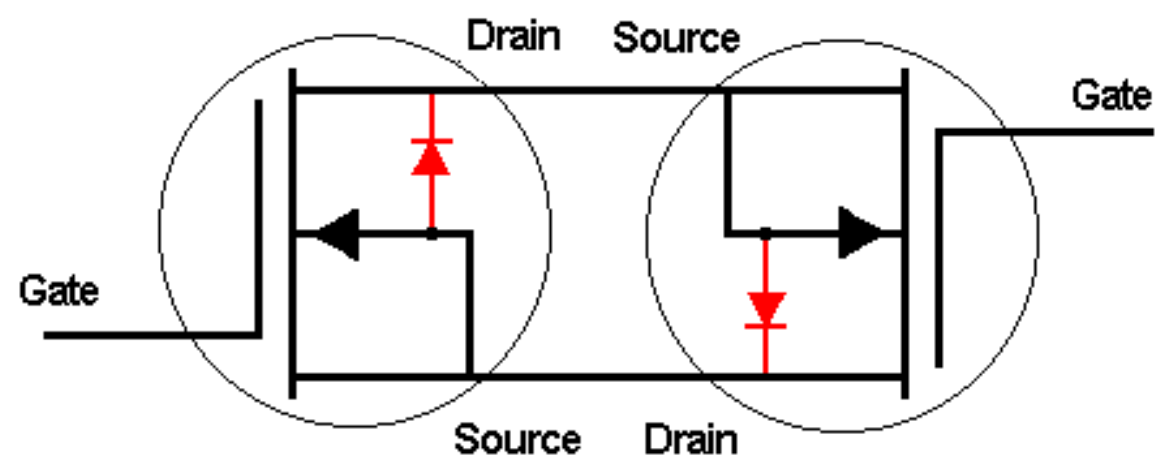

Figure 5-3: Bidirectional Switch configuration with two MOSFETs

\subsection{Bidirectional Insulated Gate Bipolar Transistor}

To eliminate the body diodes and allow current to be stopped for the time when both switches are on was important if the configuration in Figure 5-3 was to be implemented. Upon further investigation, it was decided that Insulated Gate Bipolar Transistors were a viable solution in implementing the anti-parallel switching technique. The IGBT is a device that combines the best characteristics of a Bipolar Junction Transistor (BJT) and MOSFET. It incorporates simple gate drive characteristics of the MOSFET with high current and low-saturation-voltage capability of the BJT. Just as important for the anti-parallel switching, the IGBT does not have a body diode as shown in Figure 5-4, so the configuration for switching will allow an open circuit when both gates are turned off, however two paths exist for positive and negative current flow when both IGBTs are turned on. 


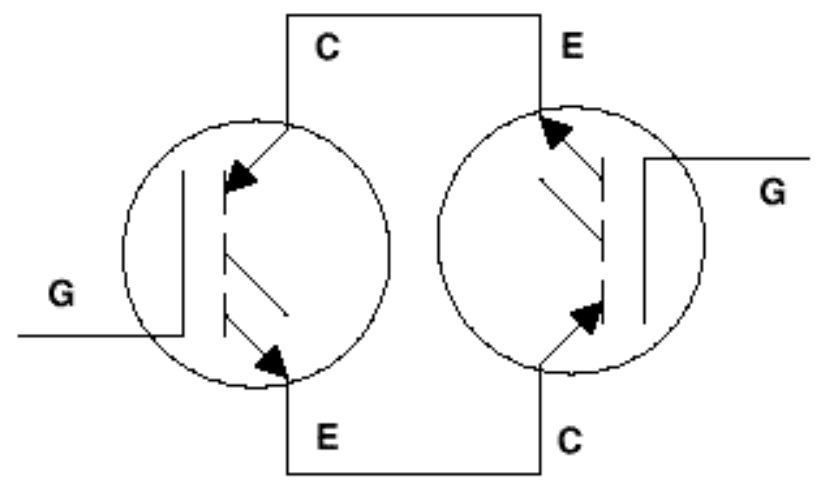

Figure 5-4: Bidirectional Switch Configuration with two IGBTs

\subsection{High Side Gate Driver Testing}

Now in order to drive these IGBTs a gate driver was to be implemented to drive each gate as mentioned earlier. However, the gate drivers output is tied to the gate of each IGBT, and this gate must be referenced to a higher voltage than the emitter. The operation of a gate driver is either low side referenced or high side referenced. Fundamentally, a gate driver will output the input pulse applied to the gate driver and reference that pulse signal to the gate but bias it to be higher than the emitter potential. The low side driver operates by referencing the emitter node to ground so that when the low side output pulse is supplied to the gate, a high voltage will turn the IGBT on, while a low pulse will turn the IGBT off. Remember the pulse within this hardware implementation is referenced with a DC offset to the triangle wave input, so the gate pulse is low at $0 \mathrm{~V}$ and high at $10 \mathrm{~V}$.

The operation of the high side driver is different from the low side driver in that the emitter is not referenced to ground. The emitter is referenced to a floating voltage based on the supply voltage of the gate driver as shown in Figure 5-5. While testing the applied voltage at the $V_{C C}$ pin of $10 \mathrm{~V}$ and diode coupled to the bootstrap pin $V_{b}$ creates an 
approximate voltage drop of $0.7 \mathrm{~V}$ to bring the bootstrap pin to $9.3 \mathrm{~V}$. Referring to the internal IC chip diagram in Figure 5-6 of the high side driver, $V_{b}$ and $V_{s}$ are nodes at collector and emitter respectively of two stacked BJTs. Coupled to the external portion of the chip at $V_{b}$ and $V_{s}$ pins shown in Figure 5-5 is a capacitor. The high side driver operates by referencing the emitter voltage to the external IGBT as shown in Figure 5-5 to the charging of the coupled capacitor between $V_{b}$ and $V_{s}$ based on the change in the High Side output between $V_{b}$ and $V_{s}$. When $V_{s}$ is referenced to a voltage, the high side output will always be $V_{s}$ and the added value from the input pulse supplied to the gate driver.

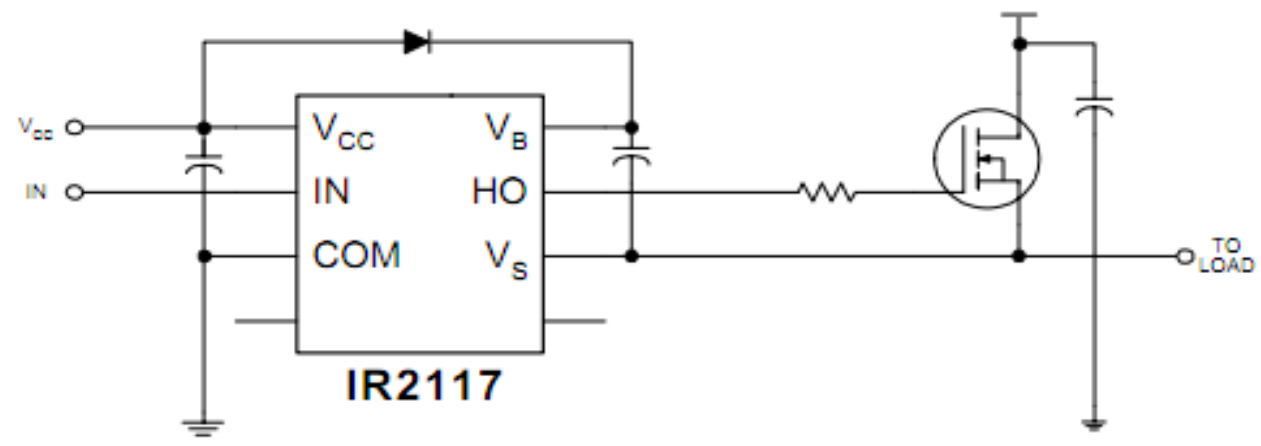

Figure 5-5: High Side Driver Configuration

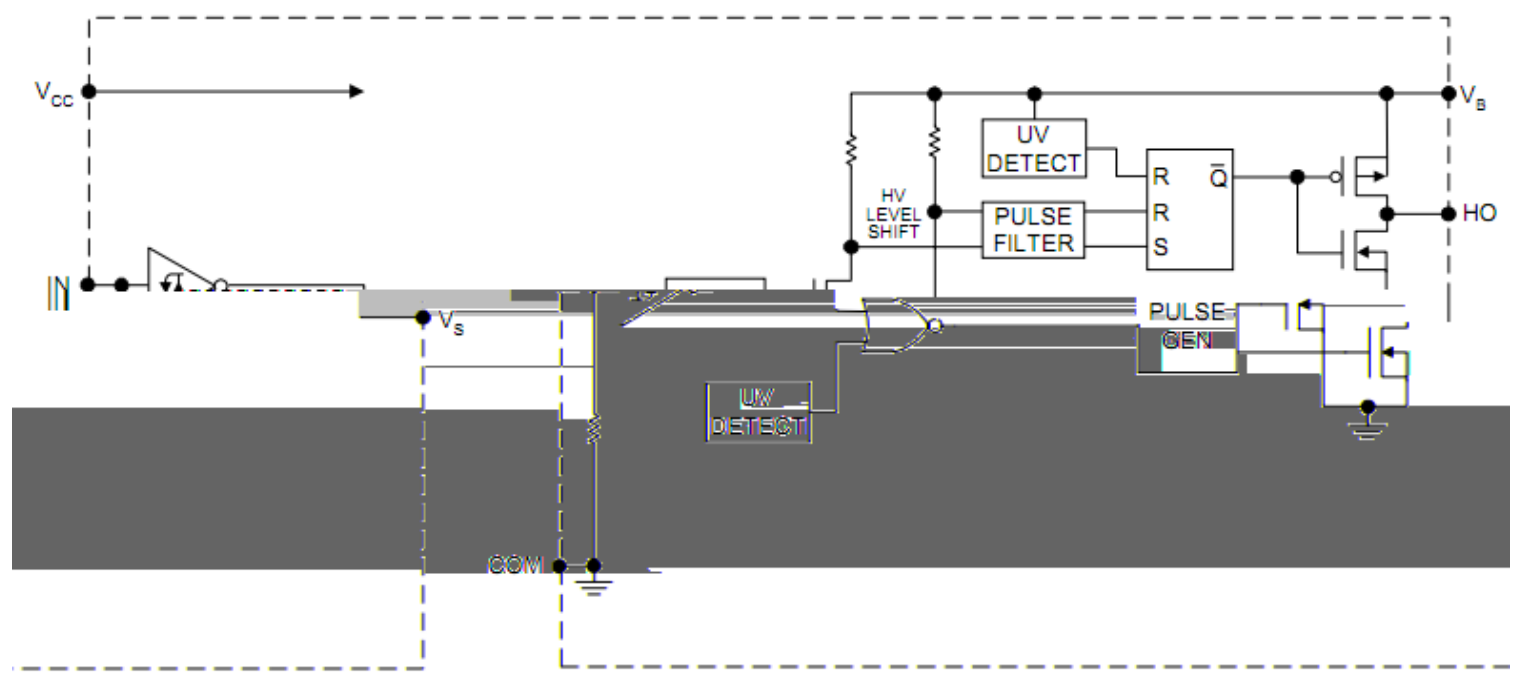

Figure 5-6: Internal High Side Gate Driver Circuitry 
The problem that arose is when using the two anti-parallel IGBTs configured to the same gate drive signal from one comparator, while referencing each emitter to Vs which was based on the gate drive supply voltage, the natural AC voltage swing at the emitters of both switches was interrupted. Through testing the circuit schematic diagram in Figure 5-7, each switch would receive the appropriate gate signal; however the emitter was trying to be referenced to a voltage based upon a DC supply. What this did in practice was reference a naturally alternating voltage at both emitters to a DC reference and forced each emitter to be roughly 10V DC. This altered the input voltage waveform to be very noisy and not sinusoidal as it was supposed to be. Therefore, these gate drivers floating voltage reference cannot be used to reference an AC node voltage in this topology as is supposed to be used for DC-DC converters where the supply is a DC voltage.

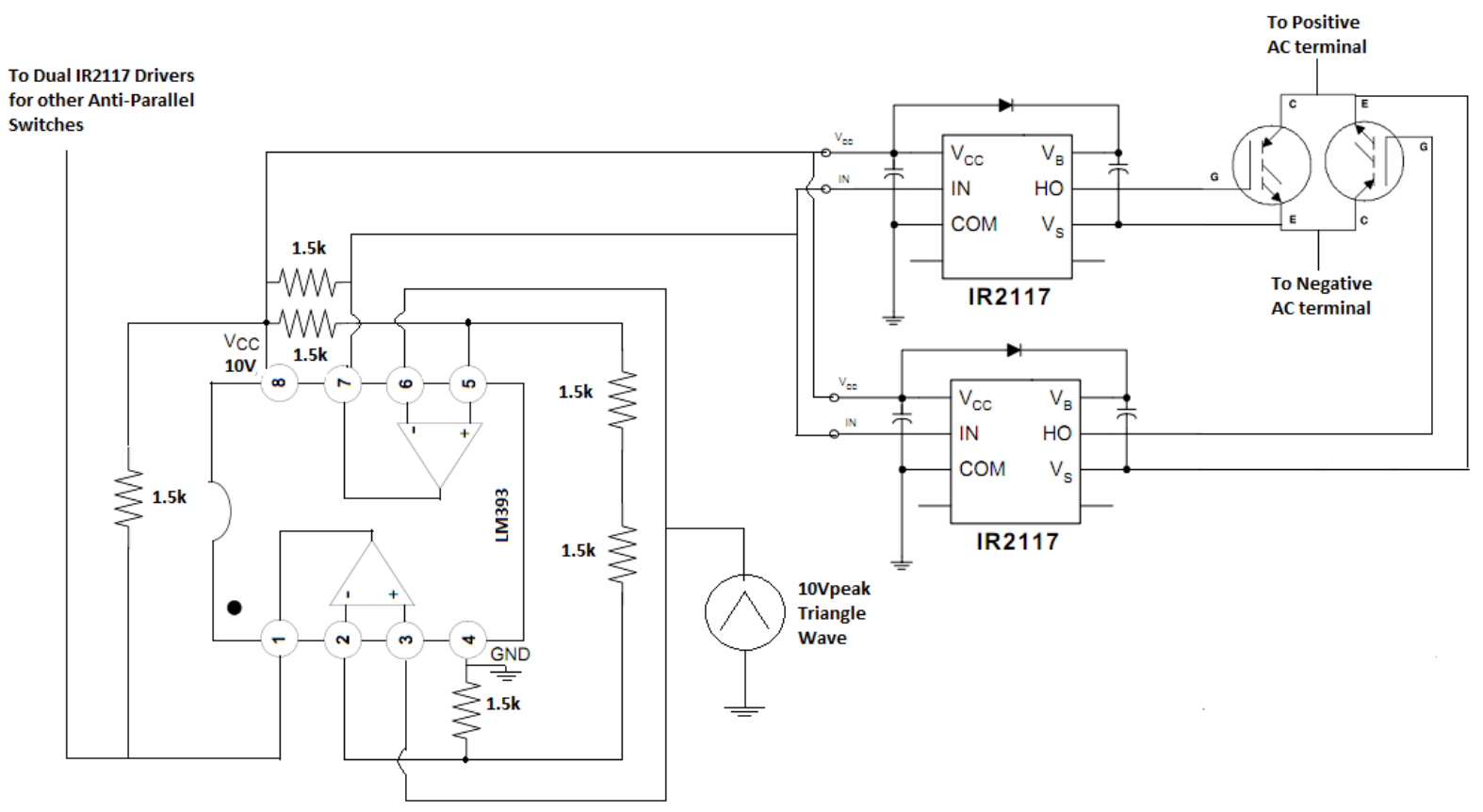

Figure 5-7: Control Circuitry with Problematic Emitter Voltage Reference 


\subsection{Low Side Driver Testing}

To eliminate a DC reference with the high side driver of the configuration in Figure 5-7, the low side driver in Figure 5-8 was used to drive the gate of the same IGBT anti-parallel configuration without referencing the source to any DC voltage. The resulting circuitry to drive each gate is in Figure 5-9 which shows that the control signal's ground and low side drivers ground are referenced together. However, the gate drive signal, which is the output of the low side driver, is only driven to the gate with no reference to ground. This was intended to reference the gate to a pulse of rail $10 \mathrm{~V}$ with $0 \mathrm{~V}$ as the low to the naturally swinging AC voltage that is at the emitter node.

As shown below, each output of the control pulse circuitry is driven to INB nodes of two separate low side drivers. The reason this was done and not having the two signals driven to each available input on one IC4428 was because the INA signal will invert the incoming signal so that OUTA will be inverted with respect to the input. This creates two signals with no overlap with respect to one another and so two separate IR4428 chips must be used with each input driven to INB and OUTB for each signal is referenced to the two separate coupled anti-parallel IGBT gates and driven in the full Push Pull converter as shown in Figure 5-9.

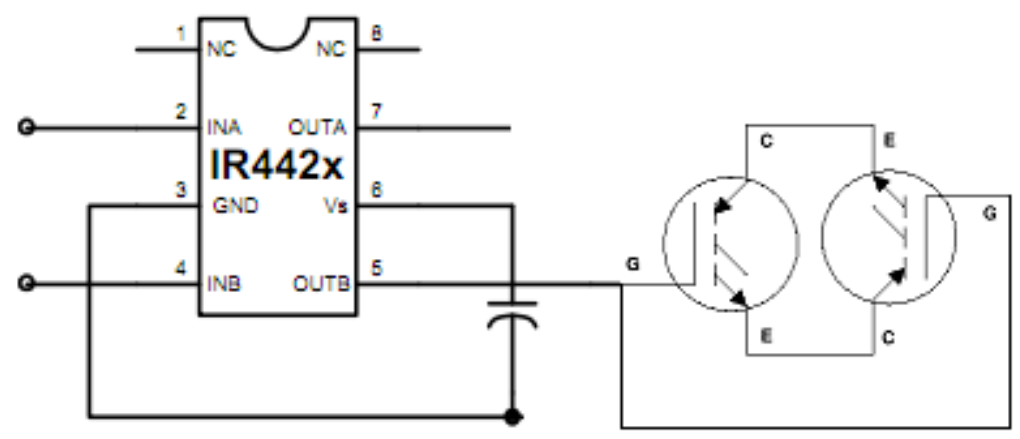

Figure 5-8: Low Side Driver without reference emitter 


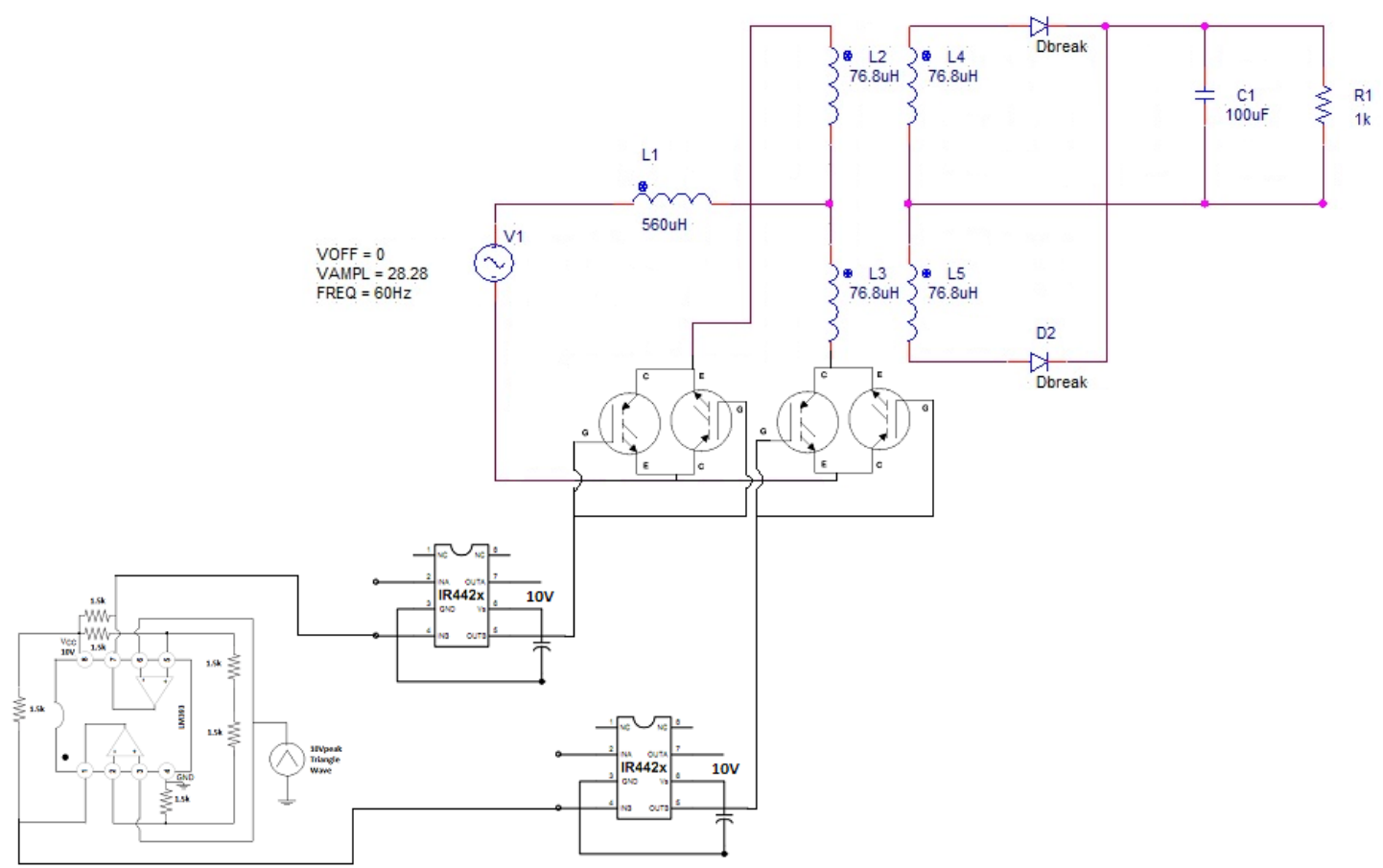

Figure 5-9: Implemented Control Circuitry and Gate Drivers to Anti-Parallel IGBTs

\subsection{Test Bench Setup}

The test bench setup is shown in Figure 5-10 which displays the wiring setup to power the converter as well as the control circuitry. Also, Figure 5-11 displays a close up of the configured testing hardware circuit layout and labeled sub-circuits that result in the final converter. Notice that the Variac is used for AC power and is driven to the power meter for input voltage, current and power factor measurement display. The DC power supply of 10V supplies power to turn on the LM393 comparator chip as well as the two IR4428 low side gate drivers. Lastly the function generator is configured to supply a triangle waveform of $10 \mathrm{~V}$ peak at $100 \mathrm{kHz}$ to the input and generates the pulses. Table 5-1 lists the equipment used to supply power to the converter as well as provide measurements of the circuits operation. The updated list of components used for converter testing is listed in Table 5-2. 


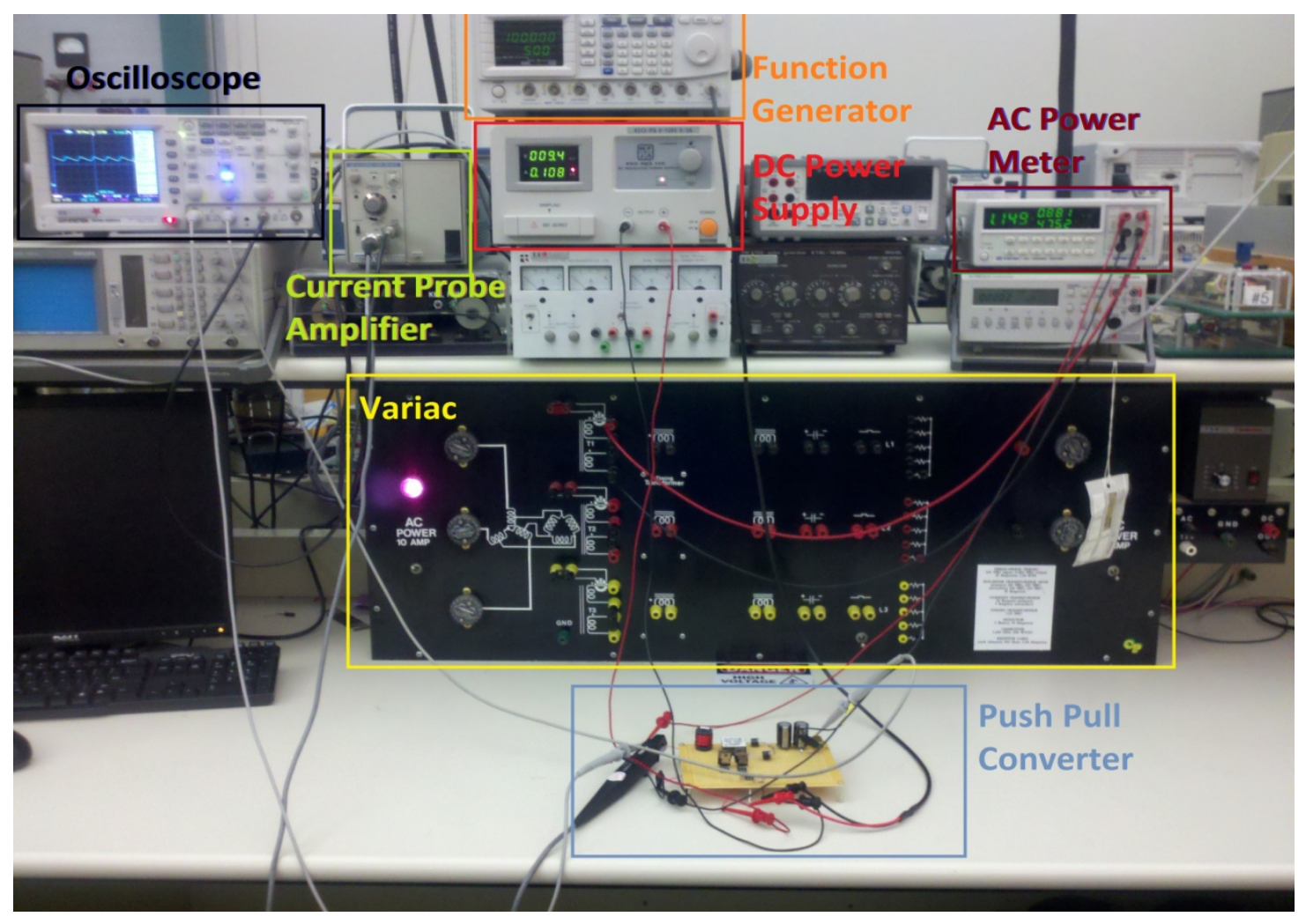

Figure 5-10: Test Bench Setup

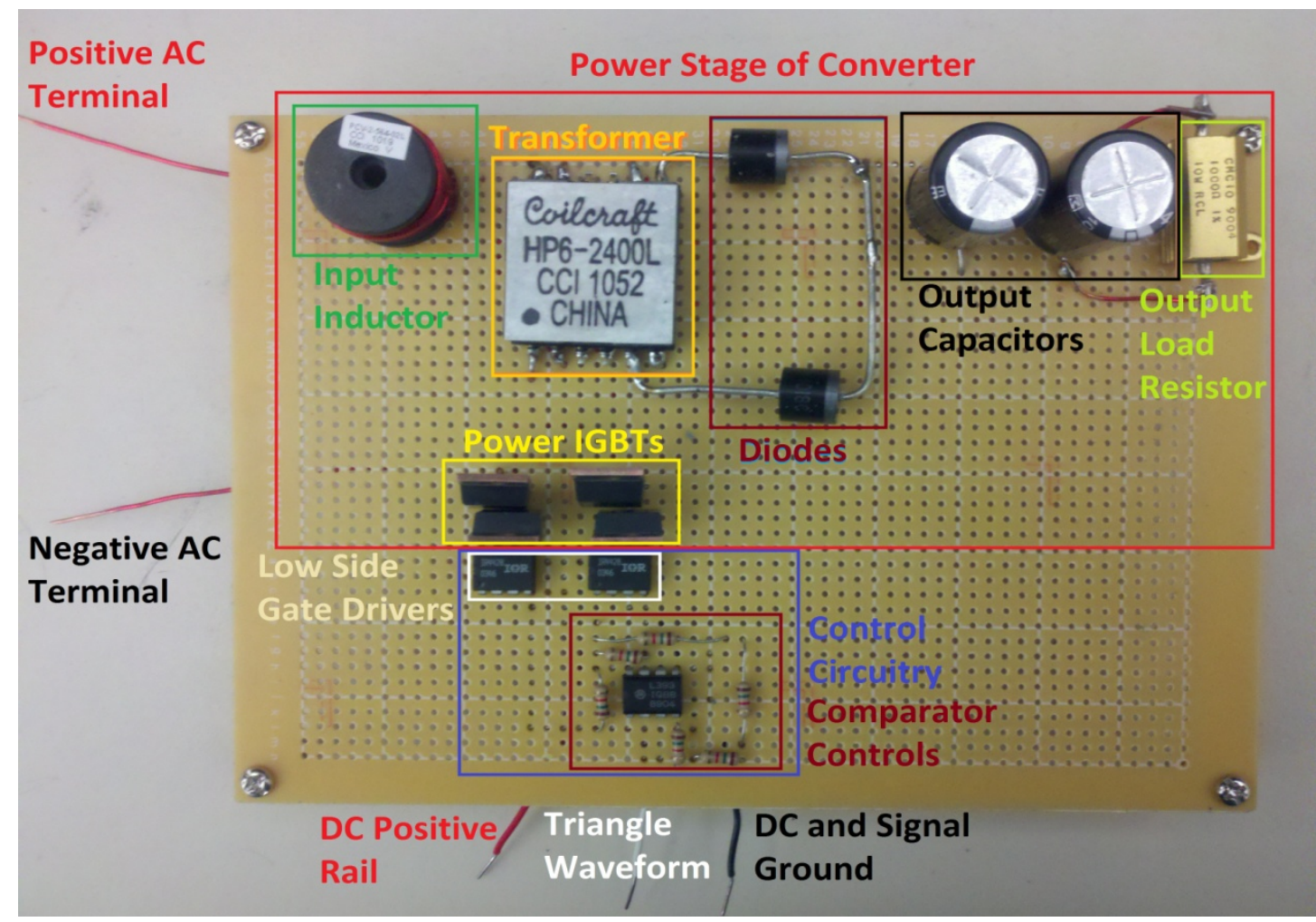

Figure 5-11: Hardware Testing Circuit 
Table 5-1: Equipment used for Testing

\begin{tabular}{|l|l|l|}
\hline Device & Model & Application \\
\hline Oscilloscope & GW-INSTEK GDS-2204 & $\begin{array}{l}\text { Measurements for Circuit } \\
\text { Waveforms }\end{array}$ \\
\hline $\begin{array}{l}\text { Function } \\
\text { Generator }\end{array}$ & GW-INSTEK GFG-3015 & $\begin{array}{l}\text { Triangle Wave Generator to } \\
\text { Comparators }\end{array}$ \\
\hline $\begin{array}{l}\text { Current Probe } \\
\text { Amplifier }\end{array}$ & Tektronix AM503 & $\begin{array}{l}\text { Input Waveform Current } \\
\text { Measurement }\end{array}$ \\
\hline $\begin{array}{l}\text { DC Power } \\
\text { Supply }\end{array}$ & MPJA 9313-PS & $\begin{array}{l}\text { Supply Voltage for } \\
\text { Comparators and Gate } \\
\text { Drivers }\end{array}$ \\
\hline Variac & Cal Poly Lab Bench & Input AC Power Supply \\
\hline $\begin{array}{l}\text { AC Power } \\
\text { Meter }\end{array}$ & GW-INSTEK GPM-8212 & $\begin{array}{l}\text { Measure AC Input Power } \\
\text { Factor, Current, Voltage }\end{array}$ \\
\hline $\begin{array}{l}\text { Digital } \\
\text { Multimeter }\end{array}$ & Agilent U3402A & $\begin{array}{l}\text { Measuring Comparator } \\
\text { Reference Voltages }\end{array}$ \\
\hline
\end{tabular}

Table 5-2: Updated Component Parts List for Hardware

\begin{tabular}{|c|c|}
\hline Component & Part Number \\
\hline Inductor & PCV-2-564-02L \\
\hline Transformer & HP6-2400L \\
\hline Switches & IRG4DC10U \\
\hline Diodes & SRP600G-E3/54 \\
\hline Capacitor & EEU-EE2G470 \\
\hline Comparators & LM393 \\
\hline Gate Driver & $6-1.5 \mathrm{k} \Omega 1 / 4 \mathrm{~W}$ \\
\hline Control Resistors & $1-1 \mathrm{k} \Omega 10 \mathrm{~W}$ \\
\hline Load Resistor &
\end{tabular}

For the parts list in Table 5-2, the transformer, switches, output capacitors, comparators, and gate drivers were changed. The transformer was changed to the HP62400L so that the original testing circuit could be maintained, as well as the change between HP5-1200L and HP6-2400L changing between $76.8 \mu \mathrm{H}$ to $86.4 \mu \mathrm{H}$ inductance per winding. For the switches, the part number represents the IGBT device that must be used because of the absence of body diodes as described previously. The comparator is the corresponding part that was described earlier which does correctly operate for this 
converter while the low side driver is now tested. The change that isn't warranted by any significant reason is the capacitor part change which incorporates two $47 \mu \mathrm{F}$ capacitors in parallel as opposed to one $100 \mu \mathrm{F}$ capacitor. The change is because the supply of parts was minimal for the $100 \mu \mathrm{F}$ capacitor and equivalently the $47 \mu \mathrm{F}$ results in $94 \mu \mathrm{F}$ total which is not significant for the output because power factor is the most important concern.

\subsection{Verification of Switching Operation}

When implementing the configuration in Figure 5-9, testing was performed to ensure that the switching operation was occurring. As mentioned previously with the coupled anti-parallel MOSFETs, no time occurred where the current was stopped because of the body diodes. With the gate floating in reference to the alternating emitter node and a 10V rail pulse applied to the gate, Figure 5-12 and Figure 5-13 shows the gate switching voltage and collector to emitter voltage for each bidirectional switch. As can be seen from these scope captures, the switches are in fact turning on and off because for any low voltage at the gate, the collector to emitter voltage goes high which indicates that there is an open circuit from collector to emitter or the switch is off. While the gate voltage is high the switch is on and signifying this is the collector to emitter voltage dropping to approximately zero which verifies that the switch is provided a short for current to flow. 


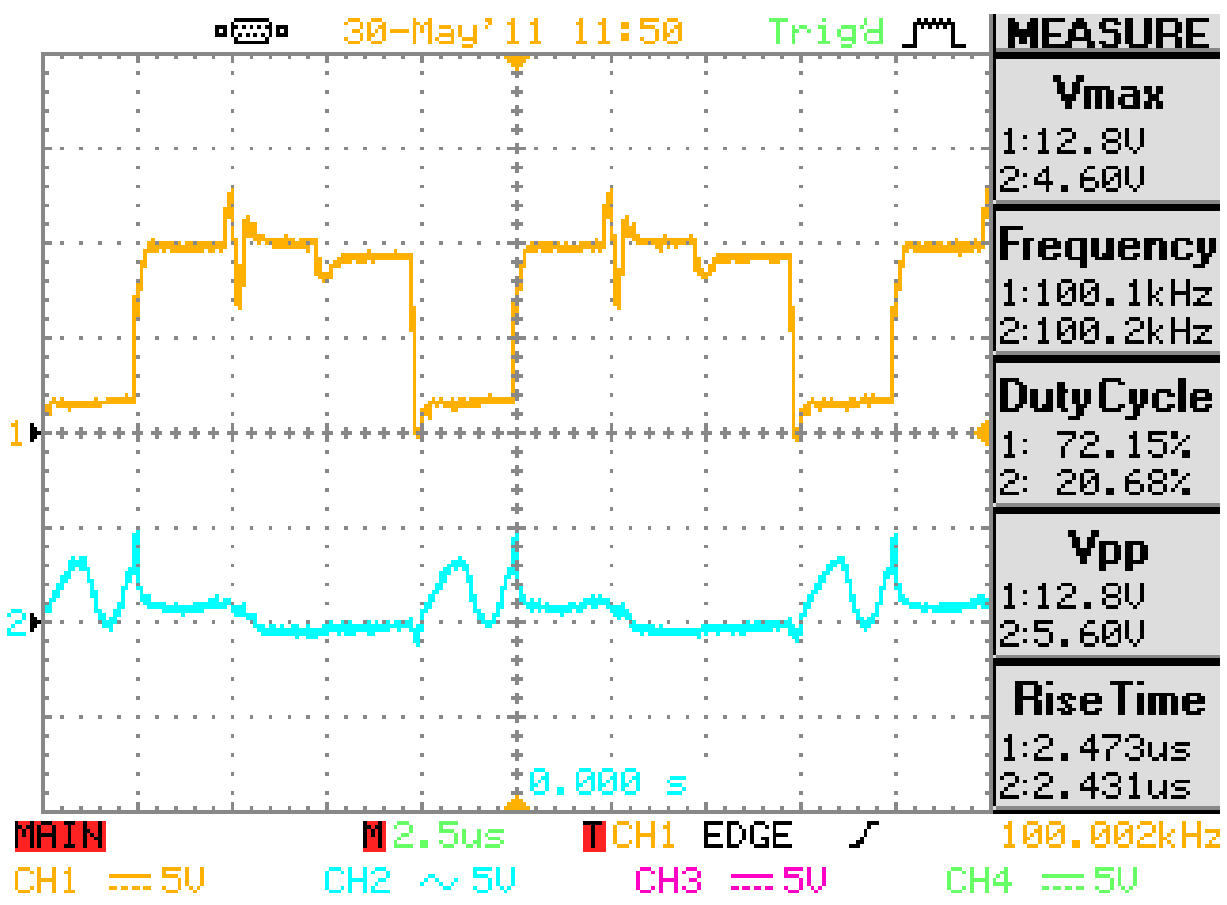

Figure 5-12: Left Switch Gate Voltage (top) and Collector to Emitter Voltage (bottom)

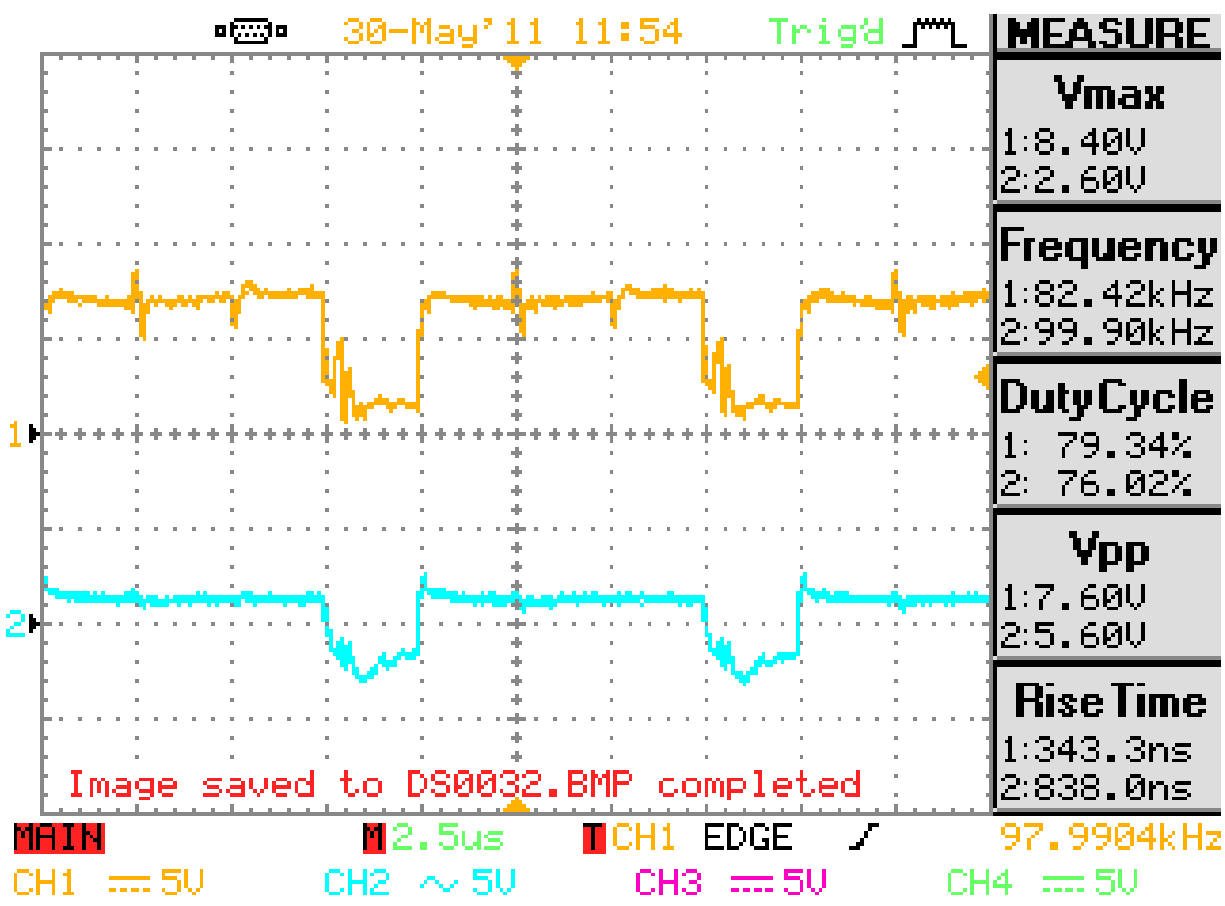

Figure 5-13: Right Switch Gate Voltage (top) and Collector to Emitter Voltage (bottom) 
Notice that the left switch which is connect to the dotted terminal of winding L2 of the transformer in Figure 5-9 has a positive collector to emitter pulse when the gate control signal goes low. While the right switch connected to the non-dotted terminal of winding L3 of the transformer in Figure 5-9 has a negative pulse across collector to emitter for a low gate control signal voltage. The occurrence of this is due to the reference of the switch with respect to the polarity of the windings dotted terminal. For a pulse created on the left switch, the dotted terminal is positive with respect to the measurement taken across collector to emitter with the scope probe. However with the right switch, since the scope probe was connected across the collector to emitter, with grounded scope probe pin referenced to the negative AC terminal as done with the left switch, and the collector now being reference to the non-dotted terminal of the transformer winding, the resulting pulse is inverted. If the scope probes ground pin was reference at the collector, the node at which the transformer connects to the switch, then the pulse would be positive.

Also important to note with these figures is the noise within these pulse signals that was not seen when the circuit was not coupled with the power stage portion of the converter. Equally as important was that the scope probe had an effect on the converters current values, waveform images, and power factor. Further investigation was done in order to pin point the operation of this converter because as Figure 5-12 and Figure 5-13 show, the converter is switching, which indicates correct operation however, EMI noise and influences from the control signal on the AC main switching seem to have an effect on the power stage portion of the converter. 


\subsection{EMI Noise and the effects of a Scope Probe}

As the converter operates a peculiar phenomenon occurs when the scope probe is connected to the negative AC terminal. Not only does the circuit operating values change when measuring input AC voltage or collector to emitter voltage across the switch, but only connecting the ground clamp of the scope probe to the AC terminal with no positive scope reference affects the circuit. The circuit operation with no scope probe measuring any device in the circuit results in the DC supply voltage and current shown in Figure 5-14 and indicates that the driving current of the supply to power the gate drive and control circuitry is low. This operation of the DC supply influences with the main AC current as well and input power factor shown in Figure 5-15, is low and rather poor respectively. To understand what is occurring the DC current probe is connected to the positive AC terminal to measure the input current without any scope probe connected. The resulting AC current is shown in Figure 5-16 which confirms the low power factor as the input current is not a pure sinusoidal waveform. 


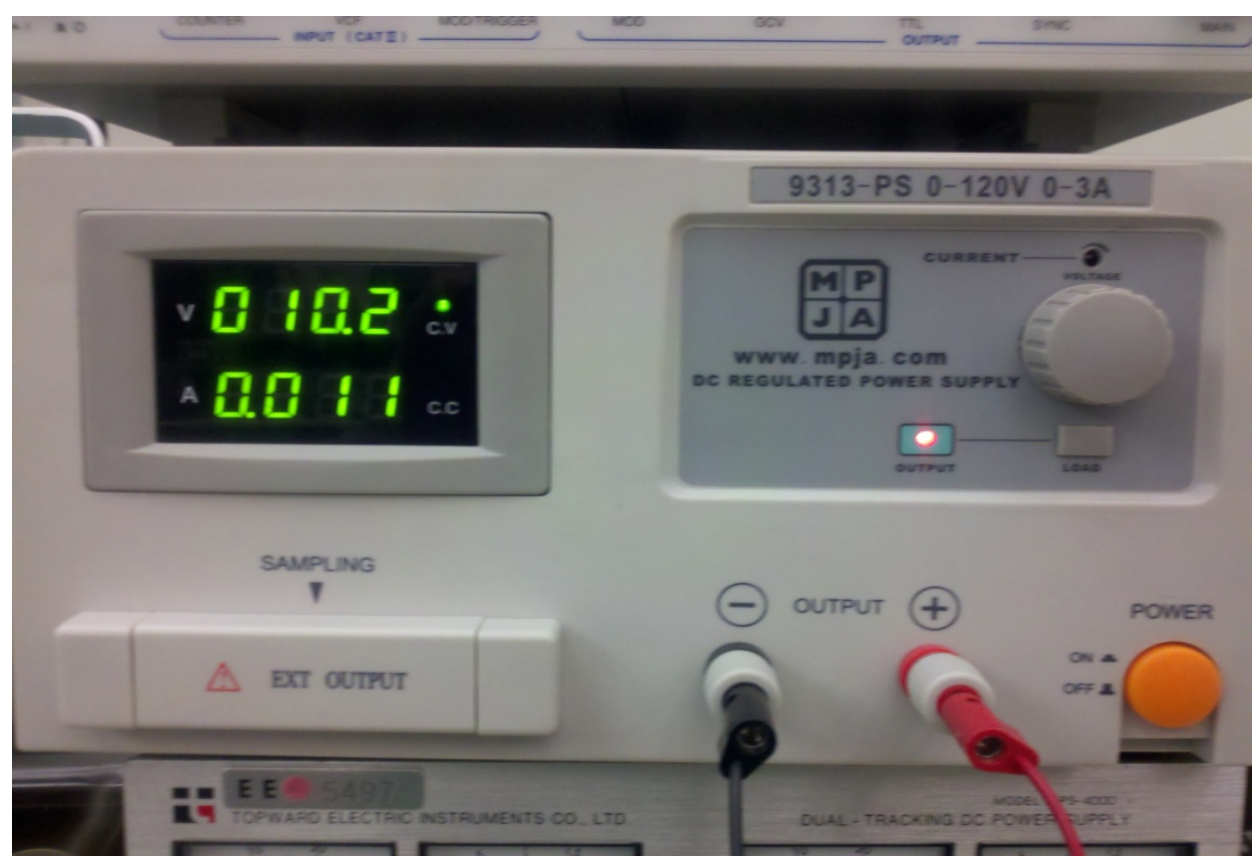

Figure 5-14: DC Power Supply Voltage and Current with Scope Probe Disconnected

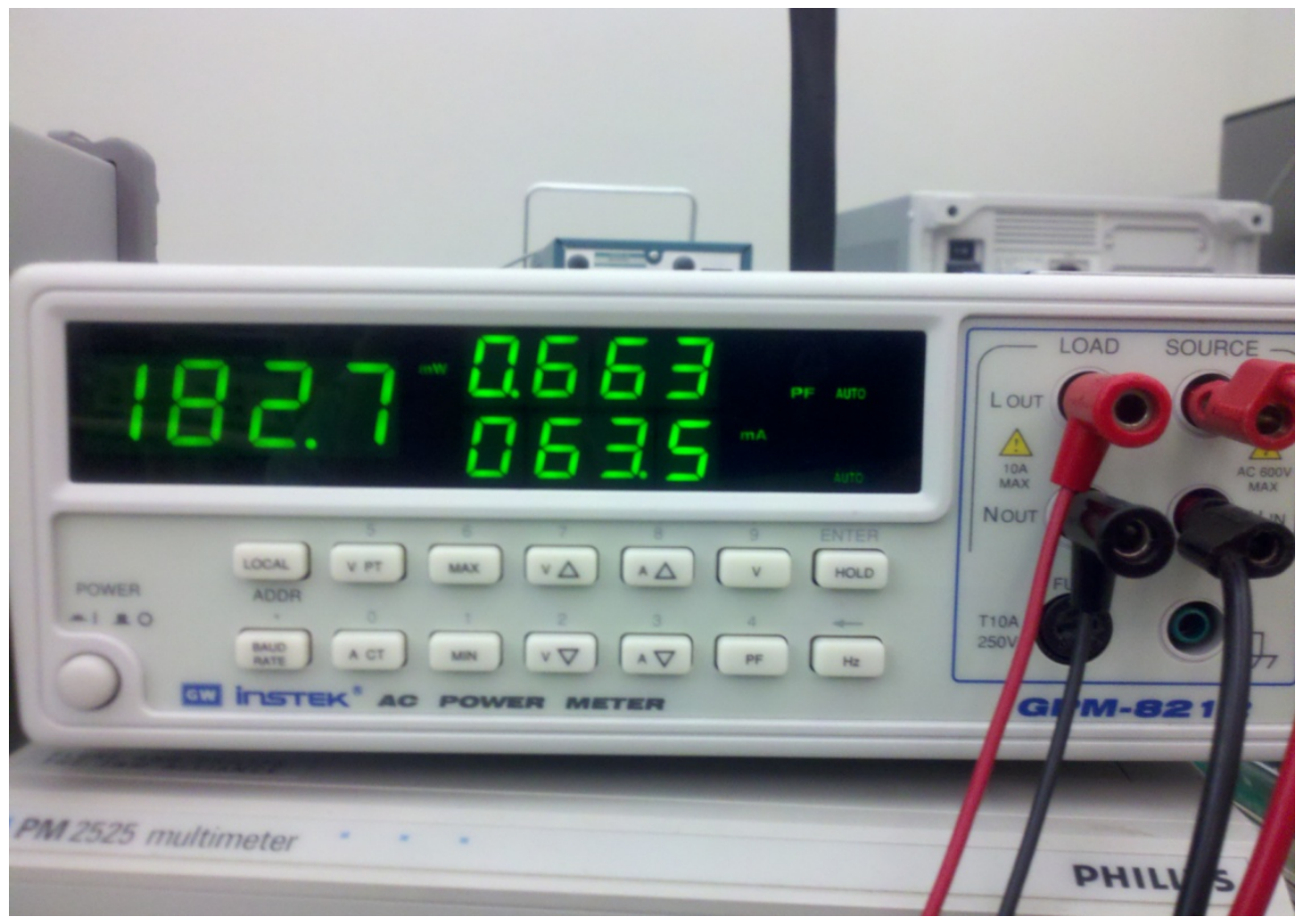

Figure 5-15: Input Power Factor and AC Current with Scope Probe Disconnected 


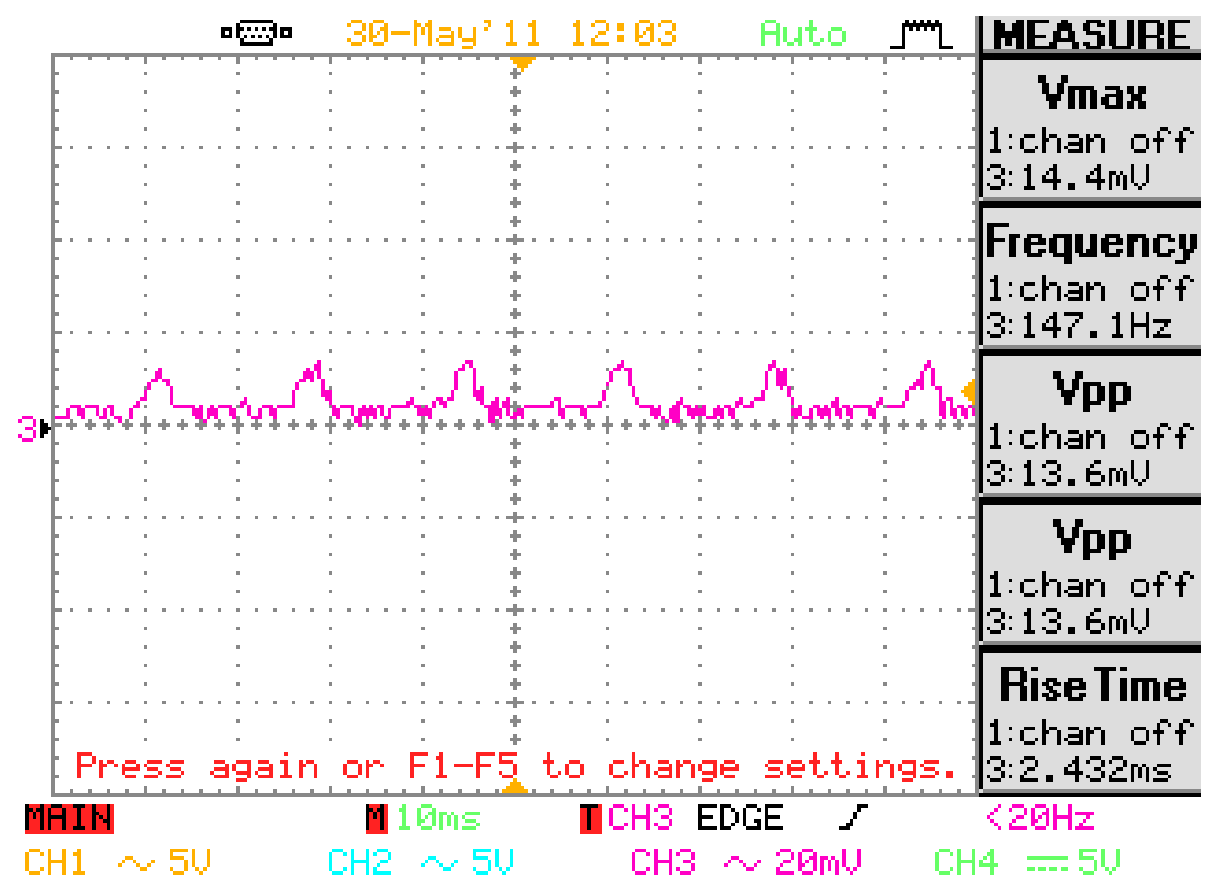

Figure 5-16: Input AC current with Scope Probe Disconnected

Now in comparison with the results in Figure 5-14, Figure 5-15, and Figure 5-16 the circuit was then tested to measure the results with the scope probe connected to the negative AC terminal. When the ground clamp of the scope probe was connected to the negative AC terminal, the DC supply for the control circuitry would experience a slight voltage drop and a larger current would be driven from the supply and comparators to the gate drivers as shown from Figure 5-17 with the constant current triggered at a limit set for the DC power supply. As well, the current increasing from the DC load, the increase would be coupled into the AC main input current as well, noting in Figure 5-18, that the current increased to $468.9 \mathrm{~mA}$ from $63.4 \mathrm{~mA}$. Also important was that the power factor jumped to 1.023 which by power factor definition would only be 1.0 maximum, but a jump of power factor from .661 to 1.023 is a considerable change to warrant discrepancies of how the scope probe could affect power factor and supply currents. To 
confirm a high power factor with the scope probe connected in relation to Figure 5-16; Figure 5-19 shows the waveform for input AC current as well as the input voltage. Astonishingly the input current matches with the reported power factor on the power meter because measured is a sinusoidal current waveform in phase with the input voltage as can be seen by the peaks being in phase. However, interesting to note is the input voltage is not a smooth sinusoidal waveform which indicates a very noise input AC signal.

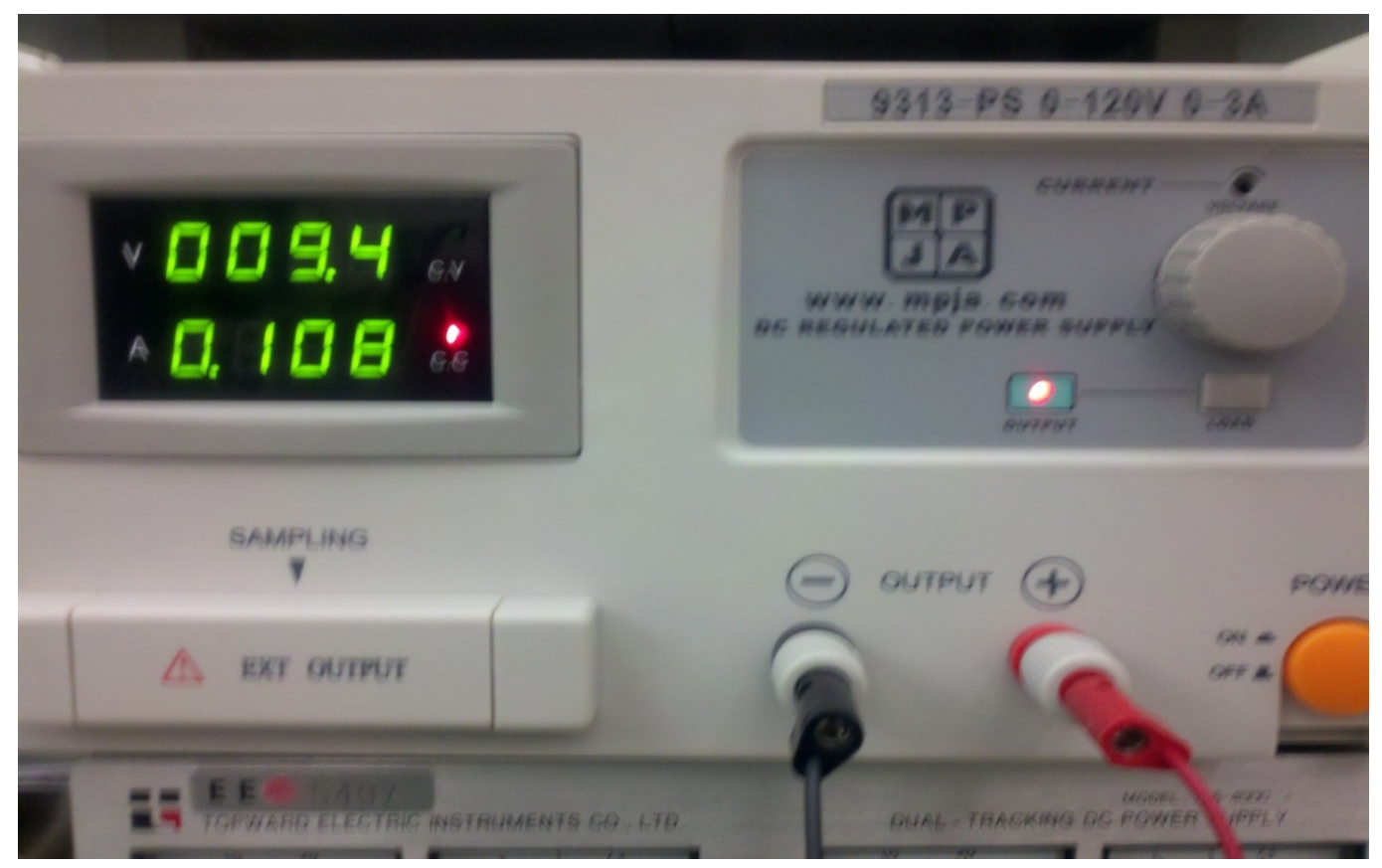

Figure 5-17: DC Power Supply Voltage and Current with Scope Probe Connected 


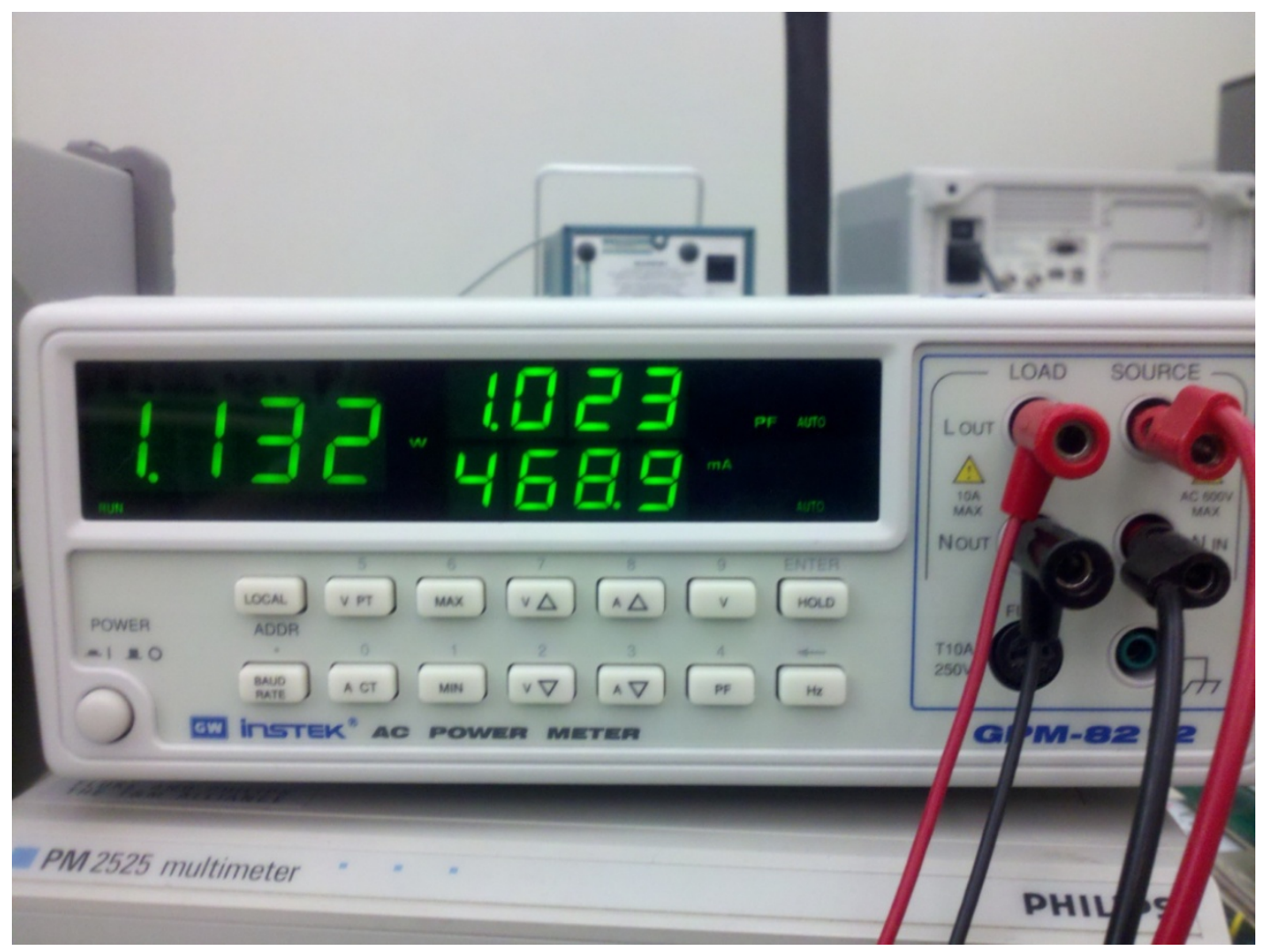

Figure 5-18: Input Power Factor and AC Current with Scope Probe Connected

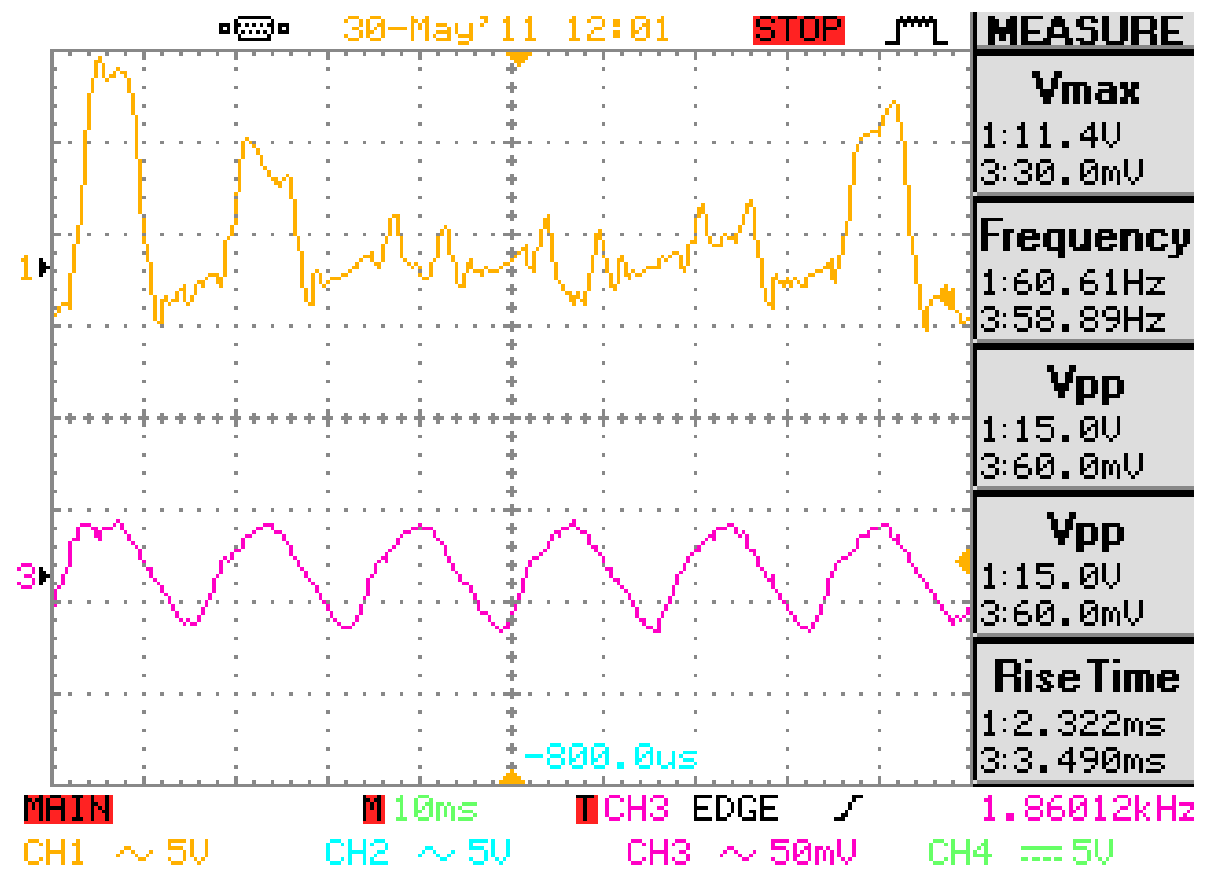

Figure 5-19: Input Voltage and AC current with Scope Probe Connected 


\subsection{Output Voltage}

With the effect of the noisy switching signals due to coupling the control signal directly to the gates of the IGBT and not allowing a path for DC current to exit the AC currents path, correct circuit operation must be investigated further before troubleshooting can be isolated to switching problems. For correct circuit operation to exist not only do the switches need to be operating correctly, the output voltage must be DC, so that rectification is provided with this converter. Figure 5-20 shows the output voltage measured across the $1 \mathrm{k} \Omega$ resistor. Shown in Figure 5-20 is a DC voltage as shown by the Vmax value of 7.44 volts as well as measured peak to peak ripple of $1.04 \mathrm{~V}$ of the output voltage. This confirms that the Current Fed Push Pull converter is rectifying and producing a DC output voltage which will correspond to DC output current by relating voltage to the output resistor. Now that operation of this converter is confirmed, further analysis must be investigated with switching and how the converter can be affected with coupling a scope probe to the negative AC terminal.

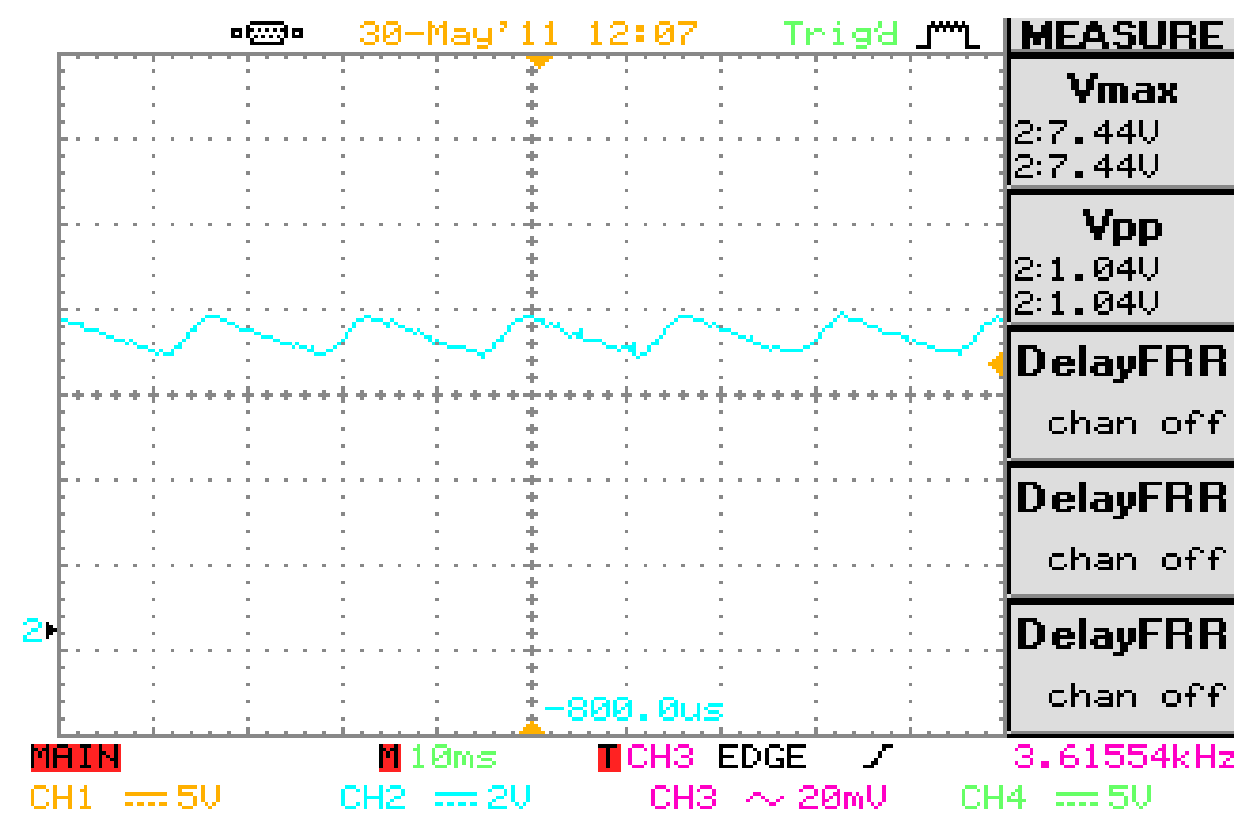

Figure 5-20: Output DC Voltage and Peak to Peak Voltage Ripple 


\subsection{IGBT Basics}

To understand the switching noise through the method used in the converter with the IR4428 low side drivers, the IGBTs fundamental structure must be reviewed. Figure 5-21 shows the IGBT internal model with a combination of output transistors and an input MOSFET. Studies and characteristics of the IGBT are located in [27] [28] and [29]. Specifically the effects of the IGBT with the Push Pull converter are from the capacitors between gate to emitter and gate to collector [27, 28, 29]. During turn on transient time and turn off transient time, the capacitors between gate to emitter and gate to collector charge and discharge respectively, which allows for the gate to emitter voltage to exceed the required threshold voltage for turn on, or below threshold voltage for turn off [27, 28, 29]. Further details are studied with the effects of current through the gate when a gate resistor is added and its specific resistance with affecting the charge of biased capacitors between IGBT terminals [27, 28, 29].

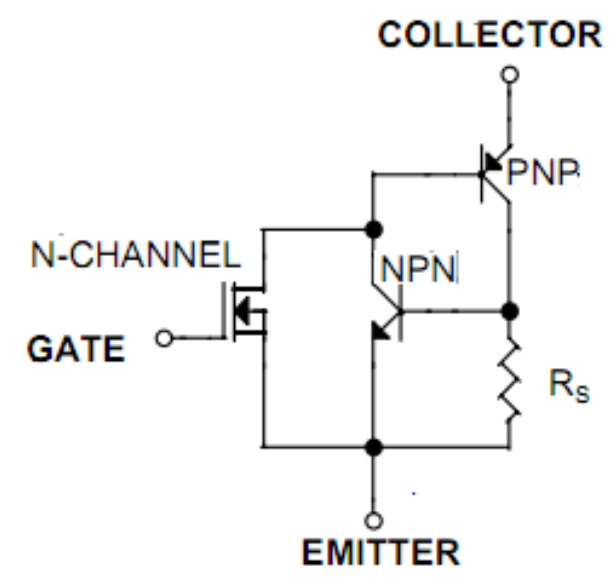

Figure 5-21: Internal Model of Insulated Gate Bipolar Transistor [27]

Since the gate builds up charge and the collectors node voltage alternates with respect to the gate, DC current effects on AC quality is high with no scope probe attach. 
The reason for this is because the gate has a buildup of DC current through the terminal capacitors of the IGBT. Since the DC control signal does not have a return path for controlling the gate voltage potential, AC main current is affected and results in the noise in the AC main switching from the induced DC control gate current.

\subsection{Parasitic Capacitance and Reducing EMI Noise}

The next step in understanding this problem and relations to switching capacitance was to look for similar noise in other PFC conversion techniques. EMI noise reduction has been concluded in [30] with the difference between conventional PFC and bridgeless PFC, noting that bridgeless PFC has large noise effects relating to parasitic capacitances. Conventional PFC fundamentally provides a ground connection reference from the output of the converter to the input line through the bridge rectifier [30].

Bridgeless PFC however has floating ground and so the output voltage is referenced to an alternating input AC line, as is done with this converter [30]. More parasitic capacitances exist for bridgeless power factor correction in respect to the switches and output, where all parasitic capacitances are referenced to earth ground, while the converter is referenced to floating ground or the negative AC terminal [30].

In respect to the results obtained from lab testing, the scope probe affected the performance of the circuit when the ground scope probe clamp was connected to the negative AC terminal. With respect to the problems addressed in [30], the solution for reducing EMI noise in bridgeless PFC is to connected capacitors from the AC input line to ground so that a high frequency path may exist between output and input [30]. This relates to the scope probe connecting to the negative AC terminal because inherent to the $10 \mathrm{X}$ scope probe is a $9 \mathrm{M} \Omega$ resistance and shunt capacitance on the order of picofarad 
size [31]. Therefore the negative AC terminal is grounded to earth ground through the oscilloscope and its internal capacitance. Once this scope probe is connected, the EMI noise can escape the now non-floating AC terminal and therefore increase PF, as well as generate a high flow of current.

\subsection{Optocouplers and Solid State Relays}

Therefore, a new model for AC switching must be implemented to reduce the gate of the IGBT from building up DC current and charge to the terminal capacitances. The current operation of the converter has effects of the DC on the AC and produces noise because the control signal is directly connected to the gate of the IGBT. Methods of providing a control signal to trigger a switch without directly coupling the signal to the gate exist and are defined as optocoupling. Optocouplers are essentially a photodiode that is isolated from a switch and triggers the gate of the switch through light emitted from the diode as a control signal is generated on the isolated photodiode control side [32]. Solid State relays are a specific application that is used for AC main switching with DC control signal that isolates each side from each other. Specifically photodiode IC relays or solid state relays types are shown in Figure 5-22.

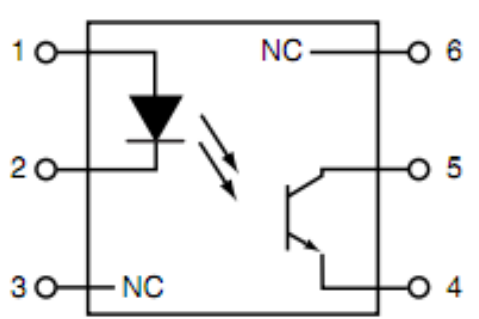

BJT Output

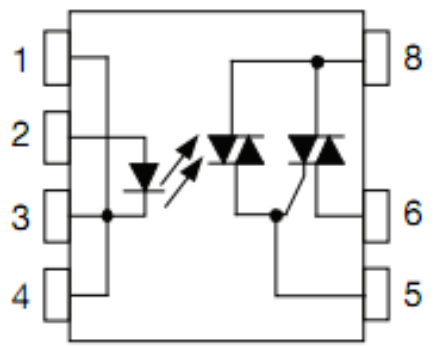

Triac Output

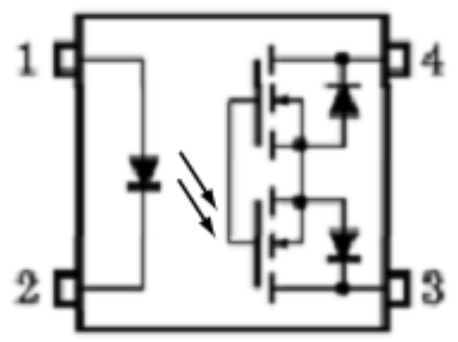

IGBT Output

Figure 5-22: Photodiode Relay Types for Bidirectional Switching [33, 34] 
The operation of the solid state relay for turning on and turning off allows AC current on the secondary side to flow and current to be impeded respectively. When both switches are on when the LED diode is lit because of a high control pulse on the diode side which is current flowing because of the voltage, both switches allow current to flow and the other diode on the opposite switch allows current to flow through it for the IGBT configuration. However when both switches are off then the body diodes impede the current in either direction and result in a fully off switch. By testing the bidirectional solid state relays above, noise is hopefully reduced in respect to what was seen when the gate was directly connected to the control pulse. Photodiode IC relays also exist with single transistors on the output but the Triac output and IGBT output with external body diodes allow for bidirectional current flow. The drawback however with these solid state relays is that when trying to use these for SMPS applications, the switching speeds are limited based on their application. Specifically the Triac output and dual MOSFET switching are used for firing angle control of an AC waveform. So in design of these chips manufacturers only work to realize speeds of tenths of millisecond turn on and turn off times up to milliseconds.

However, the BJT output optocoupler does allow for fast switching because it is a single BJT that is not directly designed for AC switching techniques. This layout though can be useful because it will allow isolation of the control side signals and DC supplies from directly coupling with the external power IGBTs from the optocoupler used for AC switching. Therefore the design in Figure 5-23 is implemented to reduce noise that was seen with the control signal directly coupled to the gate from the low side, and instead isolation is provided, but still using the BJT to drive the gates of the power IGBTs as 
shown. Utilizing a two input NAND gate with inputs tied together creates an inverted 25\% duty cycle signal across the photodiode shown in Figure 5-24.

This inversion of the signal is done so it will counter act the inversion that is done with the BJT and the pull up resistor, which inherently acts as an analog inverter. The two stage inversion will then result in the correct $75 \%$ duty cycle waveform from collector to emitter of the optocoupled BJT as shown in Figure 5-25. Note that pulse waveform on the output of the BJT across the $7.75 \mathrm{k} \Omega$ resistor is not coupled to the switches when measuring the waveforms in Figure 5-25.

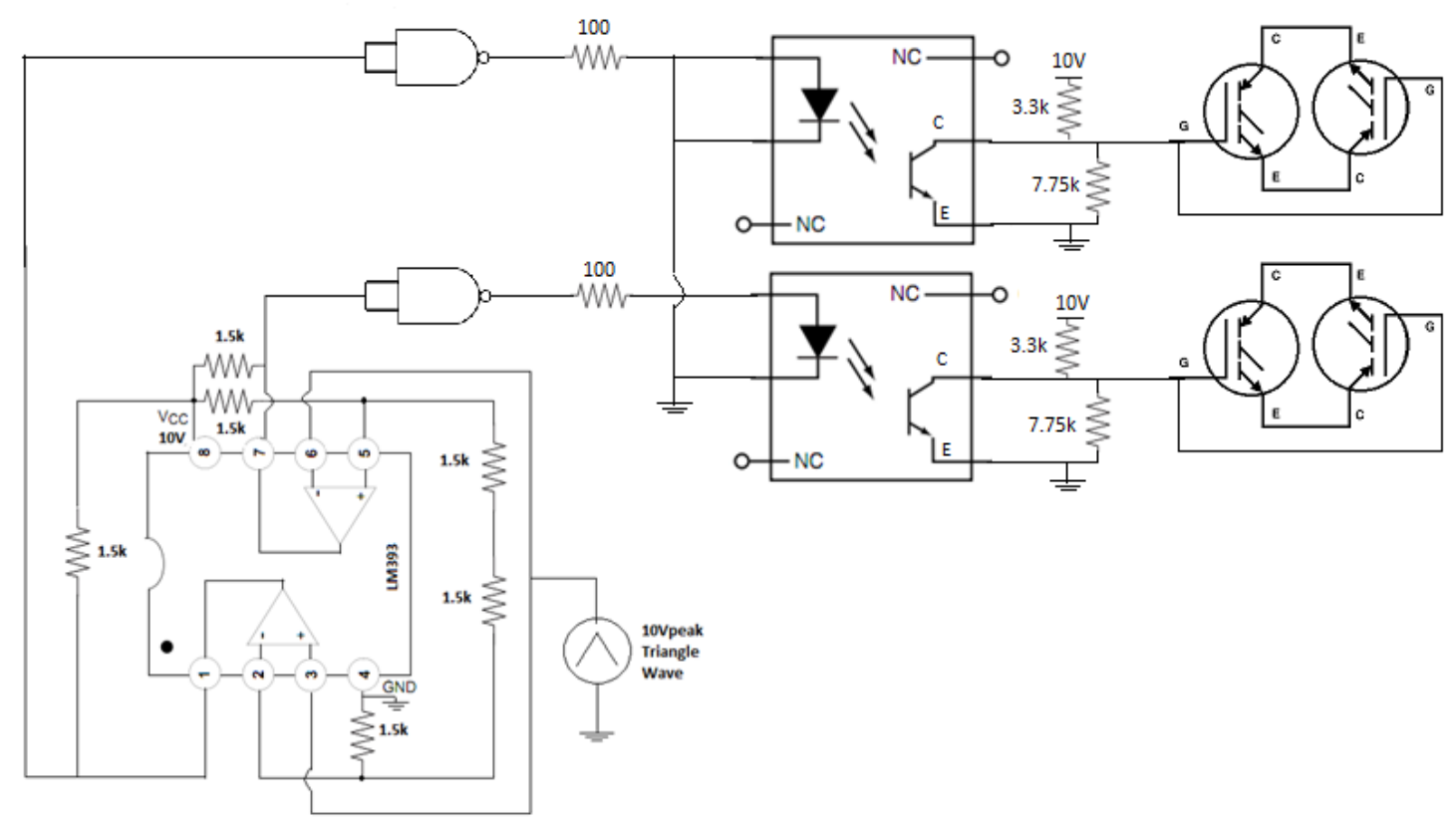

Figure 5-23: Control Circuitry utilizing Optocoupling with BJT output 


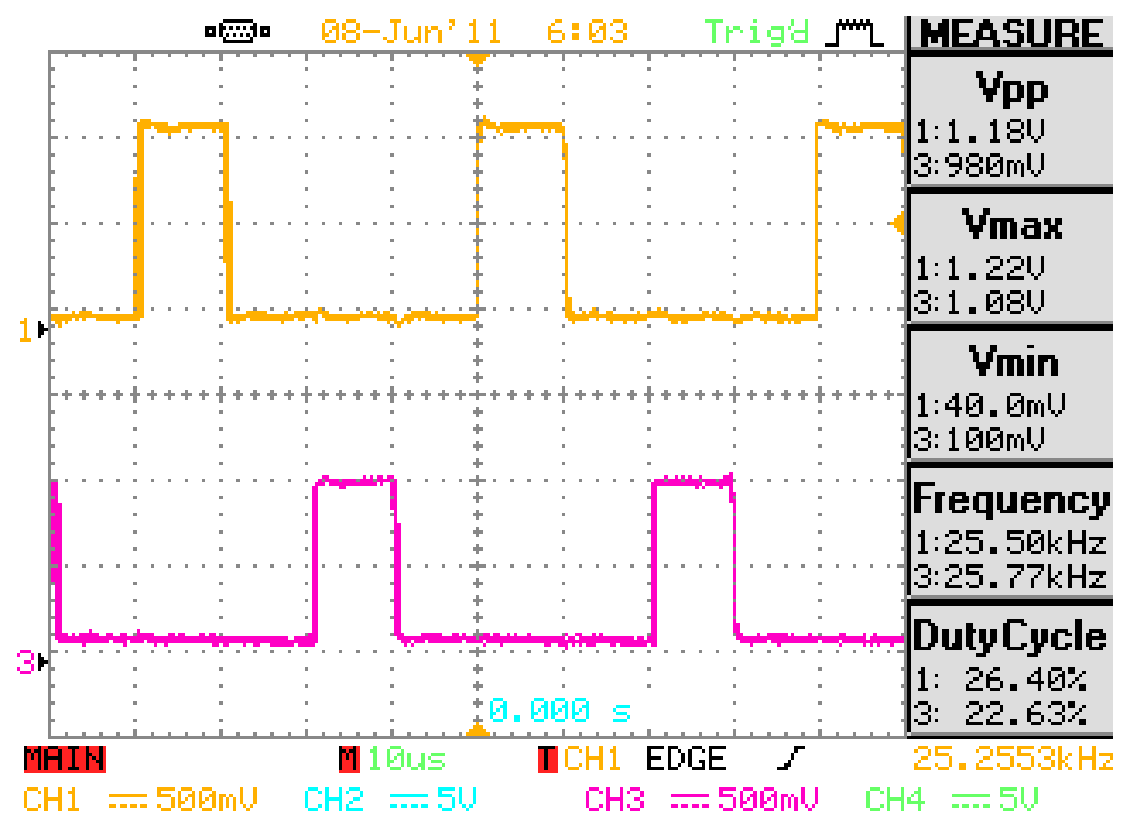

Figure 5-24: Photodiode pulse voltages for Switch 2 (top) and Switch 1 (bottom)

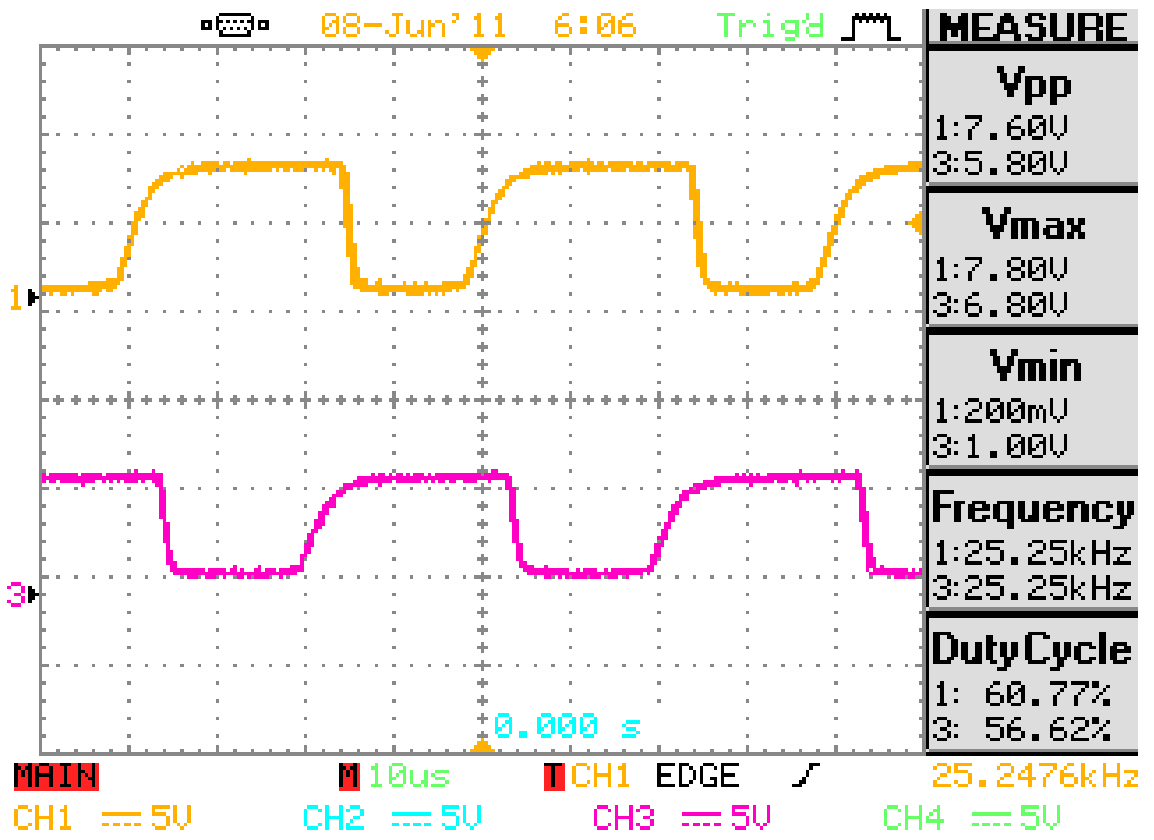

Figure 5-25: BJT output pulse from Collector to Emitter not driven to Switches

Now when the pulse measured across the collector to emitter of the optocoupler $\mathrm{BJT}$ is driven to the gate of the power IGBTs, the pulse inherits a noisy component as 
shown in Figure 5-26. This noisy characteristic observed in the gate signal is due to the inherent capacitance from gate to source and gate to drain of the IGBT. While the optocoupler BJT has inherent capacitance as well which results in the RC time delay seen in Figure 5-25, noisier traits result from the power IGBTs because the return path to ground which is provided by the $7.75 \mathrm{k} \Omega$ resistor when the no floating gate is tied to the resistor is not present for the power IGBTs because the source of these IGBTs will not be DC ground but the negative AC terminal of the input to the power converter. Therefore when referencing the pulse at the optocoupler BJT collector to DC ground the pulses below result because charge has no return path to DC ground from the IGBT sources.

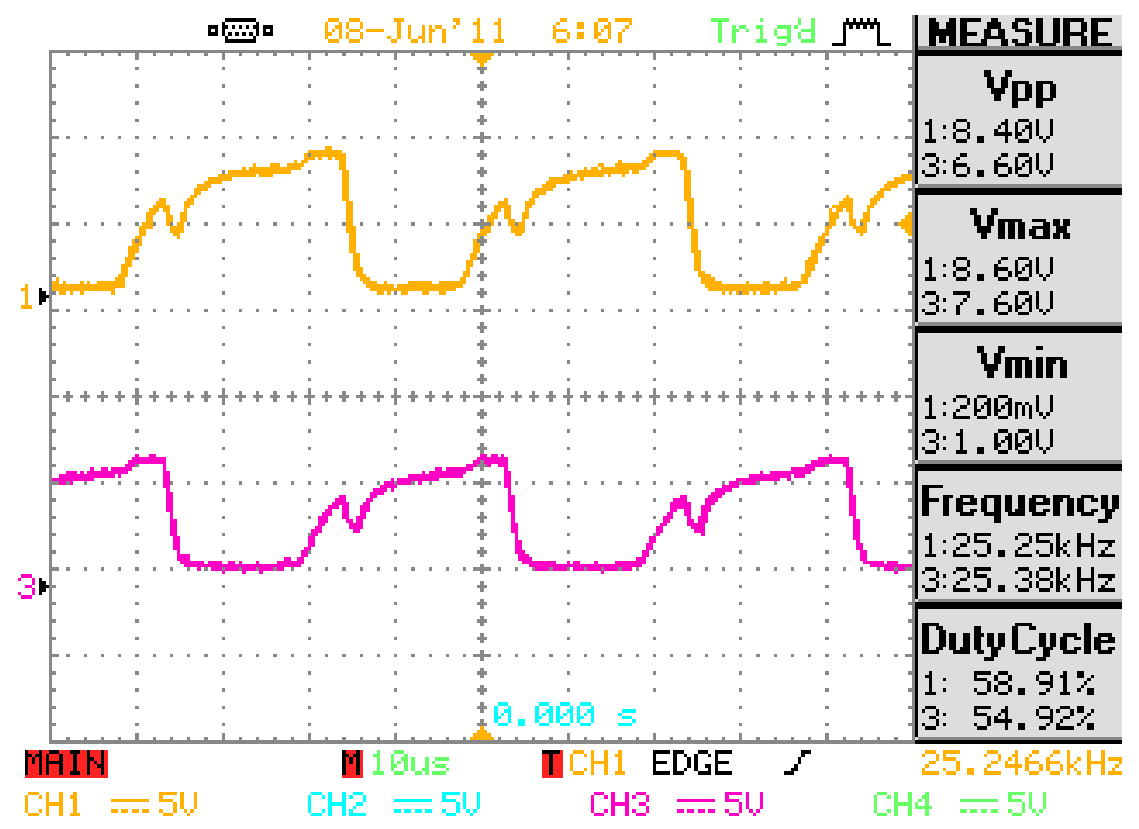

Figure 5-26: Optocoupler BJT pulse voltage connected to IGBT gate with DC ground reference 
Investigating the switching signal in Figure 5-26 further, but now in reference from gate to source of the power IGBTs, will show what type of offset is obtained in turning the IGBTs on and off. As shown in Figure 5-27 the gate to emitter voltages of the two IGBTs in one anti parallel configuration do not have their full DC offset. The reason for this is because the reference for measurement to ground is at the optocoupled BJT however the measurement is taken at the source of the IGBT which is a floating reference. Hence, this is the reason why the pulse differential between the gate to emitter of the IGBT is AC coupled.

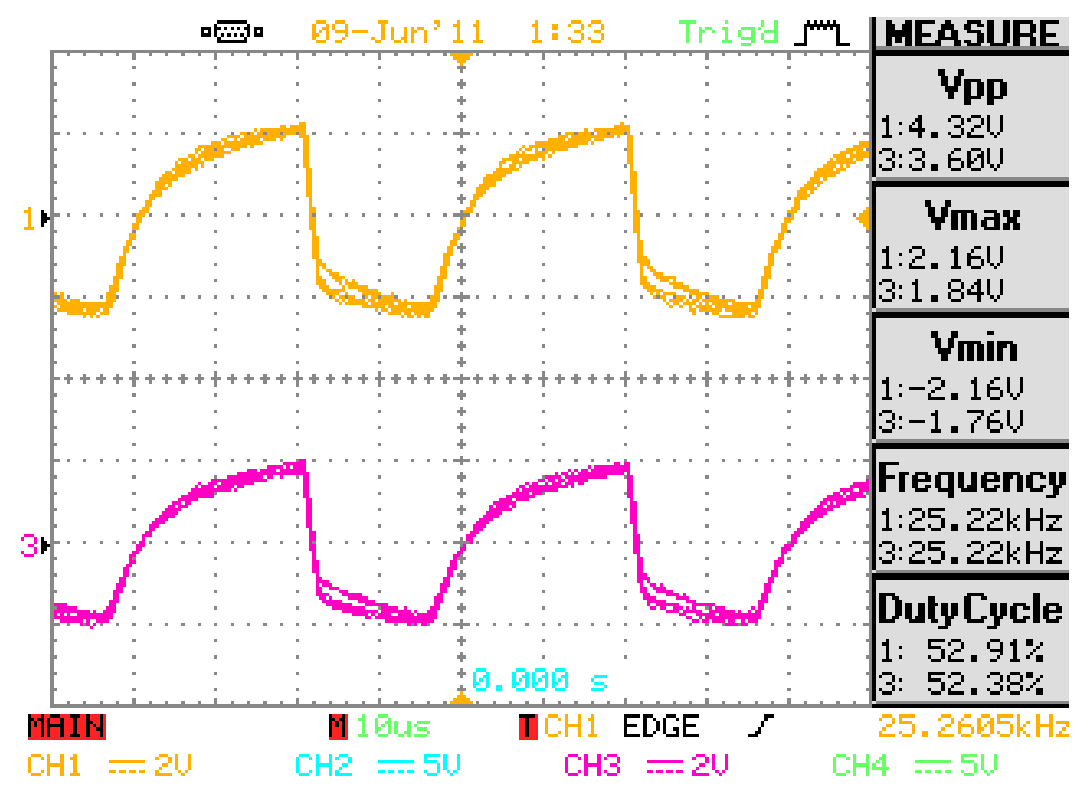

Figure 5-27: Gate to Emitter of the IGBTs showing AC coupling

Due to this AC coupling of the gate to emitter voltage, the switches are determined to never turn on because the voltage turn on for the IGBTs is a minimum of $3 \mathrm{~V}$ which is not achieved since the pulse measured in Figure 5-26 from collector to emitter of the optocoupled BJT is not across gate to emitter of the IGBT. Figure 5-28 shows that the input voltage is now a sinusoidal waveform however the input AC current 
is zero because as shown in Figure 5-29 the collector to emitter voltage across the IGBTs is the matching input sinusoidal voltage. This indicates that the switches are open and see all the applied voltage, instead of turning on and off, which would result in spiking voltages at a higher frequency. This result realizes that optocoupling is a successful possibility in reducing noise that would otherwise be coupled back to the input, however the trade off is still finding the correct configuration that will allow the gate voltage to be at a higher potential than the IGBTs emitter and not influence the AC main signal.

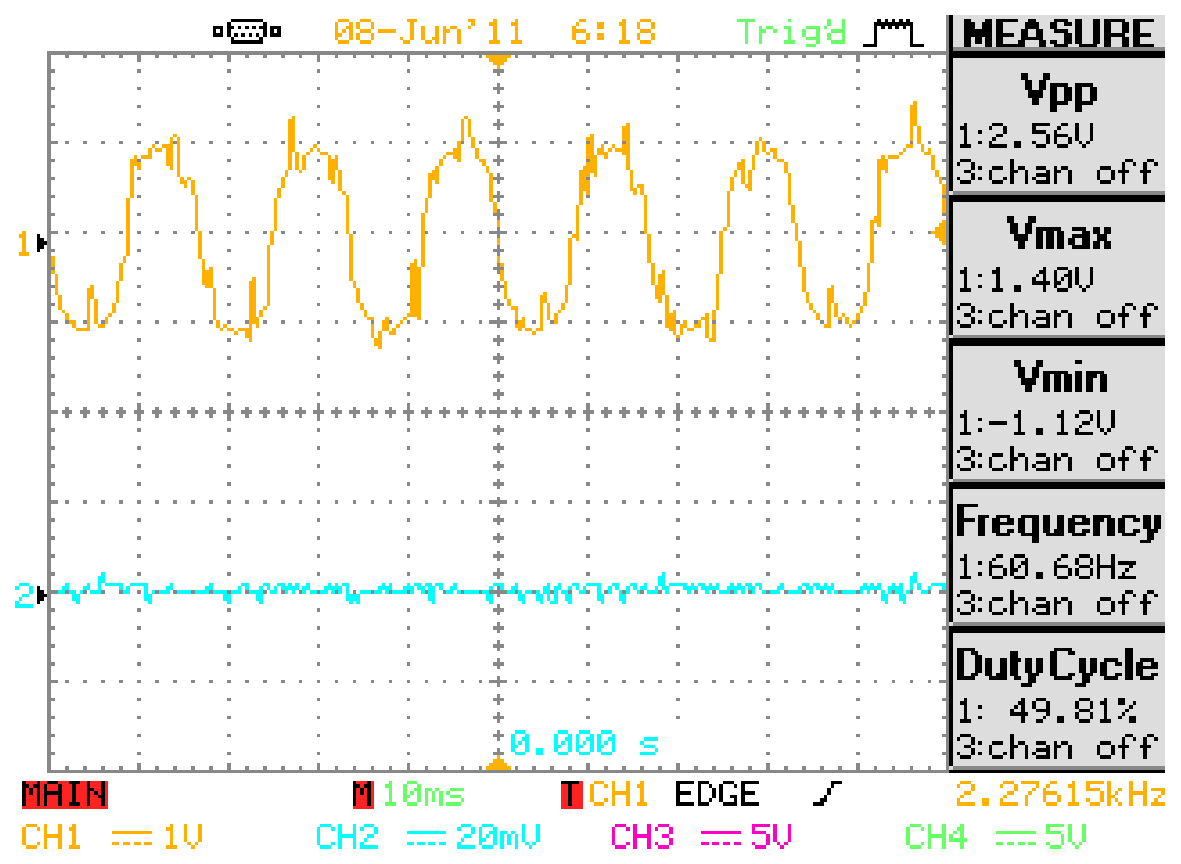

Figure 5-28: Input AC voltage (top) and Input AC current (bottom) 


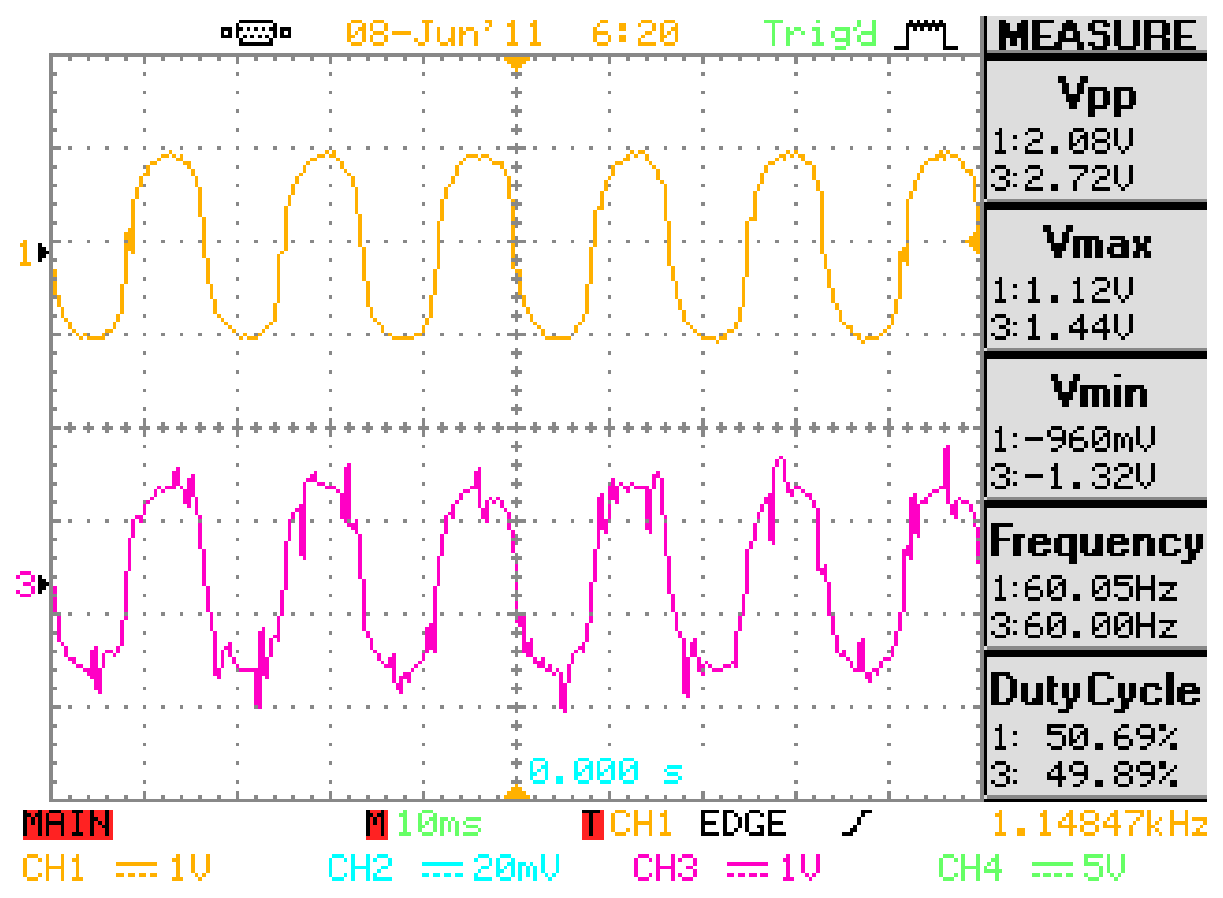

Figure 5-29: IGBTs collector to emitter voltage for left switch (top) and right switch (bottom) 


\section{CONCLUSION}

In this thesis the waveforms and data taken in simulation confirm that this new method of providing power factor correction as well as rectification using a single stage current fed push pull converter is a promising solution. Utilizing the input inductor for constant AC current flow through the input of the push pull converter, power factor correction is inherently provided. The output diodes are implemented to provide the rectification so that the final output is a DC voltage.

As simulation is confirmed to operate in providing a power factor of 0.998 with correct component sizing, hardware testing was also required to implement this circuit and ensure that real world components were able to acquire similar results to simulation. As hardware was built, multiple different testing configurations were used to supply a path for bidirectional current flow through the input switches in Figure 4-1. As simulation is not conducive to assuming real world components, Sbreak allows for bidirectional switching with ease. Most demanding of testing and design procedures was not the power stage portion of the push pull converter which essentially converts AC-DC, but instead it was implementing the control circuitry.

In utilizing a comparator configuration and one triangle waveform, two square wave pulses were created with respect to one another so that overlapping switch on times can be obtained to always allow current to flow on the input of the converter. With these square wave signals, multiple gate drive configurations were tested, as well as bidirectional switching configurations, so that AC current flow could naturally flow. As determination of gate drive operation through testing realized that DC biasing to source 
nodes that naturally want to alternate is not feasible, further testing was done to implement DC reference to AC switching.

In finding that since the source node of the bidirectional switch configurations was naturally alternating, it was determined that floating the gate without a reference to ground at the source would drive the IGBT to be on because as long as the gate was higher than the alternating source node voltage, biasing of the gate to source capacitor would charge and turn the IGBT on. This testing procedure proved to provide substantial evidence that correct operation of the converter is feasible. Indicative of this operation was the switching signals measured as well as a sinusoidal input current. Also important, was that this circuit provided rectification as shown in Figure 5-20 which confirms the full system provided the two key components of power factor correction and rectification. However, limitations were present with this design that results in needing further testing and investigation to design a more efficient switching system with this topology.

Solid state relays as mentioned are a viable solution because isolation can be provided in biasing the AC main switching without disturbing its natural alternation with DC applied voltage. The task of implementing an AC bidirectional switch that can be switched at very high frequencies, hundreds of kilohertz, is an external design for further study. Current technology utilizing solid state relays, or specifically optocoupling is limited in speed for bidirectional applications. Currently, the technology of bidirectional AC switching using optocoupling is a slower switching technology geared at AC chopping and firing angle applications. Since this is the case, application with SMPS is limited because the frequency is only in the hundreds of hertz to tens of kilohertz, while the later is very uncommon. 
So in order for the noise to be reduced and successfully implement this converter as a definitive solution for PFC, implementation of optocouplers and DC floating references must be obtained so that AC switching is not disturbed. Testing was implemented with BJT output optocouplers which provide faster switching speeds, however, inherently they are unidirectional switches, so driving these BJTs to external power MOSFETs or IGBTs must be done. As was done, an optocoupler BJT was used to drive the gates of the bidirectional switches with floating source, however because the source was floating and not reference to the BJT ground, the pulse across the IBGTs gate to emitter was AC coupled since the emitter was floating. This limitation can be solved by simply providing an optocoupler with a photovoltaic output so that the LED emits a biasing voltage across gate to emitter of the IGBT, and essentially DC offsets the gate to a higher potential than the emitter of the IGBT without direct connection. Once again, if speed in this optocoupler configuration can be increased, this solution is promising.

Lastly, several companies are implementing designs that focus attention around isolation of control signals from power switching. Specifically, Maxim Electronics has a transformer driver-IC controls bidirectional switch that may be exactly what is needed for this design. The chip incorporates a switching technique in the $450 \mathrm{kHz}$ to $900 \mathrm{kHz}$ range, so that SMPS operation can be possible, and external transformer isolation is utilized along with voltage biasing that can reference to DC or AC bidirectional switching. Figure 6-1 shows the schematic of the design and noticing its application in comparison to previously mentioned testing, it surely has its possibilities in single stage power factor correction application. 


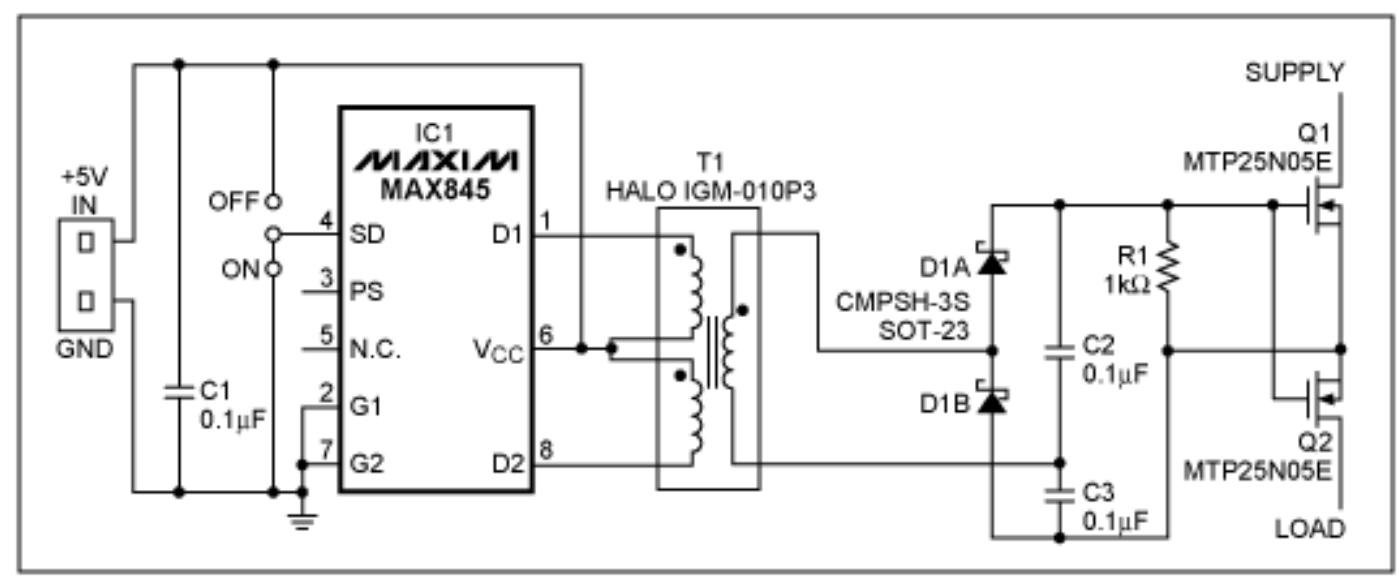

Figure 6-1: Transformer Driver-IC Controls Bidirectional Switch [35]

Utilizing controllers such as the one in Figure 6-1 or designing a method to control AC switching at high frequencies without inducing the high frequency noise into the low frequency AC main is crucial in making this topology a viable competitor for Switched Mode Power Supplies. As technology progresses, more efficient systems, as well as smaller system become more popular to provide quality power to consumers. With this converter design, bridge rectifiers are not needed, and control schemes are vastly simplified because of the converters inherent power factor correction capabilities. While further testing is warranted to bring the switching capabilities to par with the demands of the converter, correct circuit operation, and promising future results are obtainable with the designed bridgless push pull converter for active power factor correction. 


\section{BIBLIOGRAPHY}

[1] “Power Factor.” Wikipedia. Wikimedia Foundation, Inc. April 20, 2011. Creative Commons Attribution-ShareAlike License $<$ http://en.wikipedia.org/wiki/Power_factor>.

[2] "Apparent Power." Repair and Maintenance Manuals - Integrated Publishing. Integrated Publishing, Inc., 1998. Web. Feb.-Mar. 2011. $<$ http://www.tpub.com/content/doe/h1011v3/css/h1011v3_68.htm>.

[3] "PFC Decoded." Dan's Data - PC Hardware and Gadget Reviews! Atomic: Maximum Power Computing, 2003. Web. 15 Feb. 2011. $<$ http://www.dansdata.com/gz028.htm>.

[4] Prasad, A.R.; Ziogas, P.D.; Manias, S.; , "An active power factor correction technique for three-phase diode rectifiers," Power Electronics, IEEE Transactions on , vol.6, no.1, pp.83-92, Jan 1991

[5] Jovanovic, M.M.; Jang, Y.; , "State-of-the-art, single-phase, active power-factorcorrection techniques for high-power applications - an overview," Industrial Electronics, IEEE Transactions on , vol.52, no.3, pp. 701- 708, June 2005

[6] Daqing Wang; Hongqi Ben; Tao Meng; , "A novel three-phase power factor correction converter based on active clamp technique," Electrical Machines and Systems, 2008. ICEMS 2008. International Conference on , vol., no., pp.18961901, 17-20 Oct. 2008

[7] Prasad, A.R.; Ziogas, P.D.; Manias, S.; , "A new active power factor correction method for single-phase buck-boost AC-DC converter," Applied Power Electronics Conference and Exposition, 1992. APEC '92. Conference Proceedings 1992., Seventh Annual , vol., no., pp.814-820, 23-27 Feb 1992

[8] Ekemezie, P.N.; , "Design of a power factor correction ac-dc converter," AFRICON 2007 , vol., no., pp.1-8, 26-28 Sept. 2007

[9] Wang Wei; Liu Hongpeng; Jiang Shigong; Xu Dianguo; , "A novel bridgeless buckboost PFC converter," Power Electronics Specialists Conference, 2008. PESC 2008. IEEE , vol., no., pp.1304-1308, 15-19 June 2008

[10] Kanaan, H.Y.; Al-Haddad, K.; , "A comparative analysis of nonlinear current control schemes applied to a SEPIC power factor corrector," Industrial Electronics Society, 2005. IECON 2005. 31st Annual Conference of IEEE , vol., no., pp.6 pp., 6-6 Nov. 2005 
[11] Ching-Jung Tseng; Chern-Lin Chen; , "A novel ZVT PWM Cuk power-factor corrector," Industrial Electronics, IEEE Transactions on , vol.46, no.4, pp.780787, Aug 1999

[12] Fardoun, A.A.; Ismail, E.H.; Sabzali, A.J.; Al-Saffar, M.A.; , "A comparison between three proposed bridgeless Cuk rectifiers and conventional topology for power factor correction," Sustainable Energy Technologies (ICSET), 2010 IEEE International Conference on , vol., no., pp.1-6, 6-9 Dec. 2010

[13] Ismail, E.H.; , "Bridgeless SEPIC Rectifier With Unity Power Factor and Reduced Conduction Losses," Industrial Electronics, IEEE Transactions on , vol.56, no.4, pp.1147-1157, April 2009

[14] Lamar, D.G.; Fernandez, A.; Arias, M.; Rodriguez, M.; Sebastian, J.; Hernando, M.M.; , "Limitations of the Flyback Power Factor Corrector as a One-Stage Power Supply," Power Electronics Specialists Conference, 2007. PESC 2007. IEEE , vol., no., pp.1343-1348, 17-21 June 2007

[15] Fernao Pires, V.; Martins, J.F.; Silva, J.F.; , "A Single Stage Flyback PFC Converter for Testing Distance Relay Systems," Power Electronics and Drive Systems, 2007. PEDS '07. 7th International Conference on, vol., no., pp.1748-1752, 27-30 Nov. 2007

[16] Tsorng-Juu Liang; Ren-Yi Chen; Jiann-Fuh Chen; Wei-Jin Tzeng; , "Buck-type current-fed push-pull converter with ZCS for high voltage applications," TENCON 2007 - 2007 IEEE Region 10 Conference , vol., no., pp.14, Oct. 30 2007-Nov. 22007

[17] Barbosa, P.M.; Barbi, I.; , "A single-switch flyback-current-fed DC-DC converter," Power Electronics, IEEE Transactions on , vol.13, no.3, pp.466-475, May 1998

[18] "Push-pull Converter." Wikipedia, the Free Encyclopedia. Wikimedia Foundation Inc., 6 Apr. 2011. Web. 20 Feb. 2011. <http://en.wikipedia.org/wiki/Push_pull_converter>.

[19] Bell, Bob. "Introduction to Push-Pull and Cascaded Power Converter Topologies." National Online Seminar. National Semiconductor, 10 July 2003. Web. 22 Feb. 2011. $<$ http://www.national.com/onlineseminar/2003/telecom/cascade_tutorial_0710.pd $\mathrm{f}>$. 
[20] Li-jun Hang; Zheng-yu Lu; Xin-wei Liu; Zhaoming Qian; , "Comparison Research of Digital and Analog Control For Single-Stage Power Factor Correction AC/DC Converter," Industrial Electronics Society, 2007. IECON 2007. 33rd Annual Conference of the IEEE , vol., no., pp.1466-1471, 5-8 Nov. 2007

[21] Lu, B.; Brown, R.; Soldano, M.; , "Bridgeless PFC implementation using one cycle control technique," Applied Power Electronics Conference and Exposition, 2005. APEC 2005. Twentieth Annual IEEE , vol.2, no., pp.812-817 Vol. 2, 6-10 March 2005

[22] Ali, Mokhtar; Orabi, Mohamed; Ahmed, Mahrous E.; El-Aroudi, Abdelali; , "A single stage SEPIC PFC converter for LED street lighting applications," Power and Energy (PECon), 2010 IEEE International Conference on , vol., no., pp.501506, Nov. 29 2010-Dec. 1201

[23] Alcalde, A.L.P.; Mohr, H.B.; Borgonovo, D.; Mussa, S.A.; , "Experimental validation of the NIOS II processor-FPGA on the digital control of PFC converter," Power Electronics Conference, 2009. COBEP '09. Brazilian, vol., no., pp.895-900, Sept. 27 2009-Oct. 12009

[24] Lee, S.; Park, J.; Choi, S.; , "A Three-Phase Current-Fed Push-Pull DC-DC Converter With Active Clamp for Fuel Cell Applications," Power Electronics, IEEE Transactions on , vol.PP, no.99, pp.1, 0

[25] Pressman, Abraham I., Keith H. Billings, and Taylor Morey. "Chapter 2." Switching Power Supply Design. Third ed. New York: McGraw-Hill, 2009. Print.

[26] "SMPS Switching Power Supply Design: Circuits and Schematics." SMPS (Switching Power Supply)- Design Tutorials, Circuit Diagrams. Lazar Rozenblat. Web. 23 Mar. 2011. <http://www.smps.us/smpsdesign.html>.

[27] Um, K. J. (2002, April 1). Application Note 9020. IGBT Basic II. Retrieved May 31, 2011. <www.fairchildsemi.com/an/AN/AN-9020.pdf>

[28] Optocouplers and Solid State Relays. (2009, May 20).IGBT/MOSFET Gate Drive Optocoupler. Retrieved May 31, 2011, from www.vishay.com/docs/81227/81227

[29] Hefner, A.R., Jr.; , "An investigation of the drive circuit requirements for the power insulated gate bipolar transistor (IGBT)," Power Electronics, IEEE Transactions on , vol.6, no.2, pp.208-219, Apr 1991.

$<$ http://ieeexplore.ieee.org/stamp/stamp.jsp?tp=\&arnumber=76807\&isnumber=25 $6>$. 
[30] Lu, B., \& Brown, R. (n.d.). Bridgeless PFC Implementation Using One Cycle Control Technique . Technical White Paper. Retrieved May 31, 2011. $<$ www.irf.com/technical-info/whitepaper/blbapec2005.pdf $>$.

[31] Test probe. (2011, February 18). Wikipedia. Retrieved May 31, 2011. $<$ http://en.wikipedia.org/wiki/Test_Probe>.

[32] Solid State Relay. (2011, April 6). Wikipedia. Retrieved May 31, 2011. $<$ http://en.wikipedia.org/wiki/Solid_State_Relay>.

[33] Power Phototriac. (2011, January 11). Vishay. Retrieved May 31, 2011. $<$ www.vishay.com/docs/81924/vo2223a.pdf>.

[34] P176A Datasheet. (2003, March 12). Toshiba Photocoupler. Retrieved May 31, 2011. $<$ http://media.digikey.com/pdf/Data\%20Sheets/Toshiba\%20PDFs/TLP176A .pdf $>$.

[35]"Transformer-Driver IC Controls Bidirectional Switch - Maxim." Semiconductor Devices. Maxim, n.d. Web. 8 June 2011. <http://www.maxim-ic.com/appnotes/index.mvp/id/1096>. 